\title{
Uma Ferramenta Baseada em Cenários para Elicitação e Modelagem de Requisitos
}

\author{
João Caldas Júnior
}

Orientador: Prof. Dr. Paulo Cesar Masiero

Dissertação apresentada ao Instituto de Ciências Matemáticas e Computação da Universidade de São Paulo - ICMC/USP, como parte dos requisitos para a obtenção do título de mestre em Ciências de Computação e Matemática Computacional.

USP - São Carlos

Abril/1998 
Este trabalho é dedicado aos meus pais João e Tereza, pelo amor e educação recebidos durante a minha fomação de cidadão e profissional e aos meus irmãos Rodrigo e Ana Paula pela confiança que sempre depositaram no meu trabalho. 


\section{Agradecimentos}

Ao meu orientador, Prof. Dr. Paulo Cesar Masiero, pelo apoio e paciência durante a orientação. Ao Prof. Dr. Antônio F. Prado e Profa. Dr. a Solange Rezende Rodrigues, pelo incentivo e colaboração na realização deste trabalho.

Aos amigos, Sílvia Mara Abrahäo, Daniel Barbosa, Rejane Costa e Marisa Beck, Aletéia Favacho, Claudio Alex Rocha, Antônio Carlos Olivi pelo estímulo e apoio durante a realizaçăo deste trabalho.

Aós professores do ICMC-USP, Prof. Dr. José Carlos Maldonado, Profa: Dr. ${ }^{a}$ Maria da Graça Campos Pimentel, Prof. Dr. Edson dos S. Moreira, Profa. Dr. ${ }^{a}$ Maria Cristina F. de Oliveira e Profa. Dr.." Rosely Sanches pela participação sincera $\theta$ interessada em minha formação acadêmica, durante a fase de obtençăo dos créditos no curso de pós-gráduaçăa.

Aos Funcionários do ICMC-USP, pela incansável disposição e paciência.

A todos os colegas da ICMC-USP que me acompanharam, sempre dando incentivo a novas conquistas.

A Sociedade Esportiva Palmeiras, a eterna academia do futebol brasileiro, pelas incontáveis alegrias proporcionadas 


\section{Sumário}

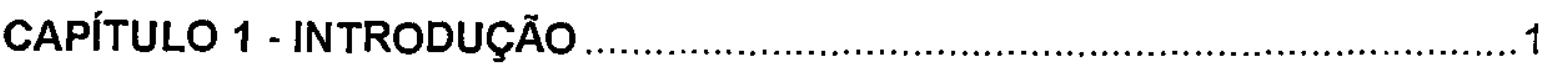

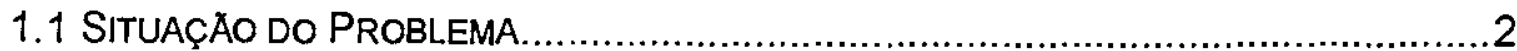

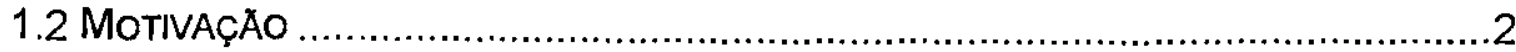

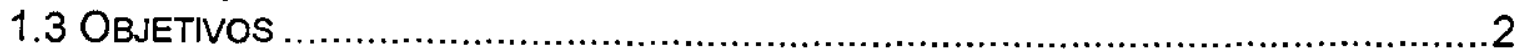

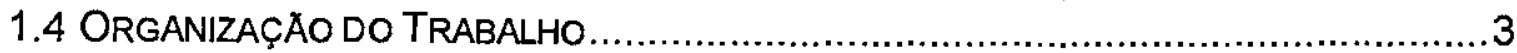

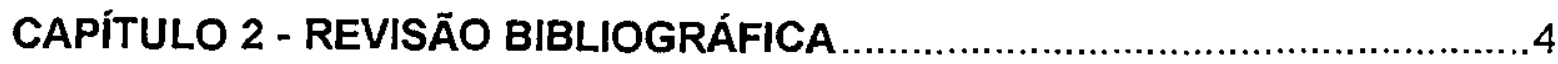

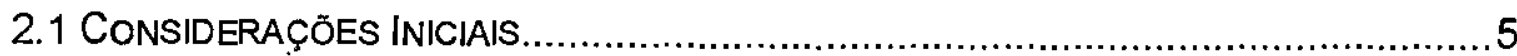

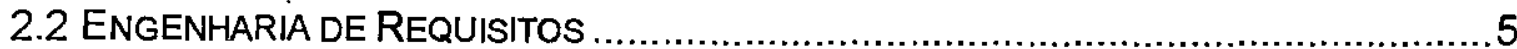

2.3 O USO DE CENÁRIOS NA ENGENHARIA DE REQUISITOS ...................................6

2.4 ABORDAGENS QUE UTILIZAM CENÁRIOS PARA ESPECIFICAÇĀO E ELICITAÇÃO DE REQUISITOS

2.4.1 Engenharia de Requisitos no Método Objectory ................................... 7

2.4.2 Engenharia de Requisitos no Método OBA........................................11

2.4.3 Construção de Cenários no Método SBRE .........................................13

2.4.4 Abordagem Formal para Análise de Cenários ......................................17

2.4.5 UORE, uma extensão ao Modelo de Casos de Uso do Método Objectory

24.6 Outras Abordagens

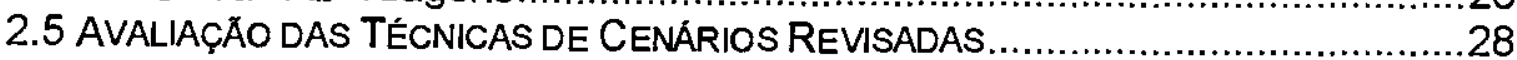

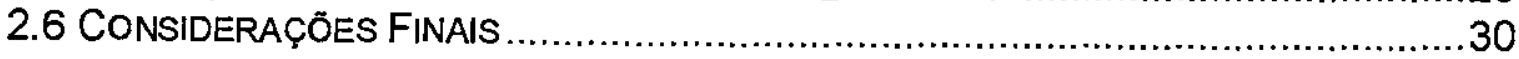

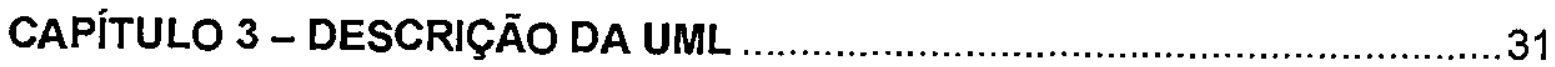

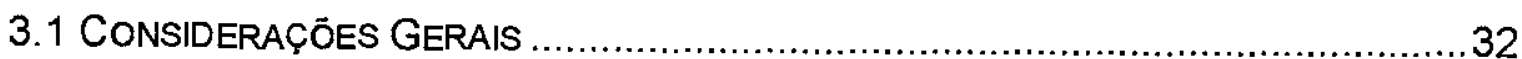

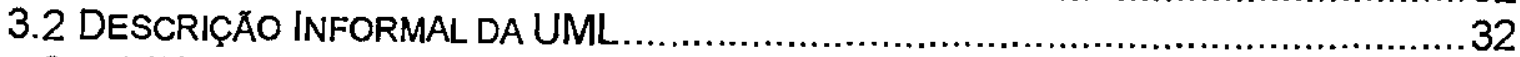

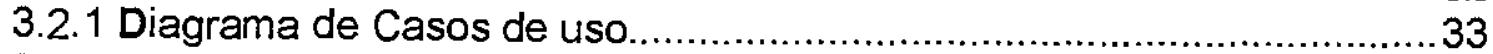

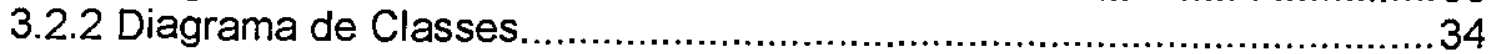

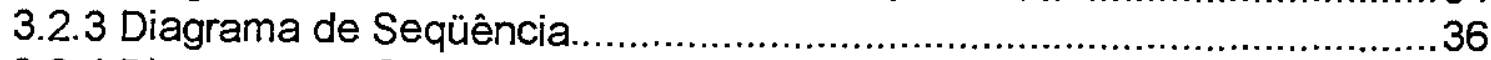

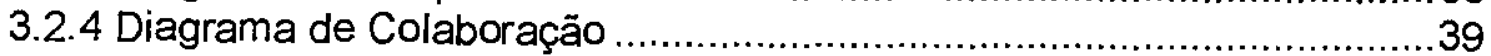

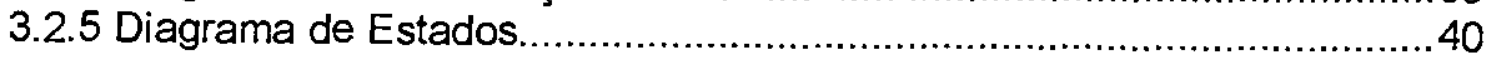

3.2.6 Diagrama de Atividades ................................................................44

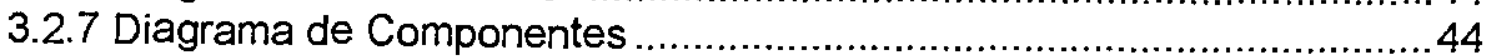

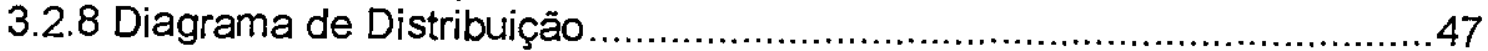

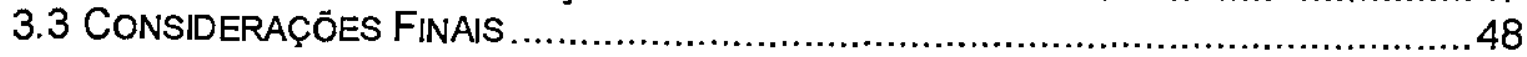

CAPÍTULO 4 - PROPOSTA DE UM MÉTODO BASEADO EM CENÁRIOS PARA ELICITAÇÃO E MODELAGEM DE REQUISITOS ..............................49

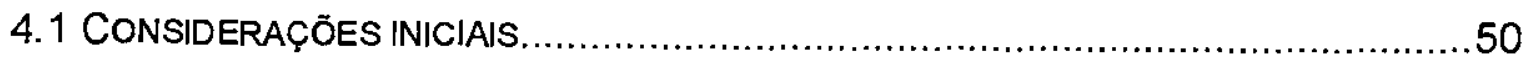

4.2 ENGENHARIA DE REQUISITOS APOIADA POR CENÁRIOS (ERACE) …................. 50

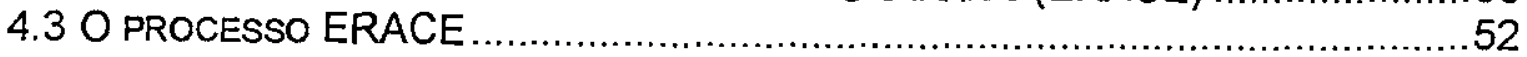

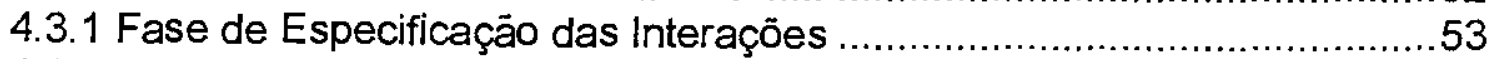

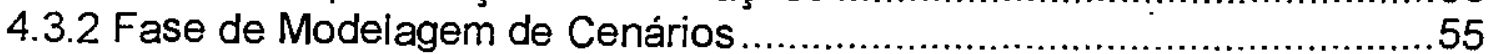

4.4 HEURISTICAS PARA A PASSAGEM PARA O MODELO DE ANÁLISE............................ 
4.4.1 Os Diagramas de Estados são construidos a partir dos Diagramas Abstratos Detalhados e dos Diagramas de Unificação das Cena.

4.4.2 Os Atores e os Argumentos são considerados candidatos a classes. Os métodos são as operaçōes.

4.4.3 As associações e as cardinalidades em geral são obtidas nos glossários.

4.4.4 O número de cenas sugere o número de submodelos de análise para a representação.

4.4.5 Construção do Diagrama de Classes do Sistema.

4.4.6 Os Diagramas de Seqüência e os Diagramas de Colaboração são construidos a partir das operaçōes identificadas no glossário do DAD.

4.5 CONSIDERAÇÕES FINAIS

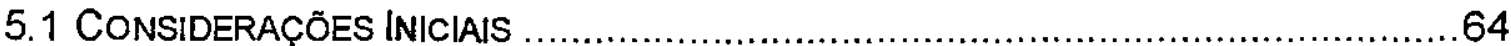

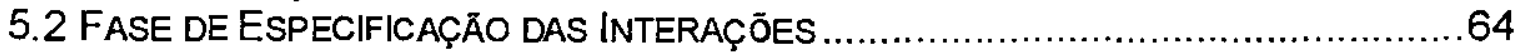

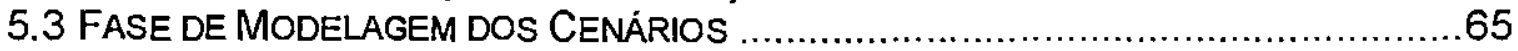

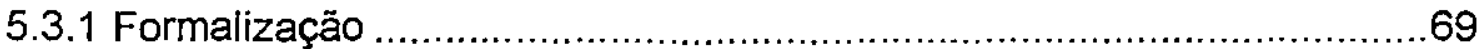

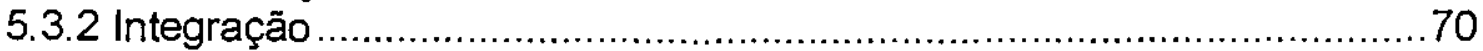

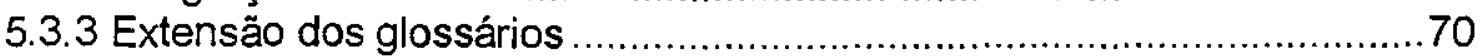

5.4 APLICAÇĀO DAS HEURISTICAS DE PASSAGEM PARA O MODELO DE ANALISE ..........70

5.4.1 Os Diagramas de Estados são construídos a partir dos diagramas de

Abstratos Detalhados e do Diagrama Unificado das Cenas. .........................72

5.4.2 Os Atores e os Argumentos são considerados candidatos a classes. ...72

5.4.3 Associações e cardinalidades em geral são obtidas nos glossários.......73

5.4.4 Um Diagrama de Classes pode ser subdivido em vários subdiagramas. 75

5.4.5 Construção do Diagrama de Classes do Sistema................................75

5.4.6 Os Diagramas de Seqüência e os Diagramas de Colaboração são construídos a partir das operações identificadas no glossário do DAD . .........77

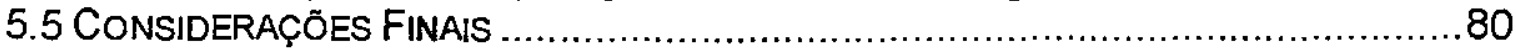

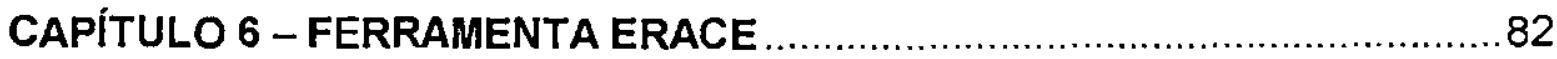

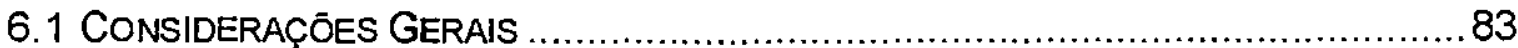

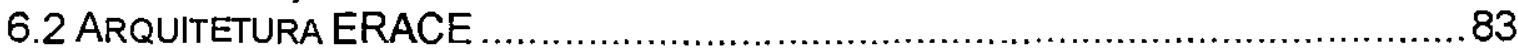

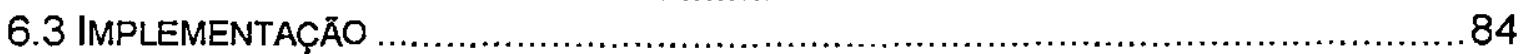

6.4 EDITOR DO DIAGRAMA DE INTERAÇÄO DAS CENAS (DIC) ............................ 84

6.5 EDITOR DO DIAGRAMA ABSTRATO DETALHADO (DAD) ............................... 84

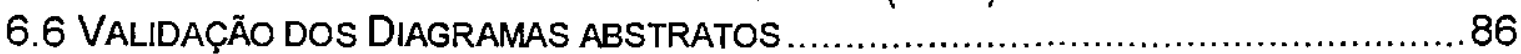

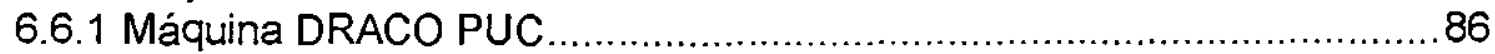

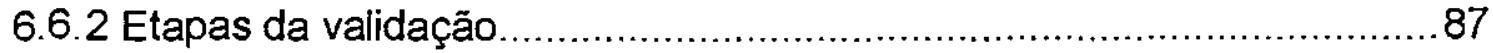

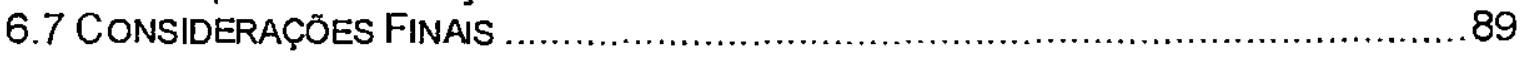

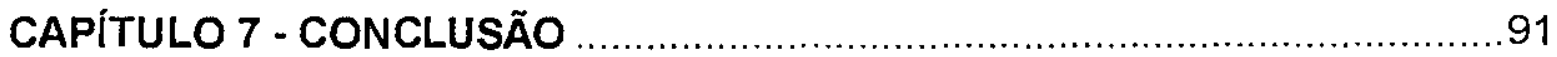

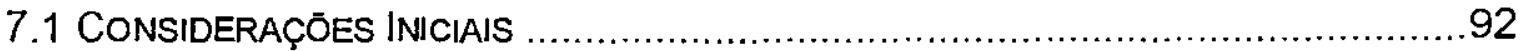

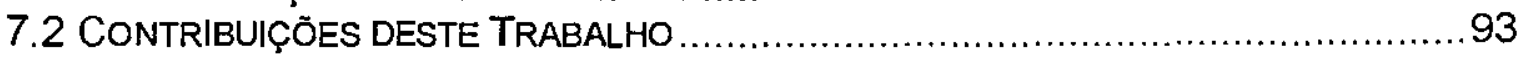

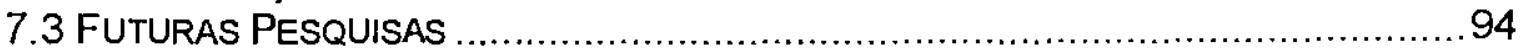

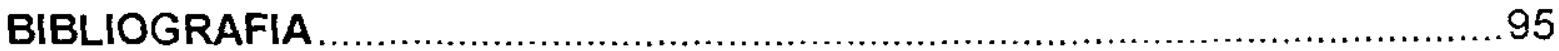




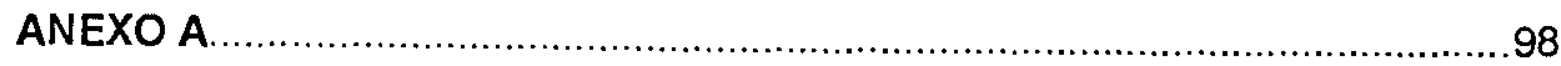

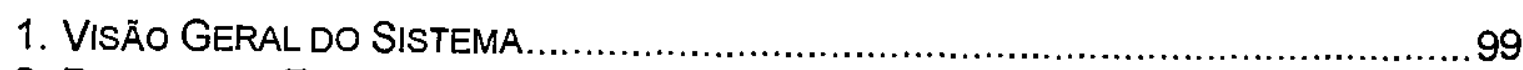

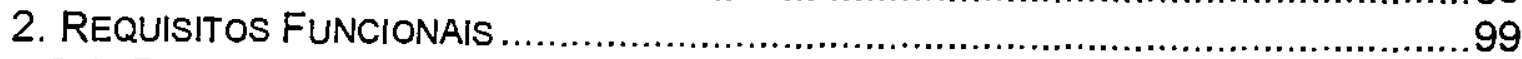

2.1. Preparação e Manutenção dos Itens Bibliográficos ...............................99

2.2. Consultas Gerais e Emissão de Relatórios..........................................100

2.3 Uso dos Itens Bibliográficos durante a redação de um texto científico. ...101

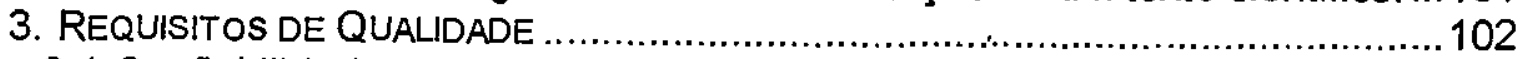

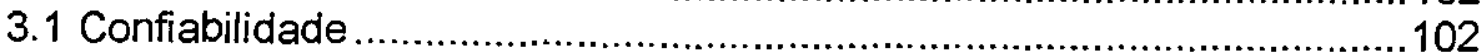

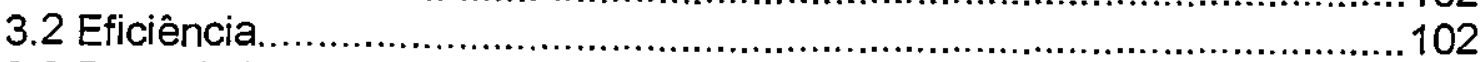

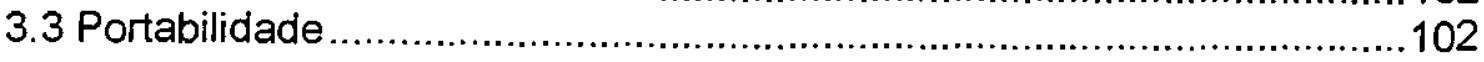

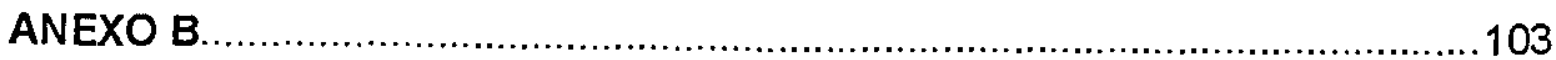

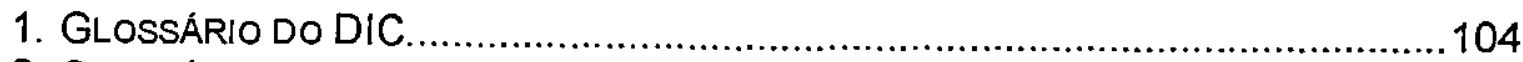

2. GLoSSÁRIO dA CENA " PREPARAÇÃo dE ITENS BIBLIOGRÁFICO” ........................ 105

3. GLOSSÁRIO DA CENA "INSERÇÃO DAS REFEREN CIAS BIBLIOGRÁFICAS NO TEXTO -

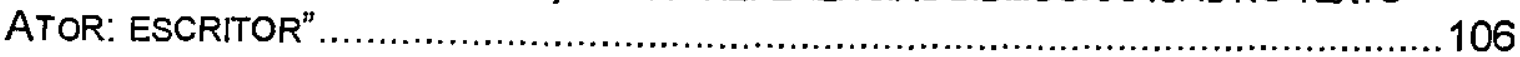

4. GLOSSÁRIO DA CENA "INSERÇÃO DAS REFERÉNCIAS BIBLIOGRÁFICAS NO TEXTO -

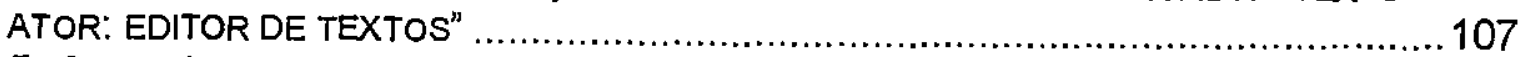

5. GLOSSÁRIO DA CENA "CONSULTA E EMISSĀO DE RELATÓRIOS" ............................107

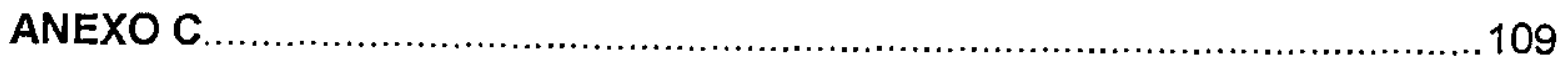

1 INTEGRAÇĀo DA FERRAMENTA ERACE COM O SISTEMA DRACO .......................110

2. GRAMÁTICA ERACE DEFINIDA PARA O SISTEMA DRACO ................................. 110

3. LÉXICO ERACE DEFINIDO PARA O SISTEMA DRACO ................................... 111 


\section{Lista de Figuras}

Capítulo 2

Figura 2. 1 Síntese do processo de desenvolvimento no método Objectory ...........8

Figura 2. 2 Exemplo de modelo de caso de uso.................................................

Figura 2. 3 Exemplo de caso de uso............................................................ 10

Figura 2. 4 Macro Visão da Arquitetura SBRE ................................................15

Figura 2. 5 Exemplo de cenário para a operação de empréstimo de livro............16

Figura 2. 6 Modelo de processo da análise de cenários .................................17

Figura 2. 7 Exemplo de uma árvore de cenários e sua gramática.......................19

Figura 2. 8 Processo do UORE ..................................................................21

Figura 2. 9 Exemplo de uma descrição de caso de uso ..................................22

Figura 2. 10 Exemplo de especificação de um caso de uso por meio de um diagrama de interação. .............................................................................24

Figura 2. 11 Exemplo de cenário abstrato de uso ..........................................25

Capítulo 3

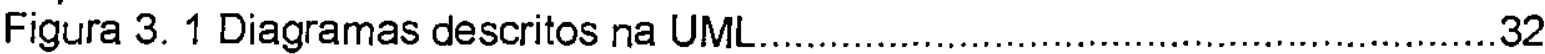

Figura 3. 2 Exemplo de Diagrama de Casos de Uso ..........................................34

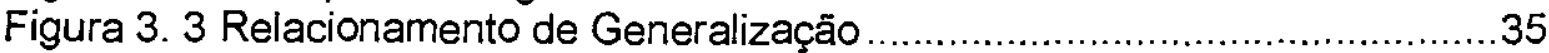

Figura 3. 4 Exemplo de Dependência entre Classes ..........................................36

Figura 3. 5 Exemplo de Relacionamento de Associação......................................36

Figura 3. 6 Exemplos de Tipos de Agregação ................................................37

Figura 3. 7 Exemplo de Diagrama de Seqüência - Operação de Chamada

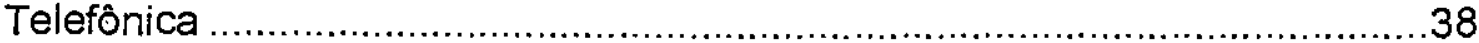

Figura 3. 8 Exemplo de Objetos do Diagrama de Colaboração ..........................39

Figura 3. 9 Exemplo de Ligação entre Objetos .............................................39

Figura 3. 10 Exemplo de Diagrama de Colaboração - Operação Impressão de

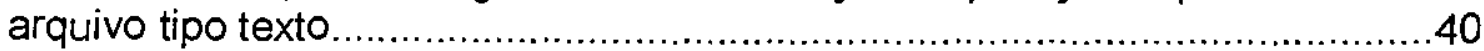

Figura 3. 11 Exemplos de eventos/ações entry e do ........................................42

Figura 3. 12 Transição de Estado ............................................................42 42

Figura 3. 13 Exemplo de Transições de Estado ............................................43

Figura 3. 14 Estado de Ação .......................................................................4 44

Figura 3. 15 Exemplo de Diagrama de Atividades .........................................45

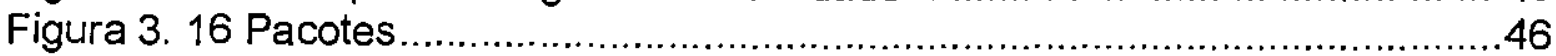

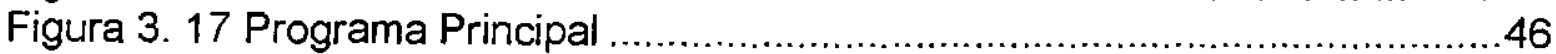

Figura 3. 18 Especificação e Corpo de Subprograma .........................................46

Figura 3. 19 Especificação e Corpo de Tarefa..............................................47

Figura 3. 20 Exemplo de Relacionamento de Dependência ...............................47

Figura 3. 21 Exemplo de Processador ..........................................................48

Figura 3. 22 Exemplo de Dispositivo de e/s...................................................48 48

Figura 3. 23 Exemplo de Conexão.............................................................. 48

Capitulo 4

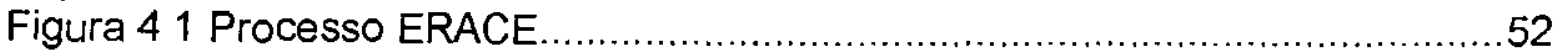

Figura 42 Diagrama de Interação das cenas de uso ......................................54 
Figura 43 Diagrama Abstrato Detalhado......................................................5

Figura 44 Gramática reconhecedora da Linguagem de Detalhamento................58

Figura 45 Exemplo da criaçäo de um DUC ......................................................60

Capítulo 5

Figura 51 Diagrama de Estados para a cena "Inserção de referências bibliográficas"

Figura 52 Diagrama de Estados para a operaçäo "Criar ficha técnica" ...............73

Figura 53 Subdiagrama de Classes para a cena "Preparação de itens bibliográficos"

Figura 54 Subdiagrama de Classes para a cena "Inserção de Referência Bibliográfica no Texto"

Figura 55 Subdiagrama de Classes para a cena "Consulta e Emissão de Relatórios"

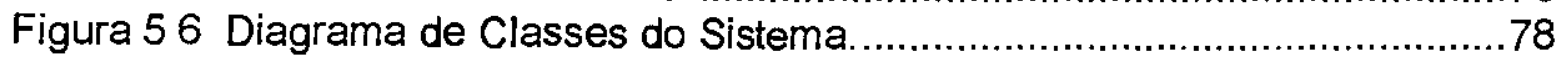

Figura 57 Diagrama de seqüência construído para a operação Criar ltem da cena de uso "Preparação de itens bibliográficos"

Figura 58 Diagrama de seqüência construído para as operaçöes "Gerar referência bibliográfica" e "Inserir referência bibliográfica"

Figura 5 9Diagrama de colaboração construído para a operação Criar Item da cena de uso "Preparação de itens bibliográficos"

Figura 510 Diagrama de colaboração construído para as operaçäo "Gerar referência bibliográfica" e "Inserir referência bibliográfica"

Capítulo 6

Figura 61 Arquitetura da ferramenta ERACE

Figura 62 Tela de visualização de um glossário

Figura 63 Tela de visualização de um glossário

Figura 64 Tela de edição de um DAD

Figura 65 Tela de visualização de programa em LD.........................................8

Figura 66 Tela de resposta da operação de validação

Figura 67 Exemplo de um fragmento da DAST gerada pelo DRACO para a cena

"Preparação de itens bibliográficos". 


\section{Lista de Tabelas}

$s$

Capítulo 2

Tabela 2. 1 Exemplo de roteiro para a operaçäo de empréstimo de livro.

Tabela 2. 2 Tabela de Avaliação.

Capítulo 3

Tabela 3. 1 Notações de Cardinalidade.

Capítulo 4

Tabela 4. 1 Glossário do DIC

Capítulo 5

Tabela 5. 1 Glossário do DIC .66

Tabela 5. 2 Glossário do DAD para a cena "Preparaçăo de itens bibliográficos" - Ator Principal". .70

Tabela 5. 3 Classes e Métodos Candidatos.

Tabela 5. 4 Fragmento do glossário "Preparaçäo de itens bibliográficos - Ator Principal".74 Tabela 5. 5 Fragmento do glossário "Consulta e Emissäo de Relatórios - Ator Principal" 74 Tabela 5. 6 Fragmento do glossário "Preparação de itens bibliográficos - Ator Principal".74 


\section{Resumo}

Esse trabalho apresenta algumas técnicas e métodos que apoiam a fase de engenharia de requisitos, bem como uma comparação entre as abordagens revisadas. Uma proposta de um processo para a engenharia de requisitos baseada na construção de cenários, compativel com a UML, é apresentada. A notaçăo introduzida, o processo de construção dos modelos de requisitos e um conjunto de heurísticas para a construção de um modelo de análise são apresentados. Um estudo de caso referente a um sistema de apoio à escrita de documentos técnicos ilustra a construção dos modelos propostos pelo procesșo. Finalmente, uma ferramenta que apoia a construção dos modelos introduzidos pelo processo é apresentada. 


\section{Abstract}

This dissertation presents several scenario techniques and methods to support the requirements engineering phase, as well as a comparison amongst the approaches reviewed. A proposal of a scenarjo-based engineering requirements process compatible with the UML notation is presented. The introduced notation, the pracess of construction of the requirements model and several heuristics to the construction of the UML analysis model_are presented. A. case study about a system to support technical documents writing illustrates the construction of the requirements model according to the proposed process. Finally, a tool that supports the construction of the models comprising the process is presented. 
Capítulo 1 - Introdução 


\subsection{Situação do Problema}

A engenharia de requisitos é uma das mais importantes fases do ciclo de vida do desenvolvimento de software. Sua principal função é gerar especificações que descrevam de forma não ambígua, consistente e completa o comportamento do universo do dominio de um problema [16].

A engenharia de requisitos tem como tarefa fundamental definir os requisitos de um software. Porém, para que essa tarefa seja realizada adequadamente, é necessário - correto entendimento do contexto do sistema, ou seja, onde realizar essa tarefa, quais os recursos disponiveis e quais os limites do sistema. Por intermédio do estudo da literatura, dos vários modelos propostos e dos constantes problemas decorrentes da má definição do software pode-se afirmar a importância do estudo e do uso de técnicas que auxiliem na produção de requisitos confiáveis [3]. Esse é o objetivo da engenharia de requisitos, que busca sistematizar o processo de definição de requisitos

Uma ferramenta que dê apoio a fase de engenharia de requisitos deve considerar inicialmente as especificações geradas por intermédio da análise das necessidades do sistema após consultas aos usuários. Existem várias maneiras de elicitar e analisar requisitos; uma técnica já conhecida que tem obtido grande destaque atualmente é a que utiliza a criação de cenários, que permitem retratar, a partir das necessidades dos usuários, os caminhos possíveis para utilização do sistema. Este trabalho enfoca principalmente a uso de cenários na engenharia de requisitos e na construção de uma ferramenta para apoio a esse uso.

\subsection{Motivação}

A engenharia de requisitos, de uma forma geral, lida com o problema de captar as necessidades dos vários usuários de um sistema e traduzir essas necessidades na forma de requisitos, que podem também ser usados para medir o sucesso de uma eventual implementação. No entanto, existem inúmeras dificuldades no momento de conciliar o entendimento do problema com a solução codificada. É bem verdade que soluçōes significativas têm sido obtidas na compreensão das especificações de um sistema e na sua implementação, porém também é verdade que a engenharia de requisitos como um todo ainda é relativamente imatura.

Assim, uma ferramenta que automatize a fase de engenharia de requisitos (baseada em uma técnica completa e relativamente simples) capaz de captar, modelar e validar requisitos, pode auxiliar em muito na especificação de um dado sistema, agilizando o seu processo de desenvolvimento.

\subsection{Objetivos}

Apesar de ser uma técnica conhecida há algum tempo, os cenários têm ganhado nos últimos anos grande destaque entre os principais autores na área de desenvolvimento de sistemas. Há vários métodos publicados recentemente, entre eles OMT [11], Objectory [6] e Fusion [15], que utilizam a técnica de construção de cenários 
em suas fases e uma grande quantidade de extensões que utilizam cenários como técnica de apoio.

Neste trabalho serão estudadas as fases de engenharia de requisitos de alguns métodos que utilizam a técnica de construção de cenários, com o objetivo de avaliar os pontos críticos que devem compor uma técnica completa para elicitar requisitos usando cenários e desenvolver uma ferramenta, baseada nessa técnica, que apoie a fase de engenharia de requisitos.

\subsection{Organização do Trabalho}

Os demais capitulos desta monografia estão organizados da seguinte forma: no capítulo 2 é apresentada uma revisão bibliográfica, cobrindo as fases de engenharia de requisitos de alguns métodos que utilizam a técnica de cenários. É apresentada também uma avaliação dessas fases.

O capitulo 3 apresenta uma descrição informal da UML (Unified Modeling Language) [21], usada para a especificação, construção, visualização e documentação de sistemas de software, assim como modelagem de negócios e outros sistemas não baseados em softwares.

O capítulo 4 apresenta a proposta de um método de apoio à engenharia de requisitos baseada na técnica de construção de cenários (O Método ERACE), descrevendo o processo e a notação adotada nos vários modelos criados no método. O método é aplicado com base em um documento de requisitos do usuário, sendo composto das seguintes fases: Especificação de Interações e Modelagem de Cenários. Também é apresentada a fase de passagem para a construção de um modelo de análise baseado na UML aplicando-se uma série de heurísticas junto aos modelos criados pelo método.

No capítulo 5 é apresentada a ferramenta ERACE, que suporta a criação de todos os modelos que são parte do método ERACE.

No capítulo 6 é apresentado um estudo de caso para ilustrar o processo de desenvolvimento do método e a aplicação das heurísticas de passagem para criação de um modelo de análise.

Finalmente, o capítulo 7 apresenta as conclusões deste trabalho, bem como as propostas para melhorias futuras em pesquisas que possam vir a ser desenvolvidas na área de engenharia de requisitos. 


\section{Capítulo 2 - Revisão Bibliográfica}




\subsection{Considerações Iniciais}

Uma das técnicas que pode ser utilizada para apoiar a tarefa de especificação e elicitação de requisitos é a construçăo de cenários. Essa técnica tenta suprir as principais falhas encontradas nos métodos tradicionais, por intermédio de uma abordagem que leva em consideração a visão do usuário na interação com o sistema.

Mas afinal, quais são os principais benefícios. gerados com a uso dos. cenários? Vemulapalli, em [1], explica que a principal vantagem dos cenários é respeitar a perspectiva do usuário, fazendo com que a coleta de requisitos atenda aos seus desejos e tornando essencial sua participação no processo. Em [2], Berard aponta que com os cenários é ainda possível: estimar a percentagem de requisitos alcançados, validar os requisitos coletados, facilitar a identificação de objetos (na Análise Orientada a Objetos) e melhorar a qualidade do software por meio de planos de teste e outras ferramentas. Além dessas vantagens, as cenários tendem a ser precisos, formais e tangiveis, isto é, podem ser usados como documento de compromisso na fase de implementaçäo (como um contrato entre o usuário e o deserivolvedor).

A demais seções deste capítulo estão organizadas da seguinte forma: na seçẫo 2.2 são apresentados aspectos e problemas da fase de engenharia de requisitos. Na seção 2.3 é analisado o uso da técnica de construção de cenários na engenharia de requisitos. $\mathrm{Na}$ seção 2.4 são revisadas algumas abordagens que utilizam cenários para especificação e elicitação de requisitos. Na seção 2.5 é feita uma avaliação das técnicas de cenários revisadas. As corısiderações finais sobre este capítulo são apresentadas na seção 2.6.

\subsection{Engenharia de Requisitos}

Em qualquer área do conhecimento, para solucionar um determinado problema, é necessário conhecer e entender esse problema. Como as demais áreas da engenharia, a construção de software defronta-se com a mesma necessidade [17].

A Engenharia de Software tem estudado os ciclos de vida de construção de software pelos últimos vinte e cinco anos. Um aspecto comum nos ciclos de vida mais conhecidos é a fase técnica que inicia o processo de análise de um sistema, chamada de Engenharia de Requisitos, que consiste basicamente na elicitação, modelagem e validação dos requisitos de um sistema [3], obtidos a partir do conhecimento e entendimento da problema em questão.

Apesar de gastar apenas 6\% [4] do esforço total durante todo o ciclo de vida, a engeriharia de requisitos, quando realizada de forma ineficiente, pode vir a gerar inúmeros problemas durante o desenvolvimento de um software. Existe uma série de métodos tradicionais para coleta de dados, porém em muitos casos é impossivel especificar completamente um problema por meio desses métodos. Segundo Kaufman, em [5], e Jenkins, em [14], os problemas mais comuns que ocorrem nessa fase são: 
- $78 \%$ dos projetos têm requisitos adicionais descobertos após a aprovação do documento final gerado pela fase de engenharia de requisitos;

- $66 \%$ dos projetos acabam por repetir a fase de engenharia de requisitos;

- Os erros encontrados depois da fase de engenharia de requisitos podem necessitar até dez vezes mais esforço para correção.

Uma das razões para que a engenharia de requisitos realizada com apoio de técnicas tradicionais gere muitas vezes resultados incompletos se deve à dificuldade dos usuários em entender e conhecer detalhes ou características do dominio de um problema. Outros impedimentos são: os problemas que muitos projetistas têm em tratar requisitos complexos, as dificuldades de administrar mudanças que possam acontecer durante e após a fase de análise e a falta de comunicação entre o analista e o usuário, que pode causar uma série de mal entendidos nas fases seguintes do ciclo de vida do software. Finalmente, a falta de técnicas que auxiliem a coleta de informações prejudica uma elicitação de requisitos precisa e mensurável.

\subsection{O Uso de Cenários na Engenharia de Requisitos}

Na literatura atual existe um grande número de contribuições úteis com respeito à elicitação de requisitos. Grande parte deste material cita de forma bastante promissora a incorporação de cenários na fase de especificação de requisitos. Cenários podem ser vistos como descrições que ajudam a definir um sistema e suas características, a partir das necessidades do usuário. Dentre as formas de representação dos cenários estão: os casos de uso propostos por Jacobson [6], Roteiros (Scripts) [10] e diagramas de interação [12].

Os cenários representam um mecanismo simples e poderoso para visualizar certos problemas que podem ter passado despercebido em alguma parte da elicitação de requisitos. Os cenários ajudam a ilustrar o comportamento de um sistema a partir da interação com o usuário e servem como técnica para ajudar a descobrir ou modificar previamente requisitos desconhecidos ou obscuros. Essa técnica consiste em representar cenas extraídas do cotidiano do domínio do problema, identificadas por estímulos e respostas do sistema, sempre com base na visão de quem gerou o estímulo. Resumidamente, um cenário deve mostrar os elementos-chave necessários para entender o que o sistema faz.

Cada cenário pode descrever uma ou mais cenas associadas com o uso hipotético do sistema. Cada uma dessas cenas deve revelar procedimentos sobre como utilizar recursos do domínio, manipular a entrada de dados e obter informação do sistema. $\mathrm{Na}$ tarefa de construir cenários é muito importante:

- identificar a granularidade de cada cenário para uma dada aplicação; 
- dividir um problema em vários cenários;

- integrar todos os cenários.

Um modelo completo baseado em cenários deve ser constituído de um grupo de cenários que reflita e interprete todos os requisitos conhecidos. Uma vez construidos os primeiros cenários, os documentos gerados devem passar por um processo iterativo de refinamento para a eliminação de possiveis problemas.

\subsection{Abordagens que Utilizam Cenários para Especificação e Elicitação de Requisitos.}

Uma grande parte da literatura atual incorpora cenários ou técnicas similares na fase de engenharia de requisitos, alegando que o uso dessa técnicas durante o processo de materialização dos requisitos pode ajudar a identificar características importantes do projeto. O processo de criação de um modelo de cenários consiste basicamente na construção de cenários e identificação dos agentes que interagirão com os mesmos. A partir desses componentes, aspectos relativos à complexidade do sistema podem ser melhor compreendidos. A documentação gerada pelos cenários pode poupar bastante tempo na elicitação de documentos.

Os cenários possuem diferentes representações que incluem narrativas, textos estruturados, tabelas, diagramas e etc. Cenários variam desde bastante informais (narrativa simples) até totalmente formais (gramáticas regulares>, passando por representações semi-formais em forma de tabelas ou diagramas. Uma das propostas de cenário que merece destaque são os casos de uso, criados por Jacobson e outros em [6]. Os Caso de Usos descrevem as maneiras de utilizar o sistema. A grande diferença entre os vários tipos de cenários e os casos de uso está no foco do contexto utilizado na representação de um domínio. Os Cenários são mais completos na descrição de um comportamento especifico do sistema enquanto que os casos de uso registram um contexto mais geral, relacionado com a interface do sistema. De uma maneira geral, um cenário é o conjunto de todas as possibilidades de interação entre um ator e um cena do sistema. Cada caso de uso, por sua vez, descreve uma dentre estas várias possibilidades de interação, isto é, um caso de uso é uma instância de um cenário.

\subsubsection{Engenharia de Requisitos no Método Objectory}

O Objectory é um método para desenvolvimento de sistemas baseado no paradigma da orientação a objetos criado por Jacobson e outros [6]. Nesse método são consideradas as fases de especificação de requisitos, análise, projeto, implementação e teste. O processo de desenvolvimento baseia-se na construção de modelos que descrevem o sistema, oferecendo visōes diferentes e complementares do mesmo.

Segundo Jacobson, o primeiro passo para captar de forma correta todos os requisitos funcionais de qualquer sistema é a construção de um modelo de requisitos, 
que descreva como um usuário em potencial usará o sistema. Tal modelo é desenvolvido com a participação dos usuários finais e as pessoas que encomendaram o sistema. Com a aplicação de vários refinamentos, esse modelo deve torna-se confiável o suficiente para que o ciclo de vida do sistema tenha prosseguimento. O modelo de requisitos consiste de:

- Modelo de Casos de Uso

- Descrição da Interface

- Modelo do domínio do problema
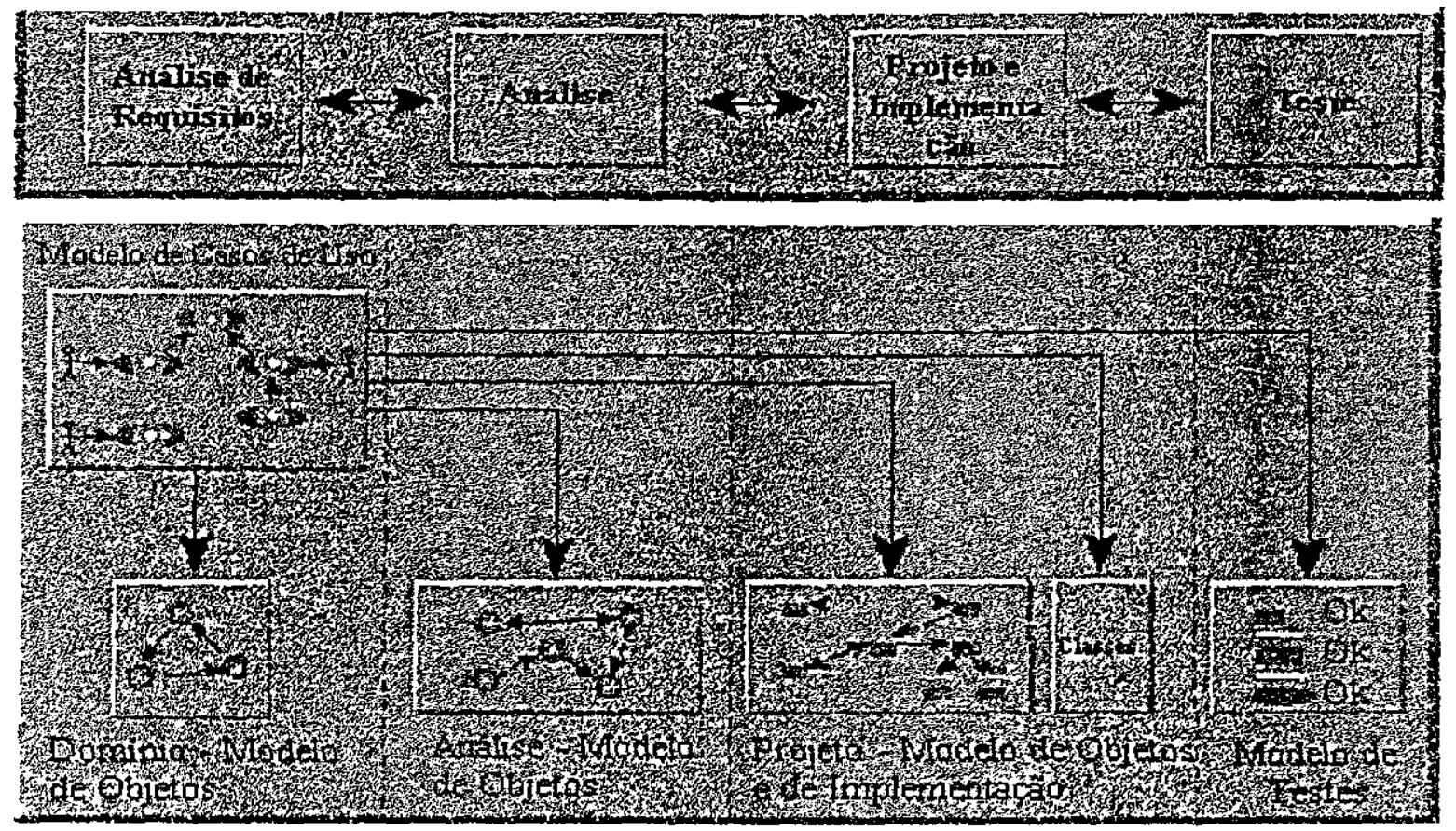

Figura 2.1 Síntese do processo de desenvolvimento no método Objectory

\section{Modelo de Casos de Uso}

O ponto de partida para a construçăo do modelo de requisitos é a especificação de requisitos do sistema. Com base nesse documento serão criados neste passo: um modelo de caso de uso; descrições da interface e um modelo do domínio do problema. Os casos de uso são usados para agrupar e organizar requisitos, a partir de uma análise do domínio do problema. Sucintamente, os casos de uso "quebram" um determinado problema em várias interaçōes, que explicam a interação do usuário com o sistema e representam os passos necessários para alcançar os resultados desejáveis para essa interação. 
O modelo de casos de uso controla a criação de todos os outros modelos (veja Figura 2.1). A funcionalidade especificada por um caso de uso é estruturada de forma lógica e robusta, porém independente de ambiente e implementação. Dentro do modelo de casos de uso são manipulados os conceitos de atores e do próprio caso de uso, definindo o que é externo (ator) e interno (caso de uso) ao sistema. Cada caso de uso do modelo apresenta uma cadeia completa de eventos que é iniciada por um determinado ator, o qual interage com o sistema seguindo as especificaçöes presentes no próprio caso de uso. Um ator representa um determinado papel que o usuário pode assumir dentro do sistema. Caso um ator utilize diretamente o sistema ele é chamado de ator primário; aqueles que gerenciam e supervisionam o sistema são chamados de atores secundários.

Individualmente, os casos de uso são identificados por seus atores. Para atribuir a um ator um determinado caso de uso é necessário recorrer ao documento de requisitos do sistema e a partir dele realizar a distribuição dos cenários. No entanto, um ator não é responsável pelo comportamento de seu caso de uso, ele apenas inicia o fluxo de eventos do mesmo. Na realidade, o sistema funciona como um caixa preta formada pelos vários casos de uso do modelo. O conjunto de todos os casos de uso deve especificar completamente a funcionalidade de um sistema. Veja a figura 2.2 para uma ilustração do modelo de caso de uso.

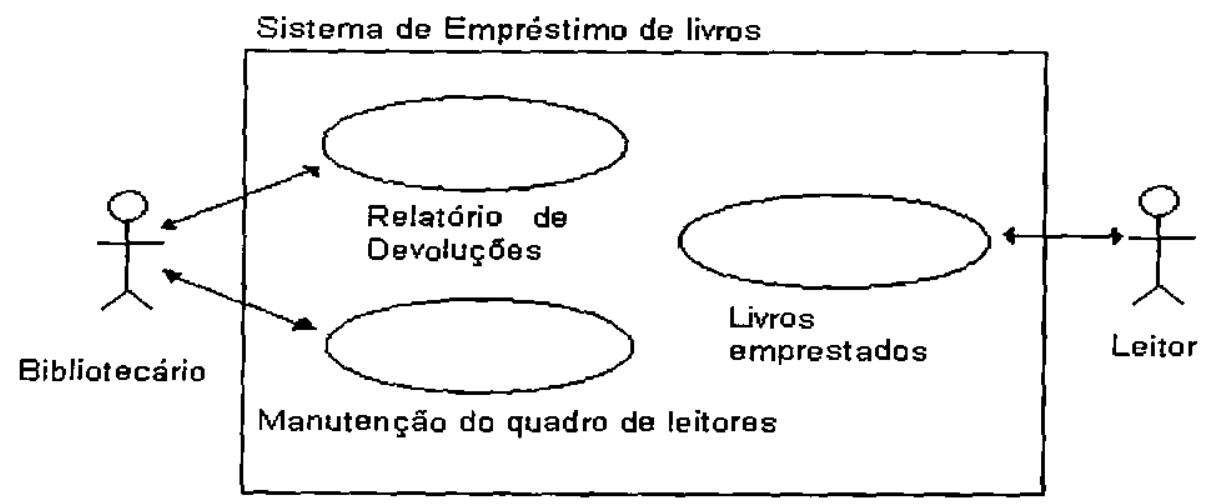

Figura 2.2 Exemplo de modelo de caso de uso. O sistema é limitado pelo retângulo. Cada ator é representado por uma pessoa fora do retângulo, enquanto que os casos de uso são representados pelas elipses dentro do retângulo.

Durante sua construção, os casos de uso são resumidos em pequenos roteiros (ver figura 2.3), que descrevem o comportamento de cada cenário do sistema. Inicia-se então um processo de refinamento para descrever com mais detalhes as informações dos casos de uso. Este processo inicia com a delimitação de um fluxo básico, que retrata o curso de eventos mais importante do caso de uso. As variantes do fluxo básico e as exceções que podem ocorrer no sistema são descritas em um fluxo alternativo. Normalmente um sistema possui vários fluxos alternativos, mas apenas um fluxo básico. Um conceito adicional usado em uma estrutura de descrição de um caso de uso é a associação de extensão. Uma extensão é usada para inserir uma descrição e assim estender a funcionalidade do caso de uso. Na Figura 2.3, é ilustrado um exemplo de caso de uso para um sistema de empréstimo de livros em um biblioteca. 


\section{Descrições de Interface}

Durante a construção do modeto de casos de uso é necessário realizar a descrição das interfaces, que deve explicar com detalhes os protocolos de comunicação usados na interação entre os atores e os casos de uso. Essa descrição deve ser realizada com base nos casos de uso e também na interação do usuário com o sistema. Muitas vezes as interfaces lidam com protocolos de hardware, por isso também é necessário relacionar as várias formas de interação com tipos e padrões de hardware.

\section{Fluxo Básico}

Um leitor entrega para o bibliotecário alguns livros para serem emprestados, 0 bibliotecário pede ao leitor que apresente seu documento de identidade e seu cartão da biblioteca que contém um etiqueta com o código de barras do usuário. O bibliotecário passa a leitora de códigos de barra sobre o cartão e recebe a seguinte informação na tèla de seu terminal

\begin{tabular}{|c|} 
Dados do Leitor \\
Nome: Rodrigo Meireles Número: $1919-1 \quad$ Endereço: Rua B.69 \\
Telefone: $\underline{738-2111}$ \\
Restrições: $\underline{\text { Nenhuma }}$ \\
Continua operação? (S/N)
\end{tabular}

O bibliotecário verifica se na tela existe alguma restrição aos privilégios do-leitor. Se não, o bibliotecário digita "S" na opção de continuar operação. O bibliotecário pode então passar a leitora de códigos de barra sobre as etiquetas dos livros trazidos pelo leitor.

\section{Fluxo Alternativo}

- Falha na leitura do código de barras

Se o sistema não identificar o leitor pelo código de barras então o bibliotecário digitará o número do cartão do leitor. Quando o leitor for identificado o sistema voltará ao fluxo básico.

Figura 2.3 Exempto de caso de usq

Essas descrições de interface são portanto uma parte essencial da descrição dos casos de uso por retratar as diferentes interfaces envolvidas na interação, e por esse motivo devem acompanha-lás. Por exemplo, uma máquina de caixa de transações bancárias tem diferentes tipos de-interface. Existe o painet para interações com $\sigma$ cliente, o qual pode incluir botões, leitoras magnéticas, etc. Entretanto, o supervisor dessa máquina também precisa de uma interface para a troca informaçöes, requisições de resumos diários e outras tarefas de supervisão. 
No decurso da criação do modelo de requisitos, é difícil definir as tarefas e principalmente as fronteiras de um sistema. Isso acontece normalmente quando a especificação de requisitos é obtida de fontes muito vagas e escassas. Uma técnica que pode ajudar no desenvolvimento de uma visão-lógicar do sistema é identificar os objetos do domínio do problema, que são objetos que têm influência direta na aplicação e no ambiente do sistema.

A partir da identificação desses objetos é possivel definir os conceitos com os quais o sistema irá lidar e identificar formas de comunicaçöes entre os vários objetos do domínio e determinar quais as funções do sistema. Dessa maneira é organizado um glossário que pode ser usado para formular a funcionalidade dos casos de uso.

\subsubsection{Engenharia de Requisitos no Método OBA (Object Behavior Analysis)}

OBA [7] é um método que pode ser usado para complementar a fase de Análise Orientada a Objetos na tarefa de identificar candidatos a objetos. A caracteristica mais importante destacada no OBA é que nessa técnica os componentes do domínio do problema são descritos de acordo com $\sigma$ seu comportamento dentro do sistema, sendo que essa descrição é realizada sob um ponto de vista que considera usuários e máquinas parte do contexto do probtema, isto é, os dois lados da interação devem sempre ser identificados e correlacionados.

No OBA, $\sigma$ comportamento de um determinacto sistema é descrito a partir de dois agentes que têm o dever de orientar a conduta desse sistema: o agente inicial e o agente participante. As Funçōes de manutenção $\theta$ gerenciamento do sistema de informaçãa devem ser identificadas a partir da participação deste dois agentes, tanto o que inicia quanto o que participa. Com isso se toma mais fácil entender os diferentes personagens que podem existir dentro do domínio de um problema.

OBA é composto dos seguintes passos:

- Passo 0 - Montar contexto da análise;

- Passo 1 - Entender o probtema;

- Passo 2 - Definir objetos;

- Passo 3 - Classificar objetos e identificar refacionamentos

- Passo 4 - Modelar dinâmica do sistema.

OBA pode ser caracterizado como sendo uma técnica iterativa com vários pontos de entrada. Na prática, cada passo do OBA é conduzido de maneira iterativa, podendo ainda ser reatizado em paratelo com os outros passos. Cada passo encerrado tenta gerar informações ou resultados suficientes para integrar a solução do próximo passo. Se ao fim 
de algum passo forem descobertas falhas nas informações coletadas ou novas questões tenham sido levantadas; uma mova iteração é necessária para completar o passo. Tơdos os passos do OBA estão internamente relacionados, para fornecer um tipo de checagem ou balanço na sua construção, permitindo verificar se a análise-do contexto é internamente consistente no decorrer de todos os passos. Os passos que tratam do entendimento e descrição do problema e a formulação dessa descrição em termos de múltiptas interações entre objetos säo o passo 0 e o passo 1.

\section{Passos 0 - Montar Contexto darAnálise}

O Passo 0 consiste de quatro sub-passos; que tem como objetivo comum gerar as informações iniciais para a fase de análise. Em particular, o primeiro sub-passo deve identificar metas comerciais a serem atcançadas; caracteristicas e objetivos do sistema; que diferem das metas por medir por estimativas de tempo e satisfaçăo os aspectos chaves do projeto. O segundo sub-passo tem $\sigma$ objetivo de identificar as fontes de consulta (documentos, dicionários, manuais, etc.) como também os usuários finais envolvidos no levantamento das caracteristicas do-sistema. $O$ terceiro sub-passo é usada para identificar as áreas centrais do sistema, pois tais áreas serão consideradas tópicos fundamentais durante a análise. Finalmente o quarto sub-passo deve gerar um plano preliminar de metas para a análise, que particione as áreas centrais de atividade, estabeleça prioridades e faça estimativas de tempo e satisfação. Esse plano será posteriormente integrado ao um plano principal, que coordenará toda a análise. O passo 0 é descrito de forma textual, destacamdo-seus sub-passos como tópicos desse-texto.

\section{Passo 1 - Entender o Problema}

Uma vez feita a anátise do contexto, o próximo passo é determinar $\sigma$ quê $\sigma$ sistema supostamente deve fazer, para quem deve fazer e quem participará destas ações. $A$ idéia básica é especificar cenários que cubram toda a furrcionalidade do sistema (idéia similar à do Objectory, de Jacobson, em seus casos de uso [6]).

Os cenários serão obtidos por intermédio de entrevistas realizadas basicamente com dois tipos de pessoas envolvidas no sistema: os usuários e os peritos do domínio. Usuánios são pessoas que executam atividades corriqueiras no sistema. A identificação dos peritos dependerá do tipo de sistema a ser construido. Genericamente, peritos inctuem pessoas que trabatham dentro do domínio ou com atguma experiência em sistemas do mesmo tipo. As entrevistas devem gerar documentos sob forma de cenários, que devem descrever em detalhes as características do sistema na visão dos entrevistados. A técnica de representação de cenários utiliza a criação de roteiros para representar as informação coletadas. As premissas básicas do OBA durante a construção dos roteiros são: escolher os cenários mais representativos, mapear os cenários dentro das atividades centrais do sistema, especificar cada passo como: agente inicial, ação; agente participante e serviço (ver tabela 2.1). Uma ação é o comportamento gerado por um agente iniciat que causa uma chamada aos serviços de um participante e um serviço é um tipo de comportamento que pode ser chamado via interface e é fornecido pelo participante. 
Cada roteiro deve conter um certo número de informações, incluindo:

- nome, que identifica o roteiro;

- precondiçöes, que denotam o que deve-ser verdade para o roteiro ser iniciado; e,

- poscondições, que denotam o que deve ser verdade quando o roteiro for finalizado.

Tabela 2.1-Exemplo de roteiro-para a operação de empréstimo de livro.

\begin{tabular}{|c|c|c|c|}
\hline \multicolumn{4}{|c|}{ Controle de empréstimo de livro } \\
\hline \multicolumn{4}{|c|}{$\begin{array}{l}\text { Nome do Roteiro: Exemplo de Empréstimo } \\
\text { Autor: Marisa } \\
\text { Versão: } 1.0 \\
\text { Précondições: Livro deve estar disponivel, leitor não tem pendências } \\
\text { Póscondiçôes: Livro Emprestado }\end{array}$} \\
\hline Agente Inicial & Ação & $\begin{array}{c}\text { Agente } \\
\text { Participante }\end{array}$ & Serviço \\
\hline Bibliotecária & $\begin{array}{l}\text { Localizar a ficha } \\
\text { do leitor } 13\end{array}$ & Ficha do leitor 13 & $\begin{array}{c}\text { Localizar uma ficha de } \\
\text { usuário }\end{array}$ \\
\hline Bibliotecária & $\begin{array}{c}\text { Verificar situação } \\
\text { de pendência do } \\
\text { leitor } 13\end{array}$ & Ficha do leitor 13 & $\begin{array}{l}\text { Verificar a situação de } \\
\text { pendência }\end{array}$ \\
\hline Bibliotecária & $\begin{array}{l}\text { Retirar a ficha do } \\
\text { livro P32 n01 } 242\end{array}$ & $\begin{array}{c}\text { Ficha do livro P32 } \\
\text { n01 } 242\end{array}$ & Retirar a ficha do livro \\
\hline Bibliotecária & $\begin{array}{c}\text { Entregar o livro } \\
\text { P32. n01 } 242 \text { ao } \\
\text { usuário }\end{array}$ & Livro P32 .n01 242 & Entregar Livro \\
\hline
\end{tabular}

Criar roteiros para qualquer tipo de sistema introduz potencialmente uma terminologia nova durante sua descrição e devido a isso, o OBA define um conjunto de glossários que deve incluir todos os termos criados nos roteiros. O propósito de obter esse consenso de terminologias é determinar uma descrição única e consistente para cada aspecto do sistema. O último sub-passo dentro do passo 1 é fornecer os atributos para os roteiros, gerando outro glossário que contém os atributos para todos os agentes, ações e serviços do sistema.

Uma das características mais importantes do OBA a normalização de vocabulário durante as fases de entendimento e descrição do problema. No entanto, a técnica de cenários representada por roteiros pode se tornar muito complexa e trabalhosa em sistemas grandes, caso não seja apoiada por uma ferramenta específica.

\subsubsection{Construção de Cenários no Método SBRE (Scenario Based Requirements Elicitation)}

O SBRE [8] é um método utilizado para estruturar as primeiras interações entre usuários e projetistas visando a obtenção rápida e eficiente de um conjunto inicial de 
requisitos. Os objetivos do SBRE são obtidos por intermédio do desenvolvimento paralelo de requisitos, do uso de cenários para exibir o comportamento do sistema, de funções de avaliação para adequação do projeto e de uma base de informações que é usada para sustentar as idéias sugeridas durante o projeto. Esse método consiste na sintetização de todas essas informações em um único processo. O SRBE não é uma substituição à fase de engenharia de requisitos do ciclo de vida de desenvolvimento, é apenas uma técnica complementar usada para coordená-la.

Os cenários são utilizados como canal de comunicação entre projetistas e usuários na elicitação de requisitos e na avaliação das soluções propostas. A arquitetura conceitual do SBRE é constituída de quatro conjuntos de informações que são criados e manipulados durante a fase de engenharia de requisitos:

- Conjunto de objetivos : inclui definições de "o quê" o sistema deve fazer e "como" deve fazer. Essas definições podem ser requisitos, padronizações ou outras fontes disponiveis.

- Conjunto de Projetos: inclui os modelos ou planos de projetos que serão formulados durante a elicitação dos requisitos. Como a forma de representação e o nível de detalhes pode variar muito, o conjunto de projetos serve como um repositório das decisões de projeto que orientarão a construção do sistema.

- Conjunto de Cenários: inclui a visão do projetista de como o sistema cumpre os objetivos definidos dentro do conjunto dos objetivos. Esses cenários deverão ser validados junto aos usuários, com o objetivo de melhorar ou definir novas soluções para o sistema.

- Conjunto de proposições: é um mecanismo que facilita a troca de idéias entre todos os envolvidos na elicitação de requisitos. Uma proposição pode ser um problema, posição ou questão relevante ao projeto. No SBRE existem quatro tipos de proposições: hipóteses, feitas pelo projetista em face de uma falha no conjunto dos requisitos; respostas, são reações do usuário às soluções propostas pelo conjunto dos cenários: Implicações, que são reservas a serem adotadas quanto a adoção de um determinada solução; $e$, notas, que são informações gerais que poderão ser relevantes em algum momento do projeto.

Como mostra a Figura 2.4, o conjunto de objetivos é criado dentro do universo do domínio do usuário e o conjunto de projetos é criados dentro do universo do domínio do projetista. A comunicação entre esses dois universos é realizada pelos conjuntos de cenários e de proposiçōes. 


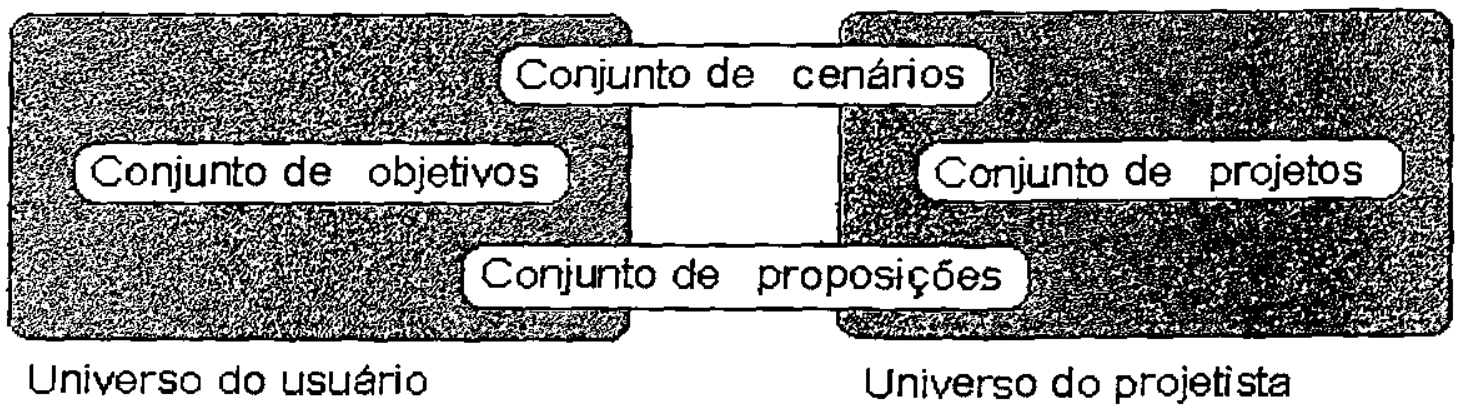

Figura 2.4 Macro visão da arquitetura do-SBRE

\section{Geração de Cenários}

O processo do SBRE (baseado no modelo de-Malhotra [9]) consiste resumidamente em um ciclo de geração e apresentação de cenários extraídos de um grupo inicial de requisitos e posteriormente refinados iterativamente ao mesmo tempo em que é mantido um alto nível no projeto em desenvolvimento. Um exemplo de cenário gerado pelo SBRE é mostrado na figura 2.5 .

Após a elaboração do conjunto inicial dos objetivos do projeto, o projetista deve formular modelos de projetos retratando como esses objetivos podem ser atingidos. Baseado no entendimento extraido desses modelos ele (o projetista) deve desenvolver cenários para demostrar como o modelo de projeto satisfará os requisitos especificados. Com relação à afqutitetura conceitual, esses cenários devem relacionar cada modelo de projeto a um objetivo em particular, isto é, cada subconjunto de cenários deve apresentar solução para aperıas um objetivo especifico.

Depois de formulado o conjunto de cenários, é iniciada a fase de avaliação desses cenários. Nessa fase é usado um mecanismo de realimentação que concilia o desenvolvimento do conjunto de projetos (projeto em alto nível) e do conjunto de objetivos (requisitos do usuário). Em geral, a avaliação de um cenário envolve a tomada da opinião dos usuários quanto ao grau de satisfação obtido a partir do conjunto de cenários.

Todas as perguntas, concordâncias e discordâncias dos usuários com relação aos cenários devem ser registradas dentro do conjunto de proposições. Esses registros podem indicar que um cenário não está resolvendo o objetivo que se propõe a resolver, nesse caso o cenário deve ser refeito de acordo com as propostas (ou dúvidas) do usuário. Se as propostas (ou dúvidas) forem muitas, pode ser necessário modificar o conjunto de objetivos, o que faz com que usuários e projetistas devam juntos reavaliar os requisitos do projeto.

A partir do conjunto de cenários modificado, a fase de geração dos cenários é iniciada novamente. $O$ ciclo deve se repetir até que todos os objetivos dessa fase tenham sido especificados em um ou mais cenários e esses cenários tenham sido totalmente aprovados pelos usuários. 
INÍCIO DO CENÁRIO: Empréstimo usando Scanner

- Um leitor chega na mesa da bibliotecária com alguns livros a serem emprestados

- A bibliotecária solicita ao leitor um documento com foto e seu cartão da biblioteca contendo sua identificação em código de barras.

- A bibliotecária lê a cartão com o scanner e a tela abaixo surge no terminal:

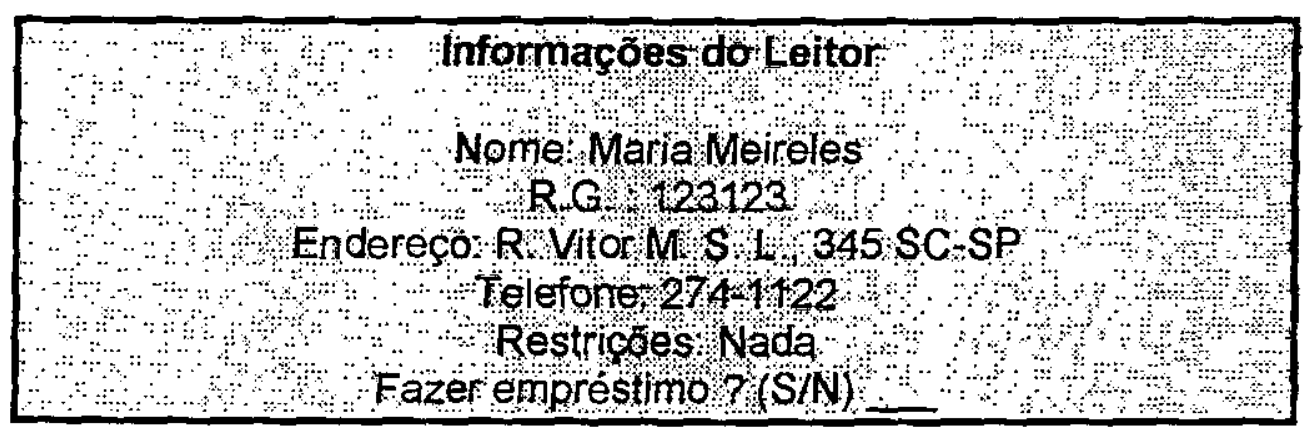

- A bibliotecária verifica a tela para ver de existe alguma restrição para os privilégios do leitor. Se não, a bibliotecária digita um "S" no campo "Fazer empréstimo", e lé o código de barras do livro, produzindo a seguinte tela:

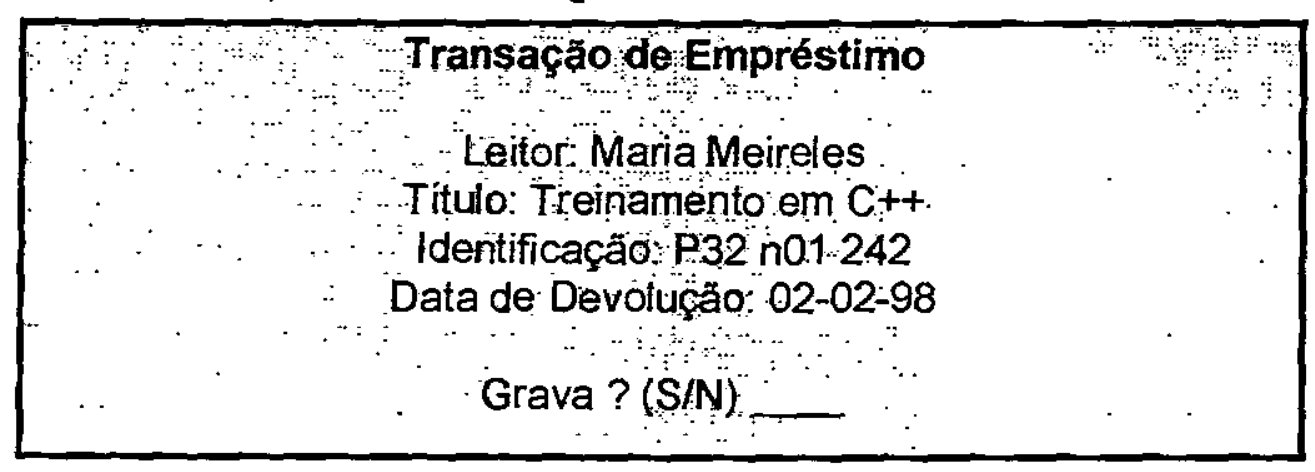

- A bibliotecária verifica a informação, imprime o livro com a data de devolução, e digita "S" no campo Gravar? Neste ponto o sistema registra o empréstimo e atualiza a informação sobre a disponibilidade do livro.

Figura 2.5 Exemplo de cenário para a operação de empréstimo de livro.

\subsection{4 - Abordagem Formal para Análise de Cenários}

A análise de cenários [10] é o processo de entendimento, análise e descrição do comportamento de um sistema, que tem como base os diferentes agentes que dele participam. A engenharia de requisitos pode utilizar a análise de cenários como canal de comunicação entre o usuário e o analista do sistema, a quem deve fornecer um perfil do usuário e o comportamento do sistema sob o ponto de visto do mesmo. 
O produto final da análise de cenários é um documento que inclui um conjunto de cenários completos, consistentes e válidos. Esse documento então torna-se parte da especificação de requisitos do sistema e deve ser usado como um guia nas fases posteriores. A Figura 2.6 mostra o modelo de análise de cenários, suas fases e o nível de interação entre elas.

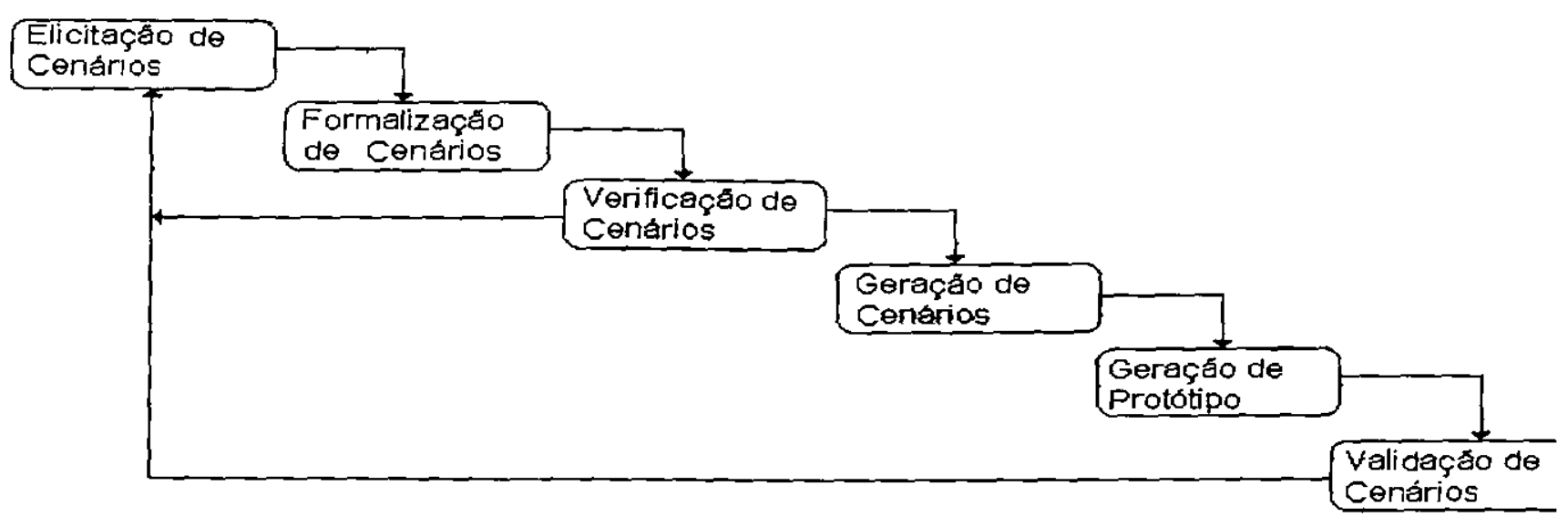

Figura 2.6 Modelo de processo da análise de cenários

O processo de análise de cenários, baseado nos trabalhos de Holbrook [8] e Rumbaugh [11], apresenta 6 fases com diferentes niveis de interação do usuário: Elicitação de cenários, inicia com a construção da árvore de cenários que é um mecanismo que descreve e representa vários cenários, cada um para uma visão (ou grupo de usuários) em particular, chamada visão do usuário; Formalização de cenários, que transforma cada árvore de cenário em uma gramática regular, usada para construir máquinas de estados que modelam o comportamento do sistema para determinadas visões (a gramática e a máquina de estados formam o que é chamado de modelo formal abstrato, usado para captar, representar e mostrar o comportamento do sistema); Verificação de cenários, em que são eliminados os problemas de inconsistências e redundâncias da análise; Geração de cenários, em que o analista usa um processo automático para gerar os cenários a partir do modelo formal abstrato; Geração de protótipos, em que o analista constrói um protótipo inicial com base nos cenários gerados; e Validação de cenários, em que o analista usa o sistema protótipo para validar os cenários e demostrar essa validação ao usuário.

\section{O Processo}

\section{Elicitação dos cenários}

- Identificar e classificar os grupos de usuários 
Os grupos de usuários podem ser classificados em: independentes, nos quais todos os usuários interagem com o sistema sem a necessidade de outros usuários e associados, nos quais os usuários necessitam de outros usuários para completar seus cenários.

- Identificar visões para cada grupo de usuários

Os grupos de usuários podem ser divididos em dois tipos de visões: ativas, nas quais o usuário é o agente da interação com o sistema e dependente, nas quais o usuário deve contar com outros agentes para ativar sua interação com o cenário.

- Construir árvores de cenários para cada visão

O analista deve construir uma árvore de cenários a partir das descrições dadas pelo usuário. Cada nó dessa árvore de cenários representa um estado descrito pelo usuário e cada ramificação um conjunto de eventos especificos para uma determinada visão.

\section{Formalização dos cenários}

- Gerar gramáticas dos cenários a partir das árvores, utilizando um algoritmo. Um exemplo de uma árvore de cenários e sua gramática é mostrado na figura 2.7 .

- Construir uma máquina de estados conceitual a partir da gramática, para cada visão do usuário.

\section{Verificação dos Cenârios}

Este passo é composto de dois sub-passos. No primeiro checa-se a gramática criada no passo anterior com base na árvore que a gerou. No segundo verifica-se a máquina de estados conceitual quanto à consistência e completitude interna.

\section{Geração dos cenários}

Para cada visāo do usuário o analista deve-gerar cenários a partir da máquina de estados conceitual daquela visão. Os cenários assumem a forma de esquemas, em que cada esquema é um caminho dentro da máquina conceitual.

\section{Geração do protótipo}

Existem vários métodos de prototipação que podem ser utilizados neste passo, porém o método mais adequado à análise de cenários é a prototipação baseada em telas, que é uma forma barata de captar a visāo externa de um sistema, a partir da perspectiva do usuário. Um ponto importante na escolha do método de prototipação é obter uma ferramenta que ofereça prototipação rápida e automática. 


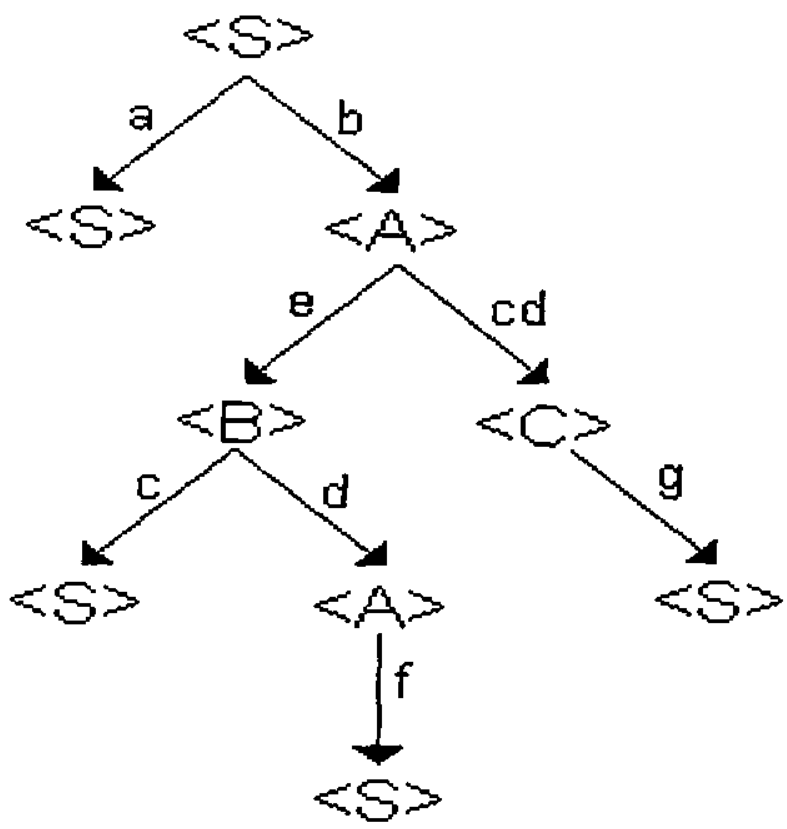

$$
\begin{aligned}
& G=(N T, E, S, R) \\
& E=\{a, b, c, d, e, f, g, c d\} \\
& N T=\{<S>,<A>,<B>,<C>\} \\
& R=\{<S>\rightarrow a<S> \\
&<S>\rightarrow b<A> \\
&<A>\rightarrow e<B> \\
&<A>\rightarrow c d<C> \\
&<B>\rightarrow c<S> \\
&<B>\rightarrow d<A> \\
&<A>\rightarrow f<S> \\
&<C>\rightarrow g<S>\}
\end{aligned}
$$

gura 2.7 Exemplo de uma árvore de cenários e sua gramática: $O$ conjunto NT representa os estados do sistema. O conjunto $E$ representa os eventos gerados a partir de cada estado. S é um elemento pertencente a NT que inicia a árvore. $R$ é um conjunto finito de regras, que relaciona os estados e eventos envolvidos nas transições.

\section{Validação dos cenários}

Para a validação ter êxito, é necessário avaliar todos os grupos de usuários identificados.

A validação dos cenários é composta de três fases:

- Validar cenários de cada grupo;

- Validar cenários de cada visão individual;

- Executar simultaneamente os cenários em grupo e individualmente.

A análise de cenários termina quando ambos: 0 analista e 0 usuário, ficam satisfeitos com a validação dos cenários. O processo de análise de cenários comporta apenas sistemas que têm uma única resposta para cada estímulo. Ele não comporta sistemas complexos, tais como controladores de múltiplos elevadores, porque não pode manusear estímulos e respostas concorrentes.

2.4.5 UORE (Usage Oriented Requirements Engineering), uma extensão ao Modelo de Casos de Uso do Método Objectory 
A fase de engenharia de requisitos do método Objectory [6] é representada pela construção de um modelo de requisitos, que utiliza os conceitos de atores e de casos de uso para representar o comportamento do sistema quando utilizado pelos usuários. No Objectory, o ator é considerado como uma classe, e os usuários săo instâncias dessa classe. Um usuário pode aparecer em várias instâncias de diferentes atores, dependendo do contexto do caso de uso. Um caso de uso é a visão da utilização do sistema para um ator especifico. Os casos de uso são descritos com termos do domínio do problema, sendo que as descriçōes dos atores e dos casos de uso formam um modelo de casos de uso, que é a primeira fase do modelo de requisitos no Objectory.

\section{Desvantagens do modelo de casos de uso}

A principal falha da engenharia de requisitos do método Objectory é a falta de sintese durante a construção do modelo de casos de uso. Nessa fase não existe uma definição clara da semântica dos casos de uso e regras consistentes sobre como eles devem ser descritos. Existem problemas também nos conceitos de atores e de casos de uso. Por exemplo, no Objectory cada caso de uso é atribuído a um ator específico, porém a descrição desse caso de uso pode envolver vários atores ao mesmo tempo, o que pode levar a uma série de erros de interpretação.

Genericamente, o modelo de requisitos do Objectory falha por não apoiar completamente algumas características fundamentais dos casos de uso:

- Casos de uso năo são independentes. Eles podem se sobrepor, ocorrer simultaneamente, ou influenciar uns aos outros;

- Casos de uso ocorrem sob condições específicas. Eles têm contextos especificos para serem iniciados e finalizados;

- O nivel de abstraçăo dos casos de uso e seu tamanho são conceitos arbitrários;

- Os casos de uso podem, na prática, exibir apenas parte de todas as possibilidades de uso do sistema.

\section{O Processo}

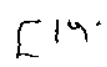

O processo proposto pelo UORE, por Regnell, em [12], visa a solução de algumas das limitações do modelo de requisitos do Objectory. O UORE propöe a construção de um Modelo de Uso Sintetizado (MUS) que estende o modelo de requisitos, adicionando-lhe uma fase de sintese onde os casos de uso são formalizados e integrados.

O UORE consiste de duas fases: fase de análise e fase de síntese, como mostra a figura 2.8. Na fase de análise é feita uma descrição dos requisitos, sendo que um modelo 
inicial de casos de uso é produzido, contendo as descrições dos atores e dos casos de uso. $\mathrm{Na}$ fase de sintese, esse modelo é formalizado e seus casos de uso são integrados, 0 que resulta na criação do modelo de uso sintetizado.

Fase de análise

A fase de análise do UORE consiste de duas atividades relacionadas:

- Identificação de atores e casos de uso;

- Unificação da terminologia.

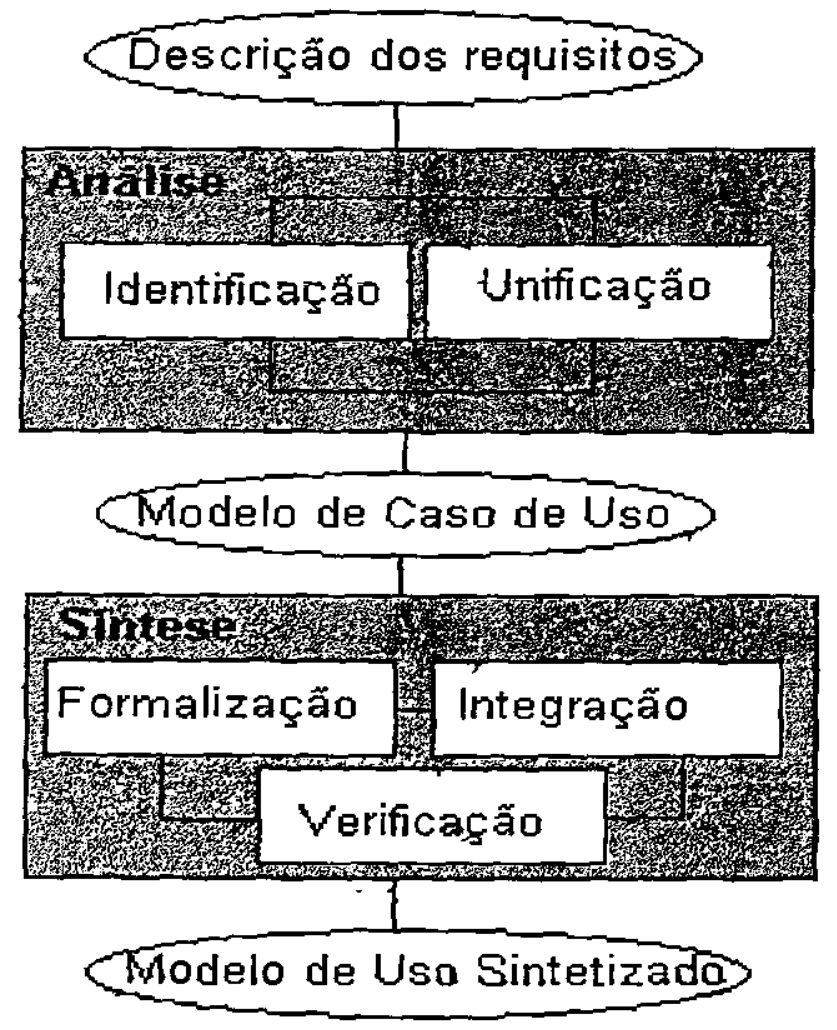

Figura 2.8 - Processo do UORE

A primeira atividade consiste em identificar e descrever atores e casos de uso: um exemplo dessa descrição é mostrado na figura 2.9. A segunda atividade unifica a terminologia dessas descriçōes. Para isso, os objetos do dominio do problema e seus atributos são identificados e descritos em um dicionário de dados, focalizando: entidades manipuladas pelos atores, operaçőes externas ao sistema e elementos da interface com o usuário. As duas atividades da fase de análise são executadas iterativamente até a criação do modelo de casos de uso do UORE. A atividade de análise do UORE difere da versão do Objectory para essa fase, pois: muda a semântica dos atores e dos casos de 
uso, identifica contextos para os casos de uso, aplica uma visão única para cada ator, unifica a terminologia e faz uma descrição estruturada dos casos de uş.

\section{Fase de síntese}

A fase de sintese consiste de três atividadẹs:

- Formalização dos casos de uso;

- Integração dos casos de uso;

- Verificação.

\section{Atores:}

Bibliotecária: supervisiona e mantém as operações do sistema de biblioteca escolar

Leito: usa os serviços de empréstimos de livros e consulta o catálogo de cartões 'on-line' do sistema de biblioteca escolar

1. Manutenção do inventário de livros, registros de livro novo

Ator: "Bibliotecária"

1.Cl Condicões de invocação:

1.Cl. 1 O sistema está pronto para transações.

\section{CF Condições de Fluxo:}

1.CF.1 A bibliotecária entra com um código de acesso válido.

1.CF.2 A bibliotecária entra com uma identificação do livro válido.

1.CF.3 O sistema possui a identificação do livro, título, autor, tipo de data e editora registrados.

\section{FE Fluxo de eventos}

1.FE.1 Um painel para fornecimento do código de acesso é dado.

1.FE.2 A bibliotecána entra com o código de acesso.

1.FE.3 O sistema verifica se o código de acesso é válido.

1.FE.4 Um painel "Entre com a identificação do livro: "é dado.

1.FE.5 A bibliotecária entra com a identificação do livro.

1.FE.6 O sistema verifica se a identificação do livro é válida.

1.EF.7 Um painel "Titulo:", "Autor", "Titulo da publicação:", "Data:" é dacło.

1.EF.8 A bibliotecária entra com Título, Autor, Tipo de publicação, Data.

1.EF.9 Um painel "Livro registrado" è dado.

\section{CT Condicões para término}

1.CT.1 O sistema está pronto para transações.

Figura 2.9 Exemplo de uma descriçăo de caso de uso. Os objetos do domínio do problema estāo em negrito e a terminologia definida está em itálico. 
Essas três atividades são executadas iterativamente até que todos os aspectos de corretitude e completitude do MUS sejam descobertos.

\section{Atividade de formalização}

O produto final da atividade de formalização é a produção de um conjunto de especificações formais de casos de uso. Essas especificaçōes são representadas em uma linguagem gráfica que expressa a ordem temporal de estímulos aos usuários, respostas do sistema e operaçóes atômicas.

A atividade de formalização é composta pelos seguintes passos:

- Identificação dos objetos abstratos de interface;

O usuário nunca se comunica diretamente com o sistema. Uma interface está sempre envolvida nessa comunicação. As entidades que formam o ambiente da comunicação são chamadas de objetos abstratos de interface. A identificação das entidades que tomam parte na comunicação ator/sistema é conseguida pela análise de todos os casos de uso e da terminologia do domínio do problema.

- Identificação das operaçōes atômicas;

Uma operação é atômica do ponto de vista de um ator se ela não requer nenhuma comunicação com esse ator durante sua execução. Operações atômicas são identificadas a partir de operaçōes do sistema que näo necessitem de interação com o ator envolvido no caso de uso.

- Criação de uma especificação para cada caso de uso.

Após identificar os objetos abstratos de interface e as ações atômicas de todo o sistema, o fluxo de eventos de cada caso de uso é transformado em um modelo de relacionamento temporal. Um exemplo desse modelo é mostrado na figura 2.10 .

\section{Atividade de integração}

A atividade de integração consiste da união das várias especificações e produçăo do modelo de uso sintetizado. O MUS é uma coleção de visões de uso, uma para cada ator.

A atividade de integração é composta pelos seguintes passos:

- Identificação de ações do usuário e do sistema; 
Ao representar formalmente um caso de uso é necessário ter um mecanismo de abstração para representar as protocolos de interação durante a parte do caso de uso controlada pelo usuário e a parte controlada pelo sistema. São usados então os termos "açס̃es do usuário" para protocolos em que o usuário está no controle, e "açס̋es do sistema" para protocolos em que o sistema está no controle.

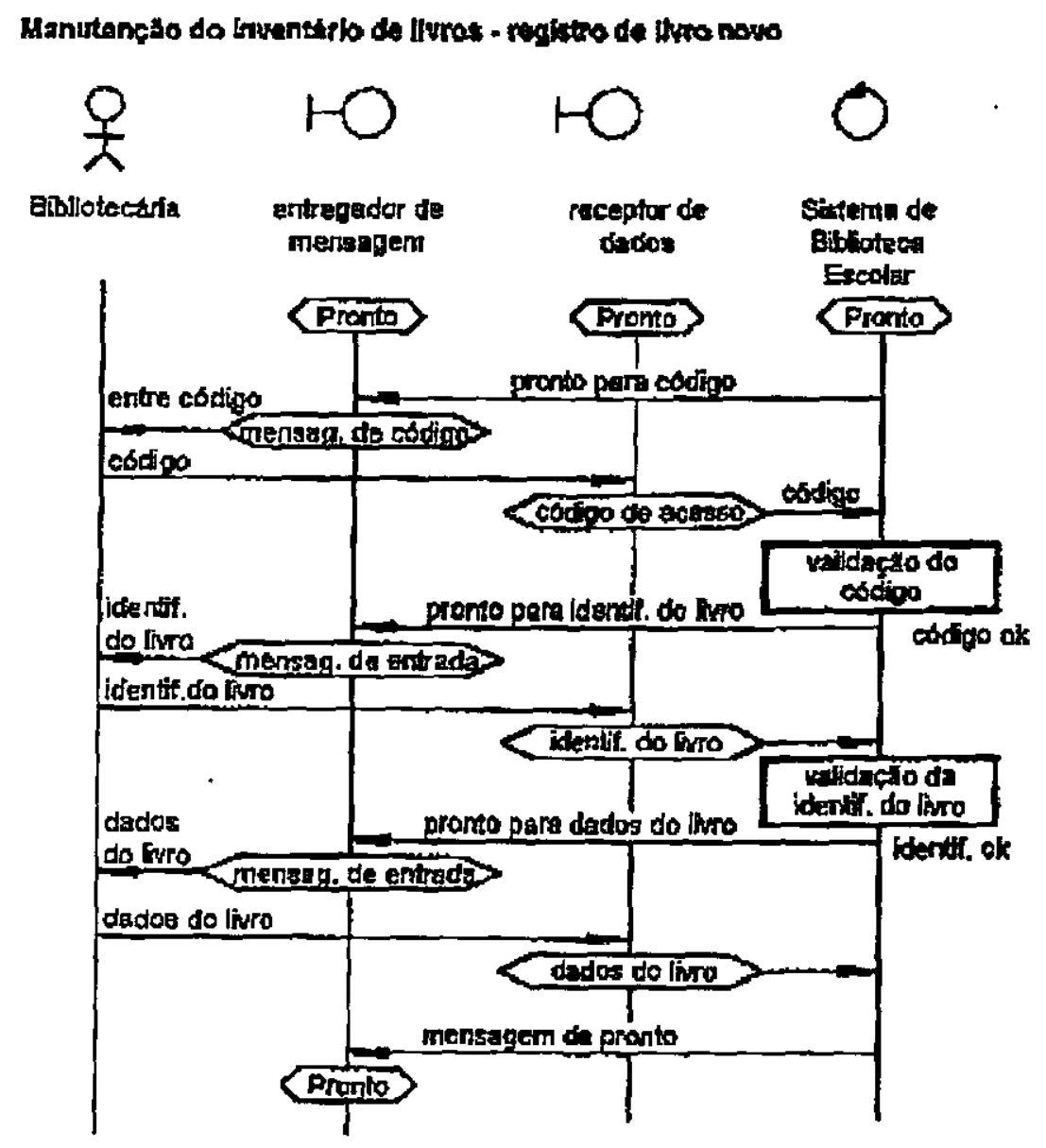

Leginda:

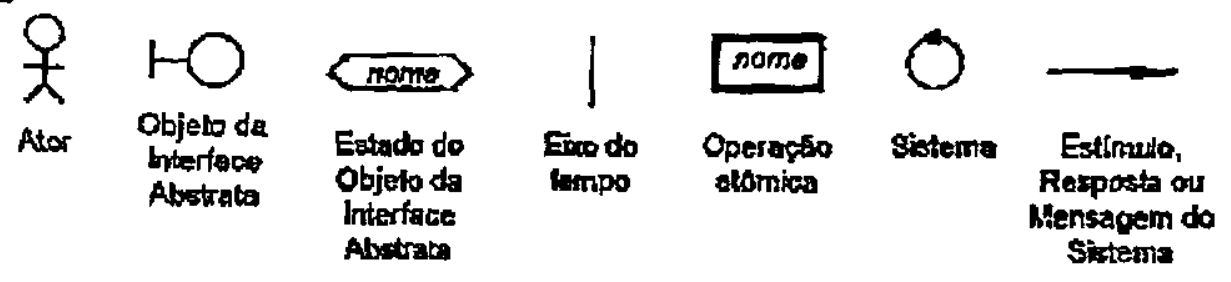

Figura 2.10 Exemplo de especificação de um caso de uso por meio de um diagrama de interação.

- Criação de cenários abstratos de uso;

Depois de identificar abstraçōes dos protocolos do sistema, cada especificação é transformada em um cenário abstrato de uso (CAU), desenhado como um seqüência de 
ações do usuário e ações do sistema, interconectadas por transições que representam as mensagens resultantes de cada ação. Um exemplo de CUA é mostrado na figura 2.11. A razão para criar esses cenários é viabilizar a sintese dos modelos quando existe um grande número de casos de uso

- Integração dos cenários abstratos de uso.em um modelo de uso sintetizado.

O modelo de uso sintetizado representa a visão geral de uso do sistema para um ator. Essa visão de uso é composta a partir da união de todos os cenários abstratos de uso produzidos para cada ator específico.

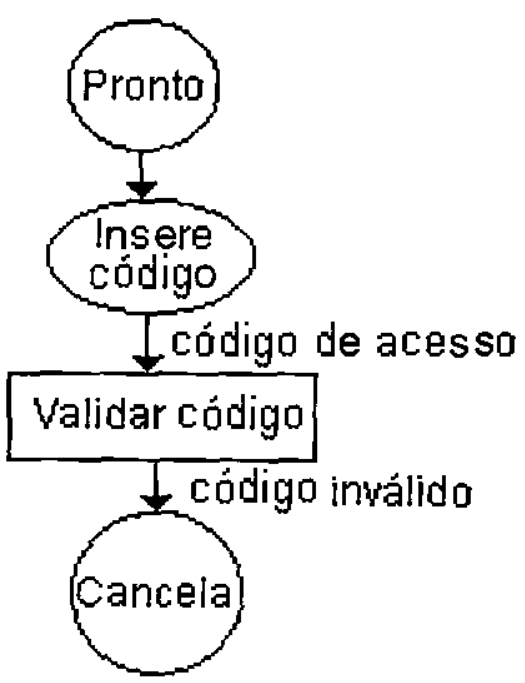

Figura 2.11 Exemplo de cenário abstrato de uso. Os circulos representam os estados inicial e final da Interação. As elipses representam as açōes do usuário e os retângulos as ações do sistema.

\section{Atividade de verificação}

O propósito da atividade de verificação é obter um MUS consistente e completo. Os dois passos que formam a atividade de verificação estão relacionados às atividades de formalização e integração, respectivamente:

\section{- Verificação das especificações de casos de uso}

Essa verificação é executada junto ao modelo criado na fase de análise do UORE. A revisão consiste em checar se a interpretação da especificação dos casos de uso foi correta, isto é, se todos os elementos do modelo estão contidos na descriçăo do caso de uso e se todos os objetos do domínio do problema estão definidos de forma consistente. 
Essa segunda verificação consiste em assegurar que o MUS cobre completamente a descrição dos casos de uso. Nesse passo, uma ferramenta poderia checar se todo cenário abstrato de uso é um caminho possivel dentro da visão de uso correspondente, pois é provável que durante a fase de síntese, novos usuários e novas ações do sistema sejam descobertas e incorporadas à visão de uso, aumentando assim o número de cenários abstratos de uso.

\section{Conclusões}

As idéias propostas pelo UORE visam a melhoria dos aspectos de identificação, descrição, formalização e síntese dos casos de uso propostos no modelo de requisitos do Objectory.

Em resumo, as principais características do UORE são:

- Aperfeiçoar os conceito de atores e de casos de uso;

- Formalizar as descrições dos casos de uso;

- Sintetizar os casos de uso em um modelo.

\subsubsection{Outras Abordagens}

Nesta seção são discutidas outras abordagens relacionadas à elicitação, análise e modelagem de requisitos.

\section{Modelagem de casos de uso para grandes sistemas comerciais}

Os cenários foram redescobertos nos métodos mais atuais, ganhando força nas pesquisas que tratam da captura e compreensão de requisitos e relacionando diferentes domínios e áreas de interesse da engenharia de software. Dentre essas contribuições, os trabalhos de Amour [13] e Kaufman [5] serão revisados abaixo:

Os casos de uso podem e estão sendo usados em uma grande variedade de abordagens de desenvolvimento. A American Management Systems (AMS) tem aplicado casos de uso com sucesso na modelagem e reengenharia de grandes sistemas comerciais [13].

A AMS utiliza uma técnica de seleção e descrição de componentes, aplicando uma série de passos durante a modelagem dos casos de uso. Esses passos são:

- a preparação de diagramas de contexto e identificação das partes externas ao sistema; 
- a identificação de atores e de casos de uso para cada ator;

- a criação de Modelos de Área Funcional que particionam coleções de casos de uso em áreas funcionais

- a criação de sumários para os casos de uso;

- o refinamento dos casos de uso identificados;

- o desenvolvimento de diagramas de dependência dos casos de uso identificados;

- identificação de funcionalidades comuns aos casos de uso e sua organização em casos abstratos de uso.

Outra abordagem para a exploração de requisitos é a chamada Prototipação rápida baseada em Cenários (PRBC) [13], que utiliza os cenários como mecanismo para evidenciar problemas na utilização do sistema e a criação de protótipos para demostrar aos usuários as funções do sistema e como ele será usado.

Uma técnica de seleção e implementação da abordagem PRBC é discutida por Kaufman em [5], explorando estratégias úteis para a criação de um modelo baseado em cenários que reflita os requisitos do sistema. Tais estratégias estão baseadas principalmente na adaptação de testes caixa preta para medir a quantidade de requisitos cobertos pela construção dos cenários. A validade do modelo pode ser checada por intermédio de um melhor conhecimento sobre o domínio do problema e técnicas de realimentação usadas quando o analista interage com o usuário.

Especificação e prototipação de um ambiente para modelagem de sistemas orientados a objetos usando uma representação canônica.

Para que a modelagem de um sistema orientado a objetos esteja completa é necessário o uso de diversas técnicas e métodos de especificação de requisitos. Cada técnica ou método produz uma visão diferente do mesmo problema, e quase todas as vezes esta visão não consegue representar completamente todos os requisitos de um sistema. Para representar requisitos de software definidos segundo diferentes técnicas e métodos, foi proposta por Davis [34] uma representação canônica (RC) para requisitos, baseada em nove elementos tais como entidade, mensagem, atributo, e dez relacionamentos entre os elementos. A RC é uma representação interna para a qual podem ser mapeados os modelos produzidos por quaisquer técnicas de especificação de requisitos. Usando a RC pode-se integrar as várias visöes de um mesmo sistema, produzidas pelas diversas técnicas e modelos de especificação de requisitos.

O trabalho apresentado em [35] propõe a especificação e prototipação de um ambiente para a modelagem de sistemas orientados a objeto. $O$ ambiente é composto de 
uma ferramenta gráfica para modelagem de sistemas orientados a objeto e de domínios encapsulados na máquina Draco-PUC [22], [27]. O ambiente para a modelagem de sistemas é integrado com a máquina Draco-PUC, que é um sistema transformacional orientado a dominios de software, que utiliza uma tecnologia de reutilização de software baseada no uso de bibliotecas de transformações. Um domínio na máquina Draco-PUC é definido por uma linguagem com analisadores léxico e sintático (parser), um preetyprinter (unparser) e bibliotecas de transformações, que realizam transformações escritas em um determinado dominio (transformações horizontais), ou para outros domínios encapsulados na máquina Draco-PUC (transformações verticais).

Para escrever especificações de requisitos definidas sob quaisquer técnicas ou modelos usando a RC, foi definida uma linguagem denominada RC. Esta linguagem RC constitui uma das partes do domínio RC definido na máquina Draco. Além da linguagem, definida por seus analisadores léxico e sintático, o domínio RC ainda possui um prettyprinter e bibliotecas de transformações.

Especificações de requisitos de determinadas técnicas e modelos são analisados e mapeados para RC. A partir da forma interna as especificações podem ser transformadas usando as transformações definidas no domínio RC. As transformaçōes horizontais transformam especificações de requisitos escritas em determinada técnica e método, em especificações definidas segundo novas técnicas. As transformações verticais do domínio $\mathrm{RC}$ são responsáveis pela implementação da especificação definida na linguagem RC em uma linguagem de alto nivel.

\subsection{Avaliação das Técnicas de Cenários Revisadas}

Neste capítulo foram apresentadas as fases de engenharia de requisitos de vários métodos que adotam cenários como forma de captar e representar o conhecimento do domínio do problema. A seguir é apresentada uma avaliação dessas fases.

Em todos os métodos revisados as especificações de requisitos do sistema são obtidas a partir da coleta de informações realizada junto aos componentes do domínio do problema. Os métodos apresentados tentam descrever o comportamento do sistema do ponto de vista do usuário, identificando agentes (atores no Objetory, iniciadores/participantes no OBA, etc) que realizam interações com o sistema.

As principais diferenças entre os métodos revisados estão relacionadas com a forma de representação e a generalidade das descrições dos cenários. As diferenças são significativas e a forma como elas se apresentam varia muito.

Pôde-se observar que os métodos Objectory, SBRE, UORE e OBA usam roteiros para descrever as cenas de utilização do sistema, possuindo um conjunto de regras para definir essas descrições. Algumas descrições exigem um contexto para inicio e término das cenas (OBA e UORE) e outras integram ao roteiro aspectos de interface como telas e mensagens (Objectory e SBRE). Um modelo diferente de descrição é a árvore de cenários 
apresentada no método de análise de cenários, que no entanto possui as limitações de não suportar a ocorrência de eventos concorrentes e interaçōes entre cenários.

Alguns dos métodos revisados possuem formas genéricas para descrever os cenários de interação (Objectory e UORE) utilizando os agentes para representar um determinado papel que os usuários podem assumir no sistema. Outros métodos, como o OBA, utilizam formas de descrições mais específicas para representar açōes e serviços dos agentes; essas descrições são depois generalizadas ao longo das descrições dos casos de uso.

Certas caracteristicas de alguns métodos analisados são fundamentais para o sucesso da técnica de construção de cenánios. Inicialmente é necessário uma definição correta da semântica dos agentes, pois quando os cenários são construídos os focos de interação com o sistema devem ser bem definidos, para não gerarem confusões na definição das cenas. Quando são criadas as descriçőes dos cenários, uma terminologia nova é criada para manipular o domínio do problema. Por isso alguns métodos (OBA, UORE) propõe a criação de glossários para unificar os termos pertencentes a um determinado domínio. Alguns métodos (Arlálise de Cenários, UORE) apresentam fases de validação dos cenários, que são fundamentais na engentharia de requisitos;, pois são meios para validar as especificações dos requisitos coletados. Finalmente, uma característica importante verificada na engenharia de requisitos do método UORE foi a preocupação com a produção de um documento contendo cenários completos e consistentes, os quais poderiam ser usados para guiar as fases de projeto e testes do ciclo de vida.

Tabela 2.2 Cada célula marcada indica umtópico suportado; uma céluła em branco indica que o tópico não foi apoiado pelo método. A Tabela não avalia se o método suporta bem ou não o recurso.

\begin{tabular}{|l|c|c|c|c|c|}
\hline \multicolumn{5}{|c|}{$\begin{array}{l}\text { Comparação das Abordagens que Utilizam Cenários para Especificação e } \\
\text { Elicitação de Requisitos }\end{array}$} \\
\hline $\begin{array}{l}\text { Abordagens que utilizam cenários } \\
\text { técnica de construção de } \\
\text { cenários }\end{array}$ & $\begin{array}{l}\text { Método } \\
\text { Objectory }\end{array}$ & $\begin{array}{l}\text { Método } \\
\text { OBA }\end{array}$ & $\begin{array}{l}\text { Método } \\
\text { SBRE }\end{array}$ & $\begin{array}{l}\text { Análise } \\
\text { de } \\
\text { Cenários }\end{array}$ & $\begin{array}{l}\text { Método } \\
\text { UORE }\end{array}$ \\
\hline $\begin{array}{l}\text { Identificação de uma } \\
\text { semântica para os agentes }\end{array}$ & $\mathbf{x}$ & $\mathbf{x}$ & & $\mathbf{x}$ & $\mathbf{X}$ \\
\hline Criação de modelos & $\mathbf{x}$ & $\mathbf{x}$ & $\mathbf{x}$ & $\mathbf{x}$ & $\mathbf{X}$ \\
\hline Integração & $\mathbf{x}$ & $\mathbf{x}$ & $\mathbf{x}$ & & $\mathbf{X}$ \\
\hline Verificação & & & & $\mathbf{x}$ & $\mathbf{x}$ \\
\hline Formalização & & & & $\mathbf{x}$ & $\mathbf{X}$ \\
\hline Validação & $\mathbf{x}$ & $\mathbf{x}$ & & & $\mathbf{X}$ \\
\hline Criação de glossários & & & & $\mathbf{x}$ & \\
\hline Geração de protótipos & & &
\end{tabular}

É importante conhecer, dentre as abordagens que usam cenários, quais podem ser aplicadas durante a fase de engenharia de requisitos, a fim de obter um processo e uma 
notação bem definidos. Na tabela 2.2 estão listados os componentes críticos na técnica de construção de cenários. Esses componentes estão relacionados com os métodos e extensões discutidos neste capítulo. O critério de classificação envolve a consideração ou não de cada tópico na tabela. Dentre os cinco métodos revisados, nenhum apresentou todos os componentes críticos mencionados, porém os métodos UORE (extensão do Objectory) e Análise de Cenários foram identificados como os que possuem mais recursos.

Assim, conclui-se que uma ferramenta completa de apoio à engenharia de requisitos deve estar baseada nas melhores características dos vários métodos revisados, contendo: uma boa base semântica; a criação de modelos completos, consistentes, válidos, formais e sintetizados e a geração de resultados para apoiar as outras fases do ciclo de vida, possibilitando assim a criação de um veículo útil para as tarefas de elicitar, modelar e validar requisitos.

\subsection{Considerações Finais}

Neste capitulo foram discutidas diversas técnicas de implementação da fase de engenharia de requisitos com base na construção de cenários. Pôde se avaliar, por intermédio das técnicas apresentadas, as possiveis alternativas para a construção de uma ferramenta de apoio à engenharia de requisitos. Na linha dos cenários formais, como os descritos no Método de Análise Formal de Cenários, é utilizada uma notação muito elaborada que pode dificultar a interação com um usuário leigo. Nos cenários informais, como os descritos no método SBRE, não existe uma estrutura pré-determinada que estabeleça os componentes básicos de um cenário e sua complexidade. Na categoria dos cenários semi formais, os métodos que suportaram mais tópicos na tabela de comparação foram o Objectory e o UORE, ambos baseados em casos de uso. Segundo Jacobson, existe uma grande lacuna entre os casos de uso e o desenho e implementaçãa do modelo de objetos. Para preencher essa lacuna é necessário a identificação dos objetos e a solução de probtemas como concofrência e consistência entre os casos de uso. Infelizmente esses métodos nảo apóiam essa fase de transiçäo. Outro problema com relação aos casos de uso é que mesmo apresentando um boa forma de abstração funcional e comportamental, os métodos não descrevem uma forma concreta de integração entre os vários casos de uso. Além disso, não existe uma verificação formal bem definida para a checagem dos vários casos de uso. De uma forma geral, todos os métodos são incompletos nos pontos considerados como fundamentais durante a construção de cenários. Entretanto, as abordagens estudadas proporcionam uma análise objetiva, que possibilita a composição de uma solução a partir da fusāo dos pontos positivos das várias técnicas revisadas. 
Capítulo 3 - Descrição da UML 


\subsection{Considerações Gerais}

Apresenta-se neste capítulo uma descrição informal da UML (Unified Modeling Language) [21], esta linguagem é usada para especificação, construção, visualização e documentação de sistemas de software, assim como para a modelagem de negócios e outros sistemas não baseados em softwares. A UML representa uma coleção das melhores experiências de engenharia utilizadas com sucesso na modelagem de sistemas grandes e complexos. Este capitulo tem como objetivo apresentar a notação da UML, pois os modelos de análise gerados a partir da aplicação do método a ser proposto serão integrados a esta linguagem.

A UML é uma evolução dos conceitos de Booch, OMT (Object Modeling TechniqueRumbaugh), OOSE (Object-Oriented Software Engineering - Jacobson) e também de outros métodos orientados ou não a objetos. A notação UML é uma combinação da sintaxe gráfica de vários métodos, com alguns símbolos removidos (porque são confusos, supérfluos ou pouco usados) e com alguns símbolos adicionados. O resultado é uma linguagem de modelagem única, comum e ampla, utilizável por usuários destes e de outros métodos.

\subsection{Descrição Informal da UML}

Para modelar um sistema, a escolha das técnicas que serão utilizadas dependerá de como um problema é considerado e como uma solução é encontrada. A UML é intencionalmente independente de processo, não definindo um processo padrão para sua utilização. Os vários diagramas que formam a notação da UML incorporam diferentes elementos propostos por vários autores. Na figura 3.1 é mostrada a organização dos diagramas descritos na UML. As demais seções deste capitulo apresentam descrições informais dos diagramas que sāo descritos na UML e estäo organizadas da seguinte forma: na seção 3.2.1 são apresentados os Diagramas de Casos de Uso. Na seção 3.2.2 são apresentados os Diagramas de Classes. Na seção 3.2.3 são apresentados os Diagramas de Seqüência. $\mathrm{Na}$ seção 3.2 .4 são apresentados os Diagramas de Colaboração. Na seção 3.2 .5 são apresentados os Diagramas de Estados. Na seção 3.2.6 são apresentados os Diagramas de Atividades. Na seção 3.2.7 são apresentados os Diagramas de Componentes. $\mathrm{Na}$ seção 3.2.8 são apresentados os Diagramas de Distribuição.

\section{UML}

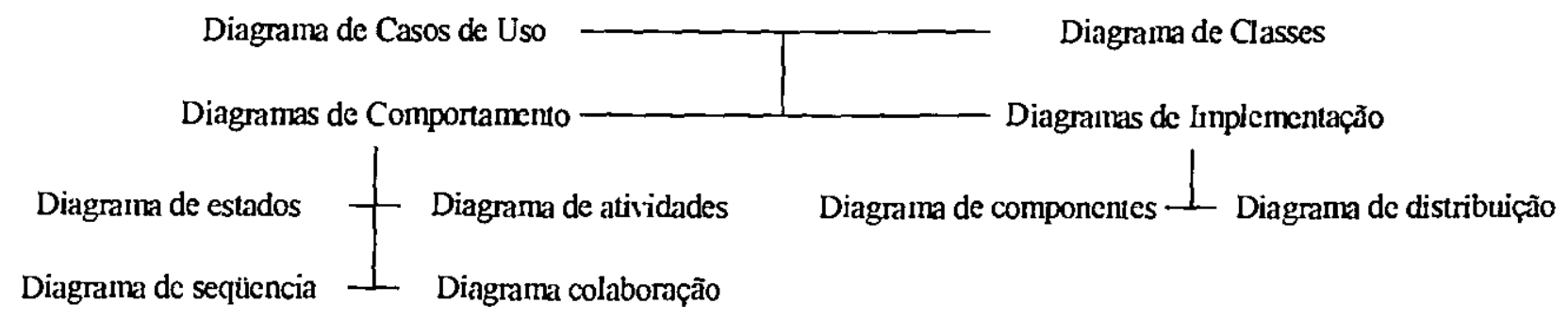

Figura 3.1 - Diagramas descritos na UML 


\subsubsection{Diagrama de Casos de uso}

Um Diagrama de Casos de uso utiliza uma coleção de casos de usos e atores para especificar ou caracterizar a funcionalidade e o comportamento de um sistema de aplicação. Os usuários ou qualquer outro sistema que possa interagir com o sistema que está sendo modelado são chamados de atores. Os atores representam os usuários do sistema, eles ajudam a delimitáto e fornecem uma visão clara do que será realizado.

Os Diagramas de casos de usos contém elementos representando os atores, relacionamentos de associação, relacionamentos de generalização e casos de usos. Pode ser criado um diagrama de casos de uso de alto nivel para visualizar o contexto e limites do sistema. É possível também criar um ou mais diagramas de casos de uso para descrever um sistema por partes. Os casos de usos podem incluir outros diagramas (de casos de usos, seqüência, colaboração, estados e de classes; que serăo estudados) como parte de seu comportamento.

Um ator é um estereótipo de uma classe e pode ser mostrado com uma representação especial de agente externo em um diagrama de casos de uso. Na UML, um estereótipo representa a metaclassificação de um elemento, isto é, mostra uma classe dentro do metamodelo da UML (i.e., um tipo de elemento de modelagem). Um ator modela um tipo de objeto que interage diretamente com o sistema mesmo estando fora do limite do sistema.

Um caso de uso é uma seqüência de transaçōes realizadas pelo sistema em resposta ao disparo de um evento, do ator para o sistema. Um caso de uso, quando realizado completamente, fornece um valor avaliável para o ator.

Os relacionamentos permitidos nos diagramas de casos de uso são:

- Associação, que representa uma conexão semântica entre caso de uso e ator. Associações são unidirecionais e são mais comuns que generalizaçōes. O nome da associaçäo é usado para identificar o propósito do relacionamento.

- Generalização, que representa um relacionamento entre casos de usos onde um caso de uso pode compartilhar o comportamento definido em um ou mais casos de usos.

Um relacionamento de generalização também apóia os estereótipos uses e extends. O tipo de generalização <<uses>> é usado para descrever o comportamento comum entre dois ou mais casos de usos. É um dos mecanismos utilizados para identificar comportamentos reutilizáveis pelas regras de negócio. 0 tipo de generalização <extends > é usado para expressar comportamento opcional por um caso de uso. A figura 3.2 ilustra um exemplo de Diagrama de Casos de Uso . 


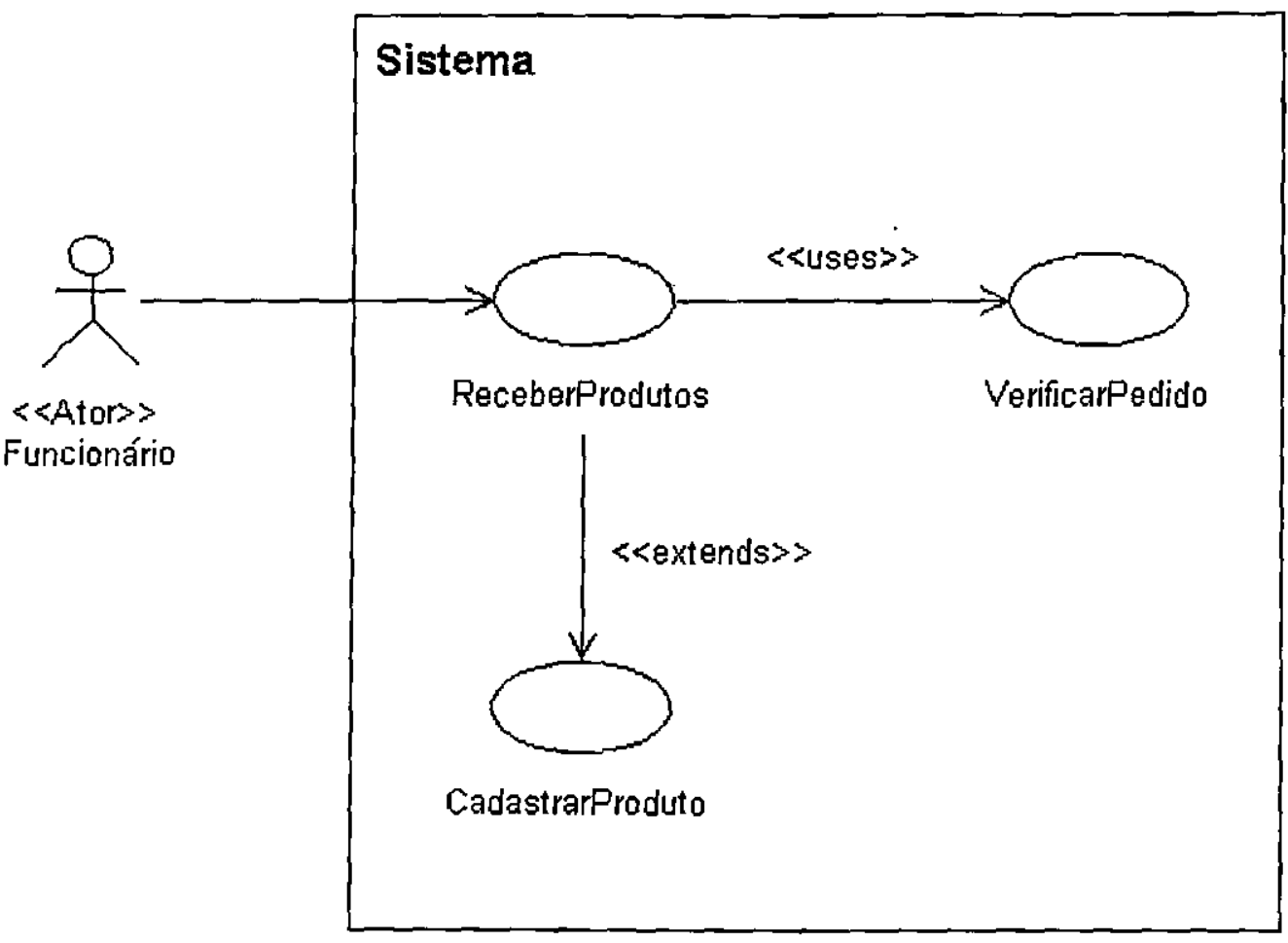

Figura 3.2 Exemplo de Diagrama de Casos de Uso

\subsubsection{Diagrama de Classes}

Um Diagrama de Classes é uma representação gráfica utilizada para descrições genéricas do sistema. Este diagrama pode conter tipos, relacionamentos e instâncias de classes. Uma classe captura a estrutura e o comportamento comum de um conjunto de objetos e é uma abstração de elementos do mundo real. Quando esses elementos existem no mundo real, são instâncias de classe e são referidos como objetos. Para cada classe que tem comportamento temporal significativo pode ser criado um diagrama de estado para descrever esse comportamento, como será visto ainda neste capítulo.

Os relacionamentos que podem existir em um Diagrama de Classes são: Generalização, Dependência, Associação e Agregação.

Um relacionamento de generalização entre classes mostra que a subclasse compartilha a estrutura ou comportamento definido em uma ou mais superclasses. Representa o relacionamento "é-um" entre as classes. A notaçăo de um relacionamento de generalização é mostrada na Figura 3.3. 


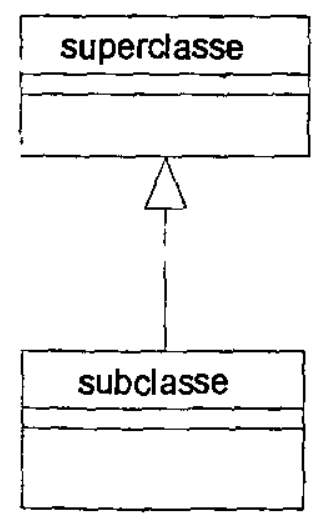

Figura 3.3 - Relacionamento de Generalização

A cardinalidade, que especifica o número de instâncias de uma classe em relação a outra em um relacionamento, é representada por anotações próximas nas linhas que conectam o relacionamento às classes. A tabela 3.1 resume as possíveis variações da cardinalidade.

Tabela 3-1 - Notaçðes de Cardinalidade

\begin{tabular}{|c|c|}
\hline Notação & Significado \\
\hline $0 . .1$ & Zero ou uma instância. \\
\hline 1 & Somente uma instância. \\
\hline $0 .{ }^{*}$ & Zero ou mais instâncias. \\
\hline 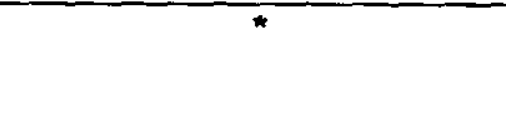 & $\begin{array}{l}\text { Default, número mínimo e máximo de } \\
\text { instâncias são ilimitados. }\end{array}$ \\
\hline 1..* & Uma ou mais instâncias. \\
\hline <literal>.." & Número exato ou mais instâncias. \\
\hline <literal> & O número exato de instâncias. \\
\hline$<$ literal $>$. $<$ literal $>$ & Faixa de instâncias especificadas. \\
\hline$<$ literal $>$.. <literal $>$, <literal $>$ & $\begin{array}{l}\text { O número de instâncias será na faixa } \\
\text { especificada ou número exato de } \\
\text { instâncias. }\end{array}$ \\
\hline $\begin{array}{l}<\text { literal>..<literal>, } \\
<\text { <iteral>.. <literal> }\end{array}$ & $\begin{array}{l}\text { Número de instancias estará em uma das } \\
\text { faixas especificadas. }\end{array}$ \\
\hline
\end{tabular}

<literal> é qualquer inteiro maior ou igual a 1. 
Um relacionamento de dependência entre duas classes mostra que a classe cliente depende da classe servidora, para sua existência. Por exemplo, a Figura 3.4 mostra que a classe Dependente depende da classe Empregado para existir.

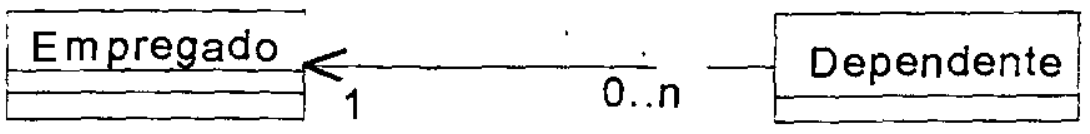

Figura 3.4 - Exemplo de Dependência entre Classes

Um relacionamento de assoclação representa uma conexão semântica entre duas classes e é o relacionamento mais utilizado. É bidirecional e é representado por uma linha ligando as classes. A Figura 3.5 mostra um relacionamento de associação entre as classes Fornecedor e Pedldo.

\begin{tabular}{llll}
\hline Fornecedor & & \\
\hline
\end{tabular}

Figura 3.5 - Exemplo de Relacionamento de Associação

Um relacionamento de agregação é uma forma especial de associação usada para mostrar que um tipo de objeto é composto, no mínimo, por uma parte de outro. Um relacionamento de agregação é também chamado de "todo-parte".

A agregação pode ser implementada na UML como agregação por referência ou agregação por valor. O default é por referência, e significa que o "objeto todo" mantém um ponteiro ou uma referência para suas partes. O losângulo vazio é usado para indicar a implementação por referência.

A agregação por valor indica que o tempo de vida das partes é dependente do tempo de vida do todo. Quando a agregação é por valor, o "objeto todo" declara uma instância atual do "objeto parte" dentro do corpo do próprio "objeto todo". O conteúdo por valor é indicado por um losângulo cheio no lado agregado do relacionamento. A Figura 3.6 mostra no lado esquerdo uma agregação por referência: a instância da classe Avião mantém um ponteiro de referência para uma instância da classe Motor. No lado direito mostra uma agregação por valor: a instância da classe Pedido cria uma instância da classe DetalhePedido.

\subsubsection{Diagrama de Seqüência}

Diagramas de Seqüência mostram uma interação organizada em uma seqüência de tempo entre os objetos participantes de uma operação e as trocas de mensagens entre eles. Esses diagramas são bastante utilizados para especificar sistemas de tempo real e sistemas complexos. Um diagrama de seqüência possui duas dimensões: vertical, que 
representa o tempo e horizontal, que representa diferentes objetos (se for necessário as dimensões podem ser invertidas).

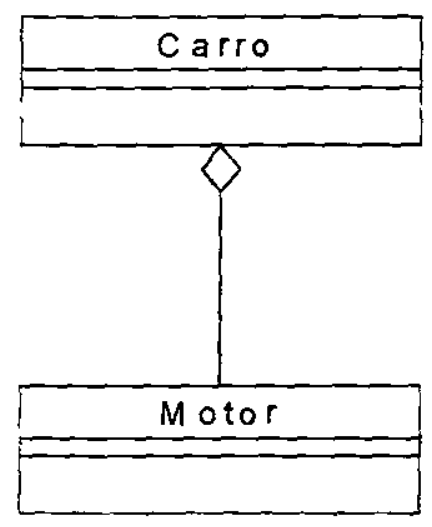

Agregaçăo por referéncia

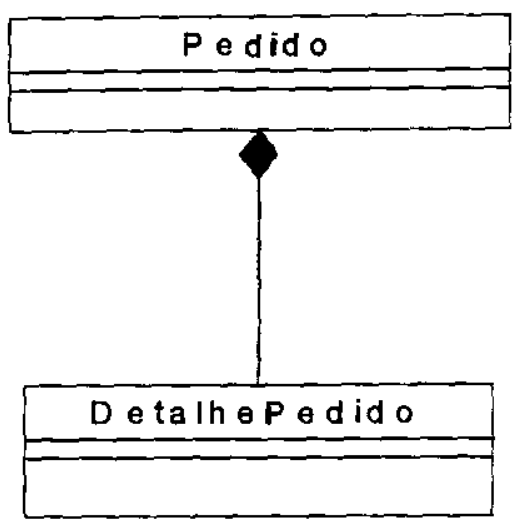

Agregaçăo por valor

Figura 3.6 - Exemplos de Tipos de Agregação

A Figura 3.7 [21] mostra o exemplo de um diagrama de seqüência para a operação de uma chamada telefônica. O primeiro passo para o estabelecimento de uma conexão é o reconhecimento do usuário Chamador. Isso ocorre com o envio de um sinal à Central, indicando que o usuário retirou o fone do gancho (1). O número desse telefone é então anexado à lista de telefones ocupados e é emitido um tom de discar para o chamador (2).

Uma vez recebido o número do telefone desejado (3), a Central verifica se este pertence à lista de telefones ocupados. Em caso positivo, um tom de ocupado é enviado ao chamador e a fase de desconexão é iniciada. Caso contrário, um tom de controle de chamada é enviado ao chamador (4), a campainha do chamado é acionada (5), e o número do Chamado é incluído na lista de telefones ocupados.

A ação do chamado de atender ao telefone (6) determina o fim da fase de conexäo e o início da fase de conversação $(7,8)$. Caso ele não atenda em um determinado intervalo de tempo, a campainha do chamado é desativada, um tom de ocupado é enviado ao chamador, o número do chamado é retirado da lista de telefones ocupados e a fase de desconexão é iniciada.

O fim da fase de conversação ocorre quando um dos usuários repõe o fone no gancho (9), e é emitido um tom de ocupado para o outro usuário (10), mas o fim da fase de desconexão ocorre somente quando o segundo usuário também coloca o telefone no gancho (11).

Vários rótulos (como marca de sincronização e descriçőes de ações durante uma ativação) podem ser mostrados na margem, próximo às mensagens ou ativações do diagrama de seqüência, como mostra a Figura 3.7. 


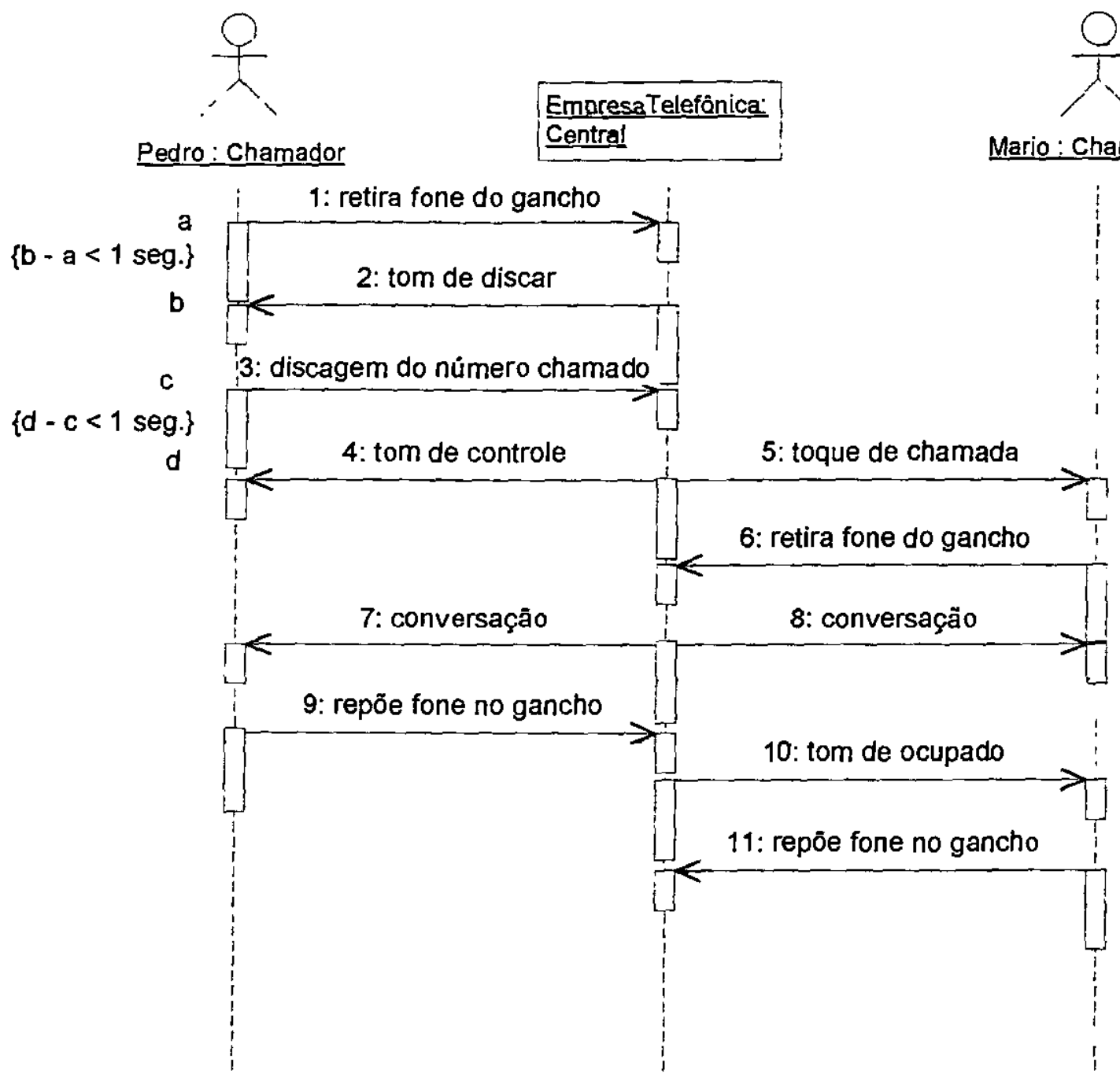

Figura 3.7 - Exemplo de Diagrama de Seqüência - Operação de Chamada Telefônica

Uma ativação mostra o período de tempo em que um objeto está executando o método associado a uma mensagem. É representada como um retângulo fino alinhado com a linha do tempo. As mensagens a serem realizadas podem ser rotuladas com um texto próximo ao símbolo de ativação ou na margem esquerda, conforme mostra a Figura 3.7 .

Uma mensagem é uma comunicação entre objetos e transporta informações que resultarão em uma ação. A recepção de uma mensagem é considerada um evento. Uma mensagem é mostrada como uma seta sólida horizontal da linha de vida de um objeto para outro. No caso de uma mensagem de um objeto para ele mesmo, a seta começa e termina no próprio objeto. A seta é rotulada com o nome de uma mensagem (operação ou sinal) e os valores de argumentos. Uma seta também é rotulada com uma seqüência de números para mostrar a ordem de seqüência das mensagens, que serão realizadas entre os objetos, conforme mostra a Figura 3.7. 


\subsubsection{Diagrama de Colaboração}

Um Diagrama de Colaboração representa a interação entre objetos e entidades por uma seqüência de mensagens que implementam uma operação ou uma transação. Esse diagrama mostra objetos, suas ligações e mensagens, podendo conter instâncias de classes simples. Cada diagrama de colaboração supre uma visão das interações ou relacionamentos que ocorrem entre objetos e/ou agentes externos no modelo corrente.

O diagrama de colaboração não mostra a dimensão do tempo, por isso as seqüéncias de mensagens e linhas concorrentes devem ser determinadas usando a seqüência de números.

Os diagramas de colaboração contém símbolos que representam objetos. As notações gráficas para um objeto são mostradas na Figura 3.8 e podem ser: um retângulo com o nome do objeto, ou um retângulo com o nome da classe, usando a seguinte sintaxe: NomeObjeto ou : NomeClasse
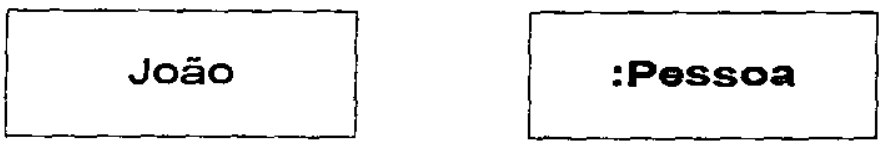

Figura 3.8 - Exemplo de Objetos do Dlagrama de Colaboração

Objetos interagem com outros objetos por intermédio de suas ligaçöes. Uma ligação é uma associação entre objetos e/ou agentes externos. Uma ligação pode existir entre dois objetos somente se existir um relacionamento entre essas classes. A existência de um relacionamento entre duas classes simboliza um meio de comunicação entre instâncias de uma classe: um objeto pode enviar mensagens para outro.

Uma ligação permite múltiplas mensagens em ambas direções. Uma ligação é representada por segmentos que ligam os objetos entre si, que ligam objetos e agentes externos ou até o mesmo objeto. A Figura 3.9 mostra um exemplo de ligação entre objetos.

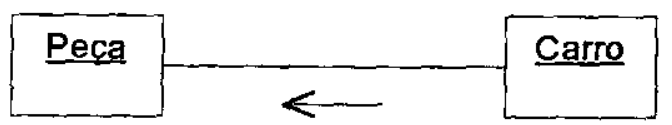

1: InserePeça (integer)

Figura 3.9 - Exempio de Ligaçăo entre Objetos

Uma mensagem transporta a invocaçäo de uma operação do objeto origem ligado ao objeto destino. Cada mensagem pode estar associada a um número, que indica a ordem em que a mensagem será executada. O Diagrama de Colaboração para a impressão de um arquivo tipo texto é mostrado na Figura 3.10. 


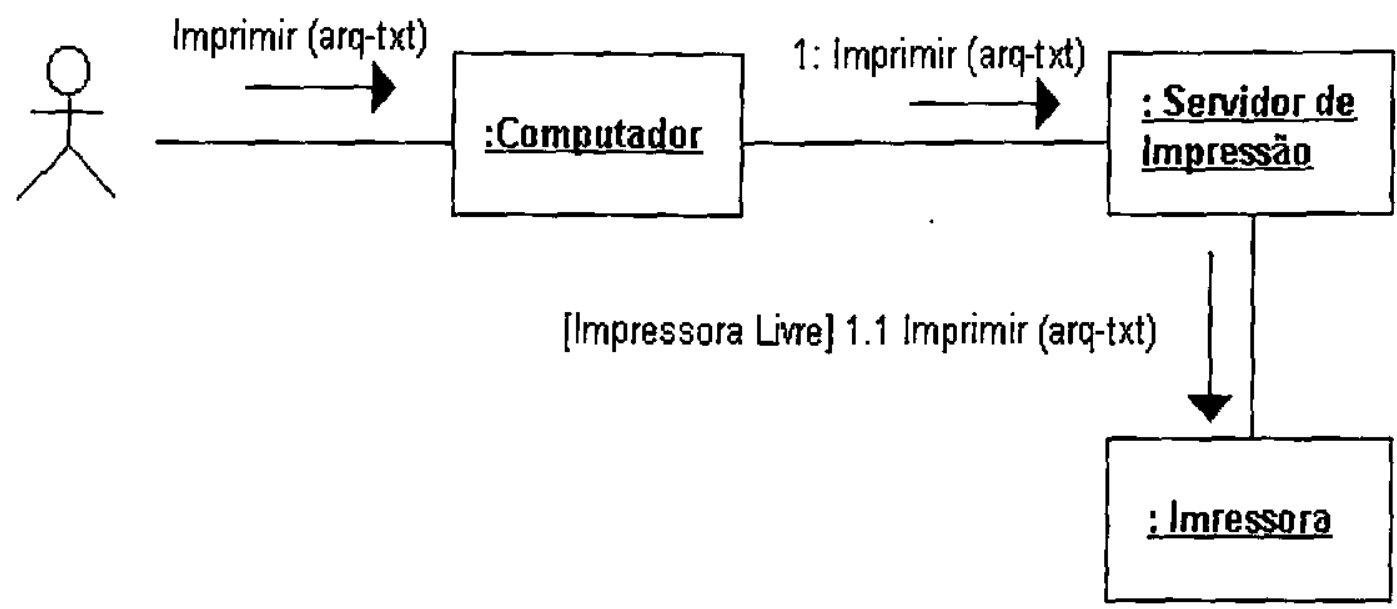

Figura 3.10 - Exemplo de Diagrama de Colaboraçăo - Operaçăo Impressão de arquivo tipo texto

\subsubsection{Diagrama de Estados}

Um Diagrama de Estados é usado para mostrar os estados de uma classe. Os eventos do diagrama de estados causam uma transição de um estado para outro e as ações resultam na mudança de um estado. Cada diagrama de estados está associado a uma classe ou a um diagrama de estados de um nivel mais alto.

Um Diagrama de estados é um grafo direcionado de estados conectados por transições. Esse diagrama mostra um estado inicial, um ou mais estados, um ou mais estados finais e as transições de estados entre eles. Uma classe que possui métodos significativos pode conter um único diagrama de estados para descrever este comportamento.

Um estado inicial é um estado especial que mostra o início do diagrama e é conectado ao primeiro estado normal com uma transição, rotulada ou não. Em cada diagrama de estado há somente um estado inicial. Um estado é uma condição durante a vida de um objeto que satisfaz alguma ação, realiza alguma ação ou espera por algum evento. Um objeto permanece em um estado por um tempo finito.

Um evento possui a seguinte sintaxe:

nome-evento(lista-argumentos) [condiçăo]

Uma ação está associada a um evento em uma transição e é considerada um processo que ocorre rapidamente e que não pode ser interrompido. Possui a seguinte sintaxe :

nome-evento(lista-argumentos) [condição] /ação^cláusulas(argumentos) 
Uma ação interna é executada em resposta a eventos recebidos enquanto o objeto está no estado. Uma ação interna está associada com um estado e consome tempo, podendo ser interrompida por algum evento.

As seguintes açōes internas têm a mesma sintaxe, mas representam palavras reservadas que não podem ser usadas para nomes de evento:

entry: a ação tem início quando entra no estado e pára a execução por conta própria;

exit: a ação tem início quando sai do estado e pára a execução por conta própria;

do: é uma açäo na qual um processo é realizado enquanto o objeto está no estado, podendo ser interrompida por eventos externos. É iniciada quando o estado é ativado, podendo terminar por conta própria ou quando o estado for desativado.

on an activity: é uma ação na qual um evento interno irá disparar uma ação que pode conter argumentos e- condiçōes (opcionais). Esta açäo fornece um controle para os eventos internos sem o disparo de açöes entry e exit. A Figura 3.11 mostra exemplos de ações entry e do.

O exemplo da Figura 3.11 [30] refere-se a um relógio despertador. A partir do momento em que o evento IniciaAcerto for recebido, as ações HabBotãoConfirma, HabBotãoCancela e DesBotãoAcerto são executadas. O evento IniciaControle ou Cancelamento é esperado e então ou ocorre a confirmação da hora escolhida ou seu cancelamento. Se ocorrer a confirmação da hora escolhida, as ações DesBotãoCancela, DesBotãoConfirma e HabBotãoAcerto associadas ao evento IniciaControle são realizadas; por outro lado, as ações DesBotãoCancela, DesBotãoConfirma e HabBotãoAcerto associadas ao evento Cancelamento são executadas.

Um estado final representa o fim da execução diagrama de estado. Pode-se assumir que o diagrama de estado associado a uma classe terminará quando o objeto for destruído. Entretanto, se necessário, pode-se usar um estado final para mostrar o término. Pode existir mais de um estado final por contexto.

Uma transição de estado é um relacionamento entre dois estados, indicando que um objeto no primeiro estado entrará no segundo estado e realizará as ações especificadas quando um evento ocorrer e se suas condições (caso existam) forem satisfeitas. Em uma mudança de estado a transição é dita "disparada". Uma transição é disparada quando o evento ocorrer. Se um evento não habilitar nenhuma transição ele é ignorado. Se ele habilitar mais do que uma transição, somente uma será disparada, de acordo com sua condição. 


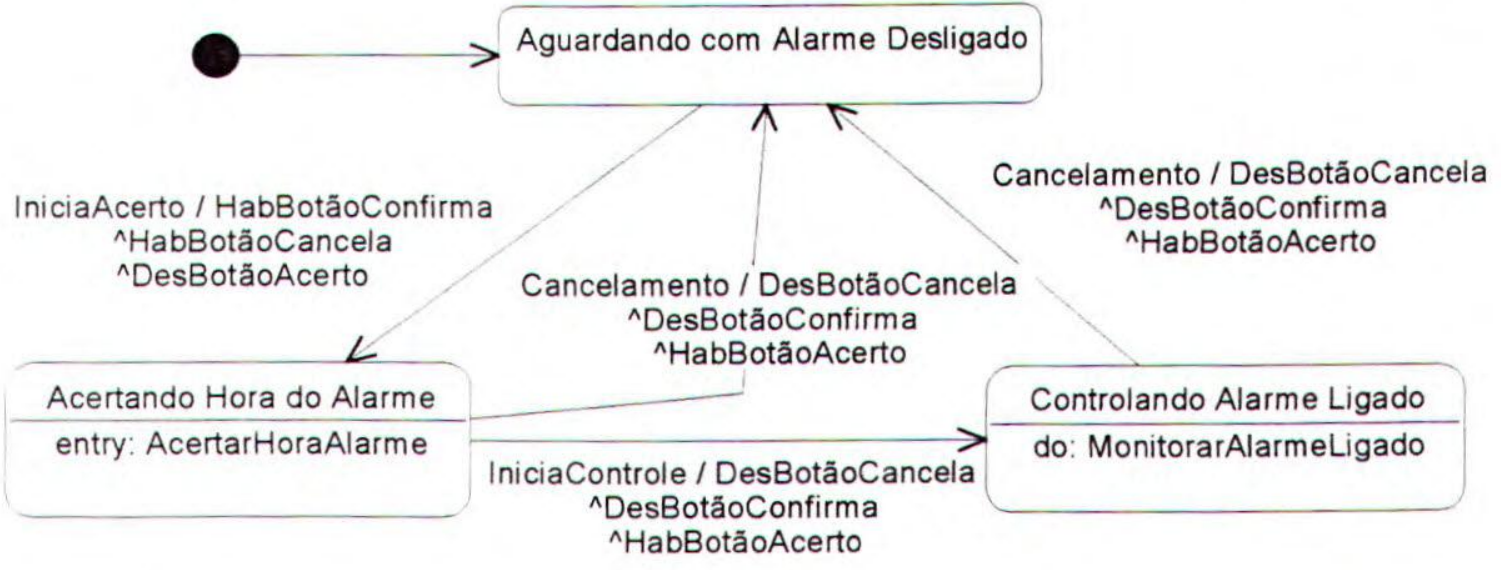

Figura 3.11 - Exemplos de eventos/ações entry e do exemplo.

A Figura 3.12 mostra a notação de transição de estado e a Figura 3.13 mostra um

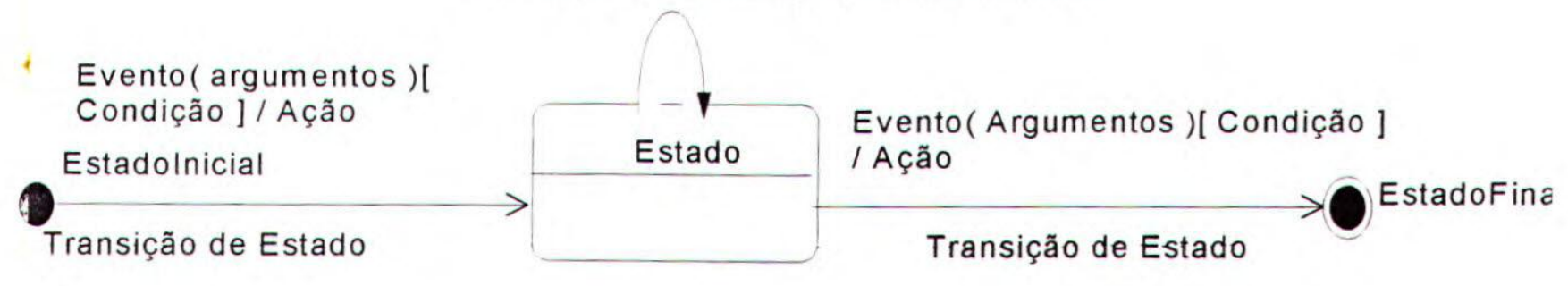

Evento(Argumentos )[ Condição ] / Ação

Figura 3.12 - Transição de Estado

Somente um evento é permitido por transição. Uma mesma transição pode ser colocada em mais de um estado se pelo menos uma delas for rotulada com uma condição, como é mostrado no estado Aguardando, onde há duas transições com o nome itemRecebido, mas com condições diferentes.

Quando uma transição possui um evento não rotulado, isto significa que a transição ocorre quando uma ação interna associada a um estado é completada. Neste caso, isto ocorre com o estado Checando. Três transições com condições saem do estado Checando. Uma condição retorna verdadeiro ou falso; a transição que contém uma condição ocorre somente se a condição for verdadeira. 


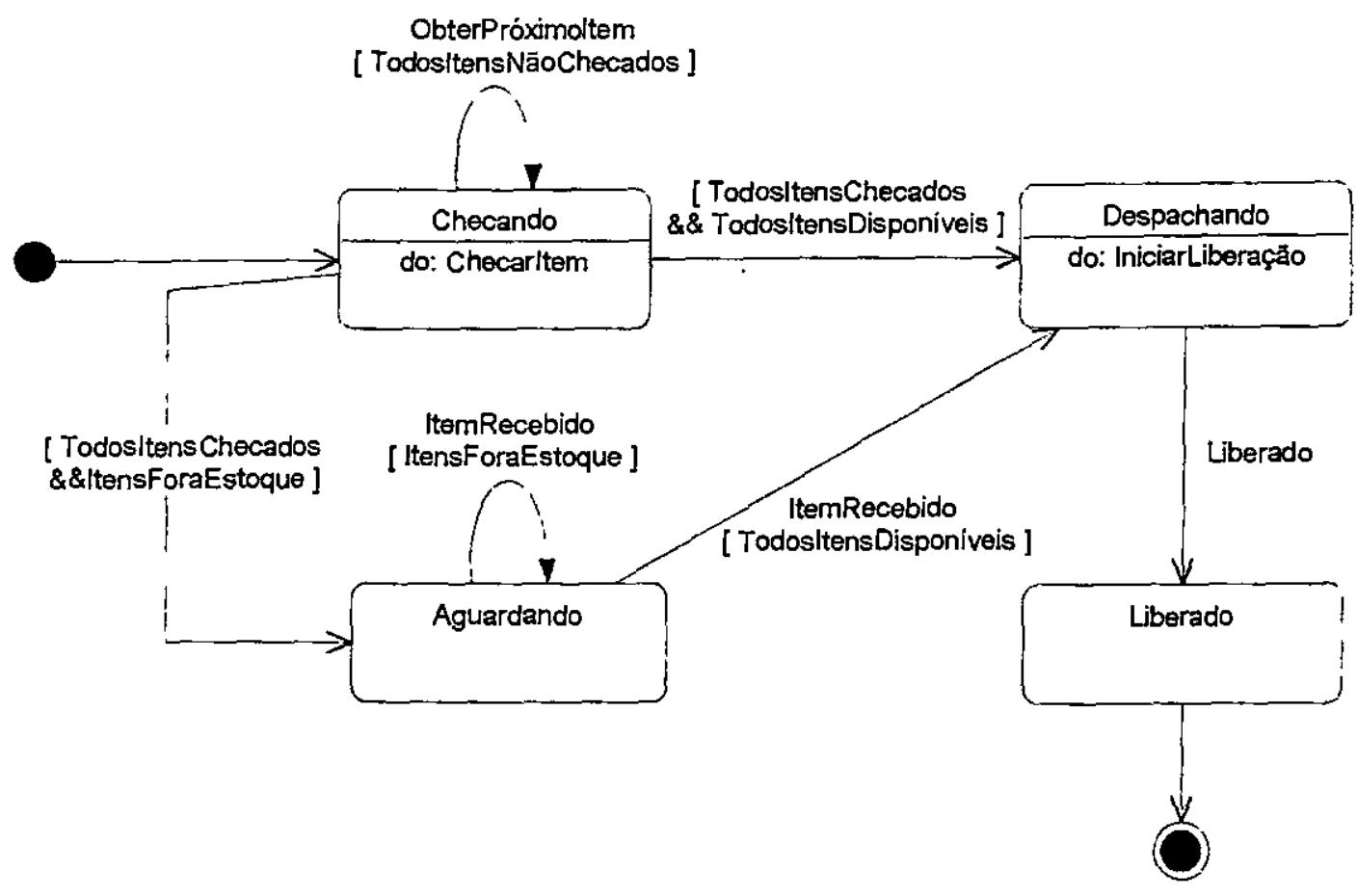

Figura 3.13 Exemplo de Transições de Estado

Somente uma transição de um determinado estado pode ser disparada por vez e as condiçöes são exclusivas para um evento. Na Figura 3.13 [30] existem três condições:

1. Para todos os itens que não foram checados obtenha o próximo item e retorne para o estado Checando.

2. Se todos os itens foram checados e todos estão no estoque, vá para o estado Despachando.

3. Se todos os itens foram checados mas nem todos estão no estoque, vá para o estado Aguardando.

No estado Aguardando não há ações internas, então este estado fica esperando por um evento. As transições do estado Aguardando são rotuladas com o evento ItemRecebido.

No estado Despachando há uma ação interna que inicia uma liberação. Há também uma única transição disparada pelo evento Liberado, indicando que a transição sempre ocorrerá quando esse evento ocorrer. Ė importante frisar que a transição não ocorre quando a ação interna é completada, uma vez que a ação interna IniciarLiberação é terminada, o estado Despachando fica esperando até que o evento Liberado ocorra.

\subsubsection{Diagrama de Atividades}

Um Diagrama de Atividades é um caso especial de um diagrama de estados em que todos os estados (ou a maioria) são ações e todas as transições (ou a maioria) são 
disparadas por complemento de açōes nos estados de origem. Um diagrama de atividades está vinculado a uma classe, a uma implementação de uma operação, ou a um caso de uso. A finalidade desse diagrama é focalizar fluxos dirigidos por processamento interno (ao invés de eventos externos).

Um estado-ação é uma simplificação de um estado com uma ação interna e pelo menos uma transição de saída. O uso de um estado-ação serve para modelar um passo na execução de um algoritmo (um procedimento).

As ações devem ser descritas por linguagens naturais, pseudocódigo ou código de linguagem de programação. A notação de um estado-ação é mostrada na Figura 3.14.
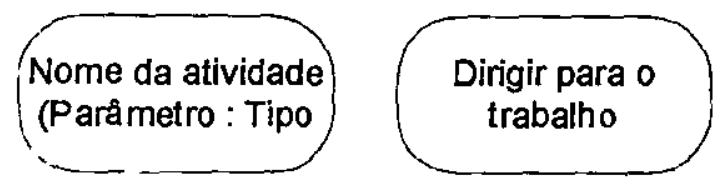

Figura 3.14 - Estado de Ação

As transições entre ações em um Diagrama de Atividades têm sintaxe semelhante a utilizada nas transiçōes do Diagrama de Estados, porém, um evento pode ser rotulado apenas na transição que liga o ponto inicial à primeira ação do Diagrama de Atividades. Transições entre ações são representadas por um segmento com uma seta rotulada por uma condição, uma cláusula ou uma expressão de ação.

Um diagrama de atividades pode mostrar uma decisāo quando condições são usadas para indicar diferentes transições possiveis que dependem de condições booleanas do objeto. Um estereótipo é fornecido para uma decisão: a forma tradicional de losângulo com uma ou mais setas de entrada e com duas ou mais setas de saidas; cada seta é rotulada por uma condição distinta sem disparo de evento. A Figura 3.15 mostra um exemplo de Diagrama de Atividades.

\subsubsection{Diagrama de Componentes}

Um Diagrama de Componentes mostra as dependências entre componentes de software, incluindo componentes de código fonte, componentes de código binário e componentes executáveis. Um módulo de software é representado como um tipo de componente.

Um Diagrama de componentes contém elementos que representam:

- Pacotes de componentes

- Componentes ou Módulos

- Pacotes

- Programa principal 
- Subprogramas

- Tarefas

Dependências

\section{Pessoa :: Conseguir Bebida}

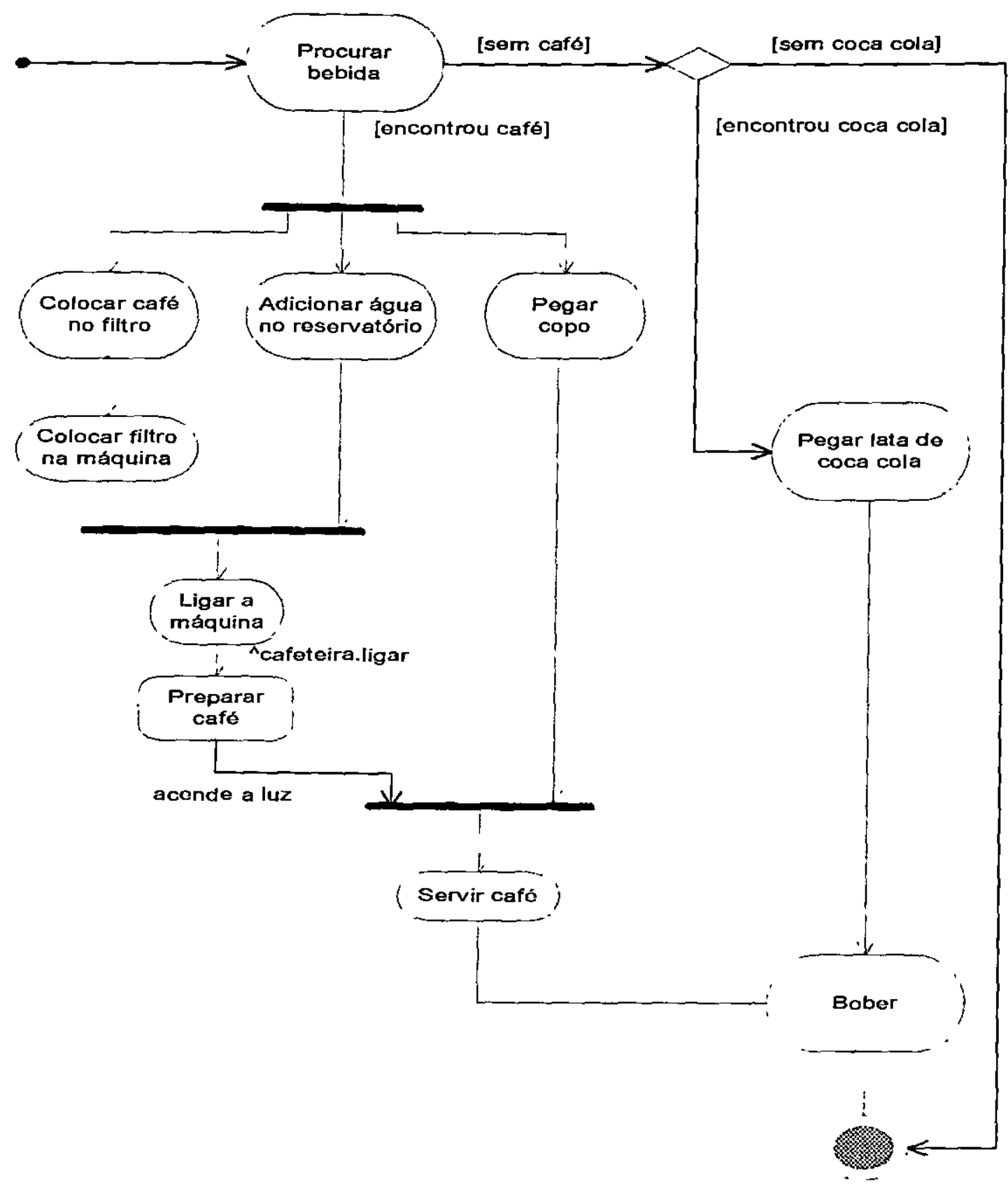

Figura 3.15 - Exemplo de Diagrama de Atividades 
Os Componentes são conectados a outros componentes por intermédio de relacionamentos de dependências. Essa conexão indica que um componente usa os serviços de outro componente.

Em um diagrama de componentes um pacote (neste contexto) consiste de um módulo de especificação e um módulo de implementação, sendo que este último é freqüentemente referido como um corpo. Por default, uma classe é declarada no pacote. Cada pacote deve ter um nome único no modelo, como mostra a Figura 3.16.
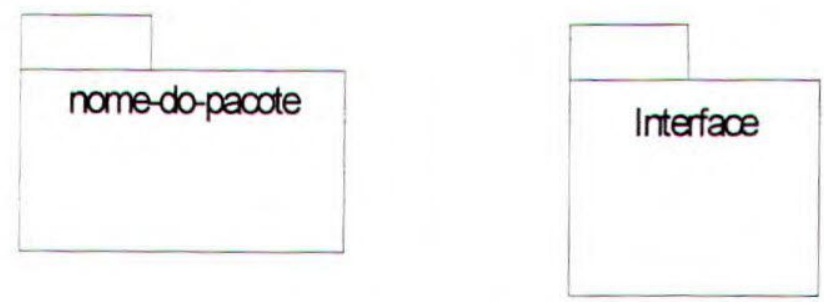

Figura 3.16 - Pacotes

Um programa principal em um diagrama de componente, consiste de um módulo que representa um arquivo que contém a raiz (origem) de um programa. $O$ nome de um programa principal é um nome de arquivo. A Figura 3.17 mostra a notação gráfica e o exemplo de um programa principal.

main

Figura 3.17 - Programa Principal

Módulos de subprogramas podem conter um ou mais subprogramas. Cada subprograma deve ter um nome de arquivo. A Figura 3.18 mostra a notação da especificação e do corpo de um subprograma.
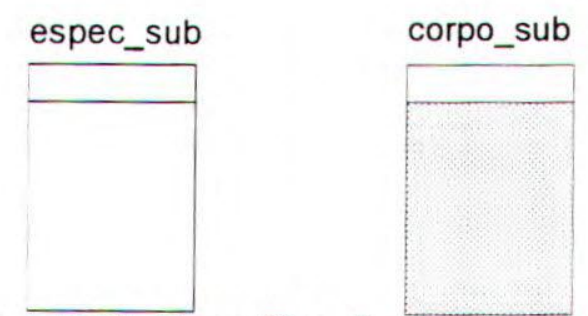

Figura 3.18 - Especificação e Corpo de Subprograma 
Os Módulos de tarefas representam pacotes com linhas de controle (threads) independentes. Como as tarefas são compiladas diferentemente de pacotes normais, é possivel alocar uma definição de classe para uma tarefa.

Cada tarefa deve possuir um nome. O nome da tarefa é um nome de arquivo. A Figura 3.19 mostra a notação da especificação e do corpo de uma tarefa.
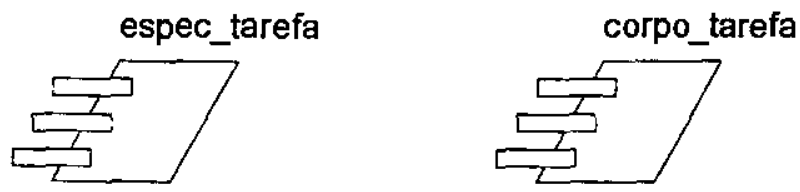

Figura 3.19 - Especificação e Corpo de Tarefa

Um relacionamento de dependência indica que um módulo em um diagrama de componente usa serviços ou facilidades de outra. Dependências em um diagrama de componente representam dependências de compilação. Uma dependência pode ser rotulada com uma descrição significativa no contexto, mas o nome não é obrigatório. A Figura 3.19 mostra um exemplo de relacionamento de dependência, no qual ContasPagar usa serviços do módulo Financeiro.

\subsubsection{Diagrama de Distribuição}

Um Diagrama de distribuição mostra processadores, dispositivos de e/s e conexões. Cada modelo contém um diagrama simples de distribuição que mostra as conexões entre os processadores e dispositivos de e/s e a alocação de seus processos para o processador.

Este diagrama mostra a organização do hardware e a ligação do software com os dispositivos físicos. O tipo do dispositivo de hardware é dado pelo seu estereótipo, tais como, processador, vídeo, dispositivo, memória, disco e outros.

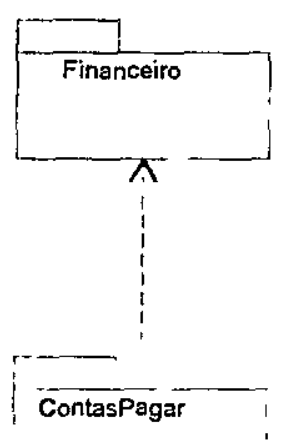

Figura 3.19 - Exemplo de Relacionamento de Dependência

Um processador é um componente do hardware capaz de executar programas. A Figura 3.20 mostra um exemplo de processador. 


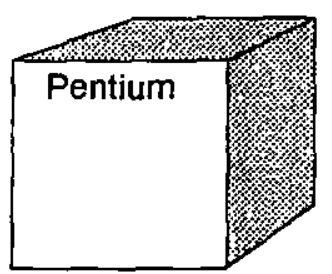

Figura 3.20 - Exemplo de Processador

Um dispositivo é um componente do hardware sem efeito computacional. Cada dispositivo deve ter um nome, podendo ser genérico, como "modem" ou "terminal". A Figura 3-21 mostra um exemplo de dispositivo.

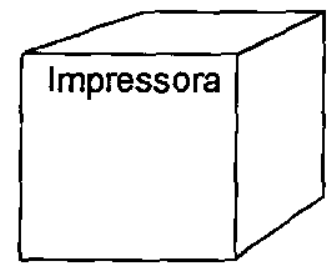

Figura 3.21 - Exemplo de Dispositivo de e/s

Uma conexão representa alguns tipos de hardware interligados entre duas entidades. Uma entidade é um processador ou um dispositivo. A ligação de hardware pode ser direta ou indireta, sendo bidirecional. Um exemplo de conexão é mostrada na Figura 3.22.

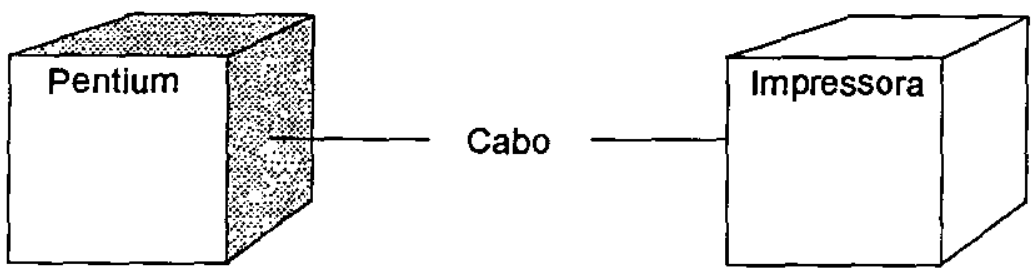

Figura 3.22 - Exemplo de Conexão

\subsection{Considerações Finais}

Foi apresentada neste capítulo uma descrição informal da UML (Unified Modeling Language) que representa uma evolução dos conceitos introduzidos em métodos como Booch, OMT, OOSE e também outros métodos orientados ou não a objetos.

A Notação da UML é formada por técnicas de diversos métodos e baseada no trabalho de vários autores diferentes. O resultado desta notação é única, comum e ampla linguagem de modelagem utilizável por usuários dos destes vários métodos e técnica unificados A UML foi descrita porque os modelos de análise gerados a partir da aplicação do método a ser proposto serão integrados a esta linguagem. 
Capítulo 4 - Proposta de Um Método Baseado em Cenários para Elicitação e Modelagem de Requisitos 


\subsection{Considerações iniciais}

Apresenta-se neste capítulo a proposta de um método para elicitação e modelagem de requisitos. Este método tem como objetivo simplificar o estabelecimento de requisitos do software para a Engenharia de Requisitos a partir dos documentos de elicitação e/ou documentos de requisitos até a elaboração de um modelo de requisitos que facilite a passagem para a construção de um modelo de análise.

A notação adotada no método está baseada na construção de cenários e foi desenvolvida com 0 intuito de facilitar a comunicação com 0 usuário durante 0 processo de modelagem dos requisitos. Essa notação é relativamente rica, visando a permitir a extração de uma grande variedade de informação e fornecer subsídios para a construção dos modelos a serem construídos nas fases de análise e projeto.

A aplicação de um método para obtenção de requisitos simplifica o entendimento dos requisitos de software devido à construção de vários Diagramas para representar os requisitos, à construção de glossários e às referências cruzadas entre os Diagramas e os glossários construídos e o documento de requisitos. Os usuários podem utilizar o modelo de requisitos para avaliar a otimização dos processos envolvidos no sistema em desenvolvimento, propondo melhorias necessárias para a definição do novo sistema.

$\mathrm{Na}$ Seção 4.2 são apresentadas as definições relativas aos cenários, com a intenção de se estabelecer alguns conceitos básicos. Na Seção 4.3 é apresentada a descrição do processo usado na composição do método e a finalidade de cada modelo de requisitos do sistema criado pelo método proposto. Na Seção 4.4 é apresentado um conjunto de heurísticas que possibilitam a construção de um modelo de análise baseado na UML a partir da documentação obtida com o uso do método proposto.

\subsection{Engenharia de Requisitos Apoiada por CEnários (ERACE)}

A proposta do método ERACE é fundir os pontos críticos das fases de engenharia de requisitos dos principais métodos que utilizam a técnica de construçäo de cenários, a fim de propor um método para elicitar e modelar requisitos através de cenários e desenvolver uma ferramenta, baseada nesse método, que apoie a fase de engenharia de requisitos. O método é baseado em um conjunto de definiçöes qụe devem ser refinadas, com 0 objetivo de produzir um modelo funcional a partir de cenários de uso. Considerando os métodos revisados (OOSE [6], OBA[7], FASA [10], UORE [12] e UML [21]), foram estabelecidas as seguintes definições:

- Usuário: é uma entidade real ou abstrata que interage com o sistema.

- Papel: é o comportamento especificado por uma entidade que participa de um contexto particular.

- Ator: um ator define um papel no qual um usuário pode interagir com um sistema. Um usuário é uma instância de um ator.

- Ator Principal: é um ator de fora do sistema que inicia as interações com o sistema.

- Ator Participante: é um ator de fora do sistema que participa, supervisiona ou gerência o sistema. 
- Evento: Um evento é uma unidade de comunicação entre o sistema e seu ambiente.

- Cena de uso: são cenas completas extraídas da interação dos atores com o sistema. A cena de uso tem um contexto para seu início e término e após serem iniciadas seguem um fluxo de eventos principal, que descreve a interação da cena sob condições normais. Todas as cenas de uso têm pelo menos um fluxo de eventos principal, podendo conter vários fluxos aiternativos, representando as ocorrências anormais durante a cena. Diferentes cenas de uso podem requerer diferentes objetos do domínio na sua interação.

- Operações: são sequências de eventos realizados dentro de uma mesma cena de uso do sistema. Uma cena de uso pode conter várias operações desde de que todas tenham o mesmo contexto de início e término.

- Objetos do domínio: são os elementos componentes do domínio do problema que participam ou săo utilizados no decorrer de uma cena de uso.

A Engenharia de requisitos estabelece o processo de definição de requisitos como um processo no qual o que deve ser feito é elicitado, modelado e analisado. Tal processo deve lidar com diferentes pontos de vista, e usar uma combinação de métodos ferramentas e pessoas. O produto deste processo é um modelo do qual se produz um documento de requisitos. Este processo ocorre em um contexto previamente definido denominado Universo de informação (Udl) e evolui durante o processo de desenvolvimento e manutenção do software.

Um método para obtenção de requisitos do software é composto de atividades relacionadas às etapas da engenharia de requisitos, compreendendo a análise de requisitos do sistema e a elaboração da especiflcação de requisitos do sistema. Durante o processo de criação dos Diagramas, com base no documento de requisitos elou documentos produzidos e coletados na elicitação, são acumuladas informações nos glossários visando a continuidade do processo com a construção de um modelo de análise.

O método proposto neste capítulo é composto do seguinte conjunto de Diagramas: Diagrama de interação das cenas de uso e Diagrama Abstrato Detalhado. No Diagrama de interação das cenas de uso são identificados os atores principais, atores participantes e as cenas de uso mais relevantes do sistema. A partir dessas definiçōes são criados os Diagramas Abstratos Detalhados, onde são detalhadas as informações coletadas no primeiro Diagrama. Nestes diagramas são registrados os vários estados de interação das cenas, os fluxos de eventos e os objetos do domínio.

\subsection{O processo ERACE}

O processo ERACE, mostrado na figura 4.1, é composto de duas fases: fase de Especificação das Interações e fase de Modelagem dos Cenários. Na fase de Especificação das Interaçőes são feitas especificações das interações que ocorrem no sistema em um diagrama que contém informaçöes sobre os atores e as cenas de uso, a base de informação para a construção desse diagrama é derivada de um documento inicial de requisitos de software, que deve conter todos os requisitos funcionais e de qualidade do software, incluindo capacidades do produto, recursos disponiveis os 
benefícios e os critérios de aceitação. Mais informações sobre a construção de um documento de requisitos podem ser obtida no relatório técnico publicado por Turine e Masiero [23]. Todas as informaçōes presentes no diagrama da fase de Especificação das Interações devem ser armazenadas em um glossário.

Esse diagrama é usado como entrada para a fase de Modelagem dos Cenários, na qual são descritas e formalizadas as operações existentes em cada cena de uso e são criados os Diagramas Abstratos Detalhados das cenas.

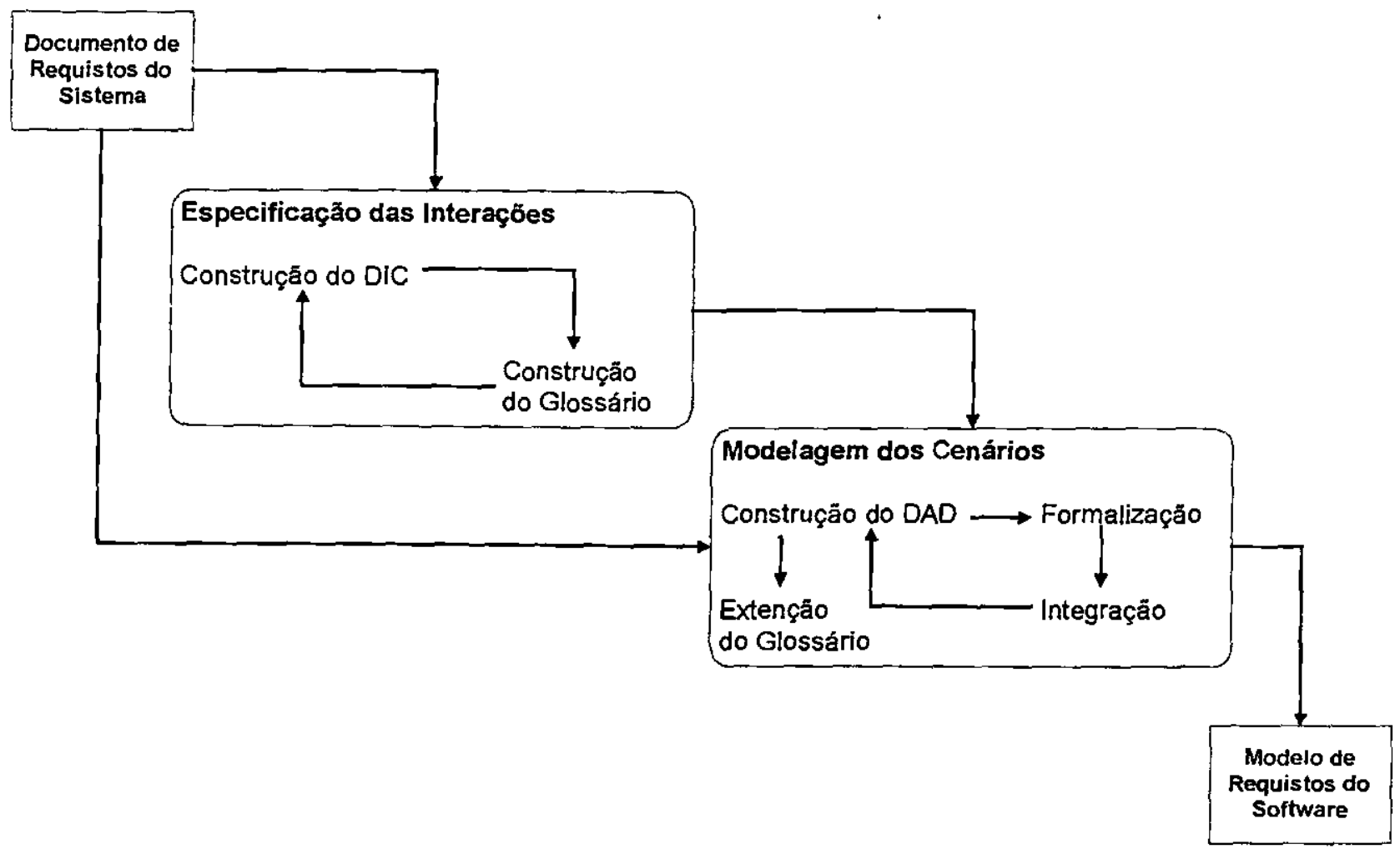

Figura 4.1 - Processo ERACE

A ERACE possui características semelhantes às dos métodos OOSE e UML. Em ambos os métodos são construídos Diagramas de Casos de Uso (use cases diagrams) bastante parecidos com os construídos na fase de Especificação das Interações do ERACE e a partir deles são feitas descrições mais especificas das cenas, no entanto, existem aspectos importantes coletados em [7],[10] e [12] durante a revisão, que os tornam diferentes, tais como:

Mudanças semânticas nos atores, cenas de uso e seus relacionamentos. No ERACE, uma cena de uso pode ter a participação de mais de um ator e podem existir dois estilos de interaçäo possiveis entre atores e cenas de uso: interação principal, na qual os atores a ela relacionados iniciam a interação com suas cenas de uso e interação participante, na qual os atores a ela relacionados participam, supervisionam ou gerenciam a interação de suas cenas de uso. Cenas que envolvem mais de um ator durante seu desenvolvimento apresentam interações especificas para cada ator que nelas interage, por isso, relacionar apenas um ator a uma determinada 
cena (como é feito no OOSE) e não especificar o tipo de envolvimento do ator com a cena (como é feito no UML), pode limitar a especificação da mesma.

Aplicação de uma visão única da cena para cada ator e Identificação de contextos para as cenas de uso. No ERACE, cada detalhamento de uma cena de uso descreve o comportamento do sistema na visão de apenas um ator, e estes detalhamentos contém condições que definem um contexto para sua iniciação. Um detalhamento de uma cena de uso completa tem um estado inicial que satisfaz seu contexto de iniciação, retornando no final do detalhamento ao mesmo estado no qual iniciou. Essas definiçōes limitam o grau de complexidade das cenas de uso, aumentam sua completitude e possibilitam uma possível integração entre as várias cenas.

Criação de glossários. Um boa solução para evitar alguns problemas típicos em descriçōes de requisitos que utilizem linguagem natural é criar um glossário para detalhar os termos usados na descrição dos requisitos. Com a formação do léxico do domínio, todo o vocabulário usado nas especificações e detalhamentos das cenas de uso pode ser sintetizado e unificado, facilitando o entendimento dos Diagramas.

\subsubsection{Fase de Especificação das Interações}

A fase de Especificação das Interações é composta por duas atividades relacionadas:

- Identificação dos atores e das cenas de uso e dos estilos de interação, criando-se um Diagrama de interação das cenas de uso (DIC)

- Documentação do léxico do domínio em um glossário

\subsubsection{Construção do Diagrama de Interação das Cenas de uso (DIC)}

A primeira atividade envolve a identificação das fronteiras de interação do sistema, a elicitação e a descrição dos atores e cenas de uso. Ainda no Diagrama, são especificados os estilos de interação entre cada ator e as cenas de uso em que estes estão envolvidos, como também os relacionamentos entre as cenas de uso.

O processo de construção de um Diagrama de interação das cenas de uso é composto pelos seguintes passos: identificação dos atores; identificação de um conjunto de cenas de uso caracteristicas e seus relacionamento e identificação das associações de interação entre atores e cenas de uso; e identificação das dependências entre as cenas de uso. A figura 4.2 mostra um modelo de Diagrama de interação das cenas de uso.

Identificaçäo dos atores: um ator é identificado a partir de sua interação com o sistema e pelos eventos que envia para ou recebe do sistema. Nem sempre um usuário é necessariamente um ator, já que o mesmo usuário pode representar vários papéis no sistema, tendo assim mais de um ator para representá-lo. Um ator é representado por dois tipos de ícones: o de uma figura humana, para representar papéis

desempenhados por usuários humanos e o de um computador, para representar papéis desempenhados por subsistemas ou outro tipo de software auxiliar. 


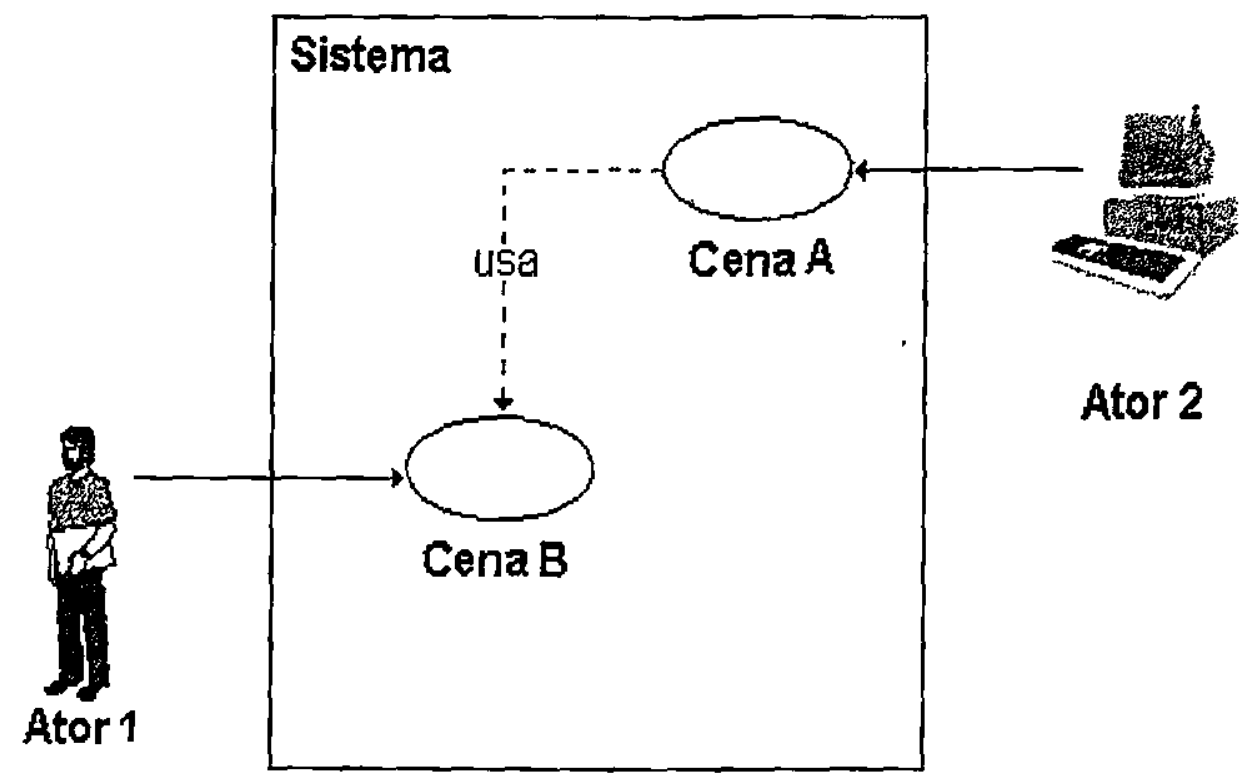

Figura 4.2 Diagrama de Interação das cenas de uso

Identificacão de um coniunto de cenas de uso: as cenas de uso são identificadas a partir do documento de requisitos. O conjunto das cenas de uso de um DIC deve cobrir as principais operaçōes do sistema. As operações agrupadas em uma mesma cena estão relacionadas por terem um mesmo contexto de início e término, isto é, todas as operações de um cena devem iniciar e terminar em um mesmo estado do sistema. Uma cena de uso é representada como uma elipse contendo o nome da cena.

Identificacão das associacões entre atores e cenas de uso: Um ator interage com uma cena quando inicia ou participa de algum ponto da cena fornecendo informaçōes para o sistema ou recebendo informações. A participação de um ator em uma determinada cena é mostrada conectando-se o icone do ator com o símbolo da cena de uso por de uma segmento de reta sólido. O estilo da interação é mostrado por pontas do segmento de reta: um segmento de reta com apenas uma seta na extremidade próxima à cena de uso retrata uma interação de um ator principal na cena; um segmento de reta com setas em ambas as extremidades retrata uma interação de um ator participante na cena.

Identificacão de dependências entre cenas de uso: A dependência entre duas cenas é identificada quando existe um relacionamento de uso entre elas. Um relacionamento de uso de $A$ para $B$ indica que uma instância de uma cena de uso $A$ também inclui o comportamento especificado em B. Um relacionamento tipo "usa" entre cenas de uso é mostrado por um segmento de reta tracejado. O segmento de reta possui uma seta na extremidade próxima à cena de uso que é usada por outra cena, 
com rótulo <usa>. Na figura 4.2 existe um relacionamento de dependéncia entre as cenas A e B.

\subsubsection{Construção do Glossário do DIC}

A segunda atividade consiste na unificação da terminologia do sistema em um glossário, no qual säo descritas as cenas de uso especificadas, os atores pertencentes ao domínio e seus atributos. Esse glossário é composto pelas colunas nome, tipo e descrição. O nome é um identificador alfanumérico único para o domínio do problema. O tipo identifica se é uma cena ou um ator. As descriçöes de cada elemento do glossário devem ser baseadas no documento de requisitos do sistema. Um exemplo de formato de glossário construído na fase de Especificação das Interações é mostrado na tabela 4.1.

A descrição da terminologia do sistema é fundamental na formação de um léxico do domínio, no qual todos os termos relevantes do documento de requisitos são unificados. A terminologia será gradualmente estendida e revisada quando mais e mais Diagramas forem especificados e detalhados. As duas atividades da fase de Especificação das Interações são executadas iterativamente

Tabela 4.1 Glossário do DIC

\begin{tabular}{||c|c|c|}
\hline NOME & TIPO & DESCRIÇÃO \\
\hline$<$ nome da cena1 $>$ & Cena & Descriçäo da cena 1 \\
\hline <nome do ator1 $>$ & Ator & Descrição do papel exercido pelo ator1 \\
\hline <nome da cena2> & Cena & Descrição da cena 2 \\
\hline <nome do ator2> & Ator & Descrição do papel exercido pelo ator2 \\
\hline
\end{tabular}

\subsubsection{Fase de Modelagem dos Cenários}

$\mathrm{Na}$ fase de Modelagem dos Cenários são feitas descrições das operação realizadas em cada uma das cenas de uso identificadas na fase de especificação. Estas descrições devem ser então formalizadas pela construção de cenários formais e integradas, por intermédio da construção de Diagramas Unificados das Cenas, com o objetivo de compor um conjunto de modelos finais que permitirão a compreensão do domínio da aplicação e servir como material inicial para as próximas fase do ciclo de vida do sistema. A fase de Modelagem dos Cenários consiste de quatro atividades:

- Construção dos Diagramas Abstratos Detalhados

- Formalização

- Integração

- Extensão do glossário

\subsubsection{Construção dos Diagramas Abstratos Detalhados (DAD)}

$\mathrm{Na}$ primeira atividade são criados diagramas que visam a identificação com detalhes as várias operações realizadas durante o desenrolar de uma cena. Uma cena é composta por estados, que representam ações realizadas pelo sistema e um conjunto de transições (eventos), que representam estímulos, interaçōes e mensagens em nivel de interface. 
Os Diagramas Abstratos Detalhados devem ser construidos a partir da visão de cada ator que participa de uma determinada cena, pois atores diferentes que participam de uma mesma cena provavelmente gerarão eventos diferentes, passando por estados diferentes. Por exemplo, uma cena $A$ que contém a interação de dois atores, terá Diagramas Abstratos Detalhados diferentes, um para cada ator que com ela interage.

O ERACE define dois tipos de estados em um Diagrama Abstrato Detalhado, os estados intermediários, que representam operações do sistema que só podem ser executadas a partir de um dada interação e os estados iniciais. Toda cena contém um estado inicial que representa o contexto de inicio da mesma; uma cena completa é composta por um conjunto de operações que iniciam no estado inicial e após um número qualquer de eventos retornam a ele. A semántica de um estado inicial é diferente da dos outros estados intermediários, pois ele não representa uma ação do sistema, mas sim uma pré-condição necessária para o início e término da cena.

Como já foi dito, uma mesma cena pode possuir vários Diagramas Abstratos Detalhados a ela relacionados, um para o seu ator principal e outros para cada ator participante. A única diferença existente entre os diagramas construídos para os dois tipos de atores é que no caso do Diagrama Abstrato Detalhado do ator participante, o estado inicial e todos os estados em que 0 ator participante colabore devem estar relacionados a um estado intermediário presente no Diagrama Abstrato Detalhado do ator principal, visto que foi ele quem iniciou a interação da cena.

Existem dois tipos de fluxos de eventos em um DAD: um fluxo principal, que é composto de seqüências de eventos de uma operação realizada com sucesso dentro da cena e um fluxo altemativo, que são eventos que podem descrever algum tratamento de erros durante uma operação, interrupções realizadas durante uma operação ou qualquer tipo de evento que esteja fora do fluxo principal.

Cada Diagrama Abstrato Detalhado é composto por uma seqüência de estados e um conjunto de transiçōes. A semântica e a notação descrita nesta seção são substancialmente semelhantes à notação de statecharts, descritos por David Harel em [19], apresentando porém algumas modificações e particularidades. Na figura 4.3 é mostrado um exemplo de um DAD.

Um estado intermediário é representado por um retângulo com os cantos arredondados contendo o nome do estado em seu centro. Os estados iniciais possuem notação um pouco diferente, apresentando bordas mais grossas que os intermediários. Um cena completa tem apenas um estado inicial, podendo ter $n$ estados intermediários para várias operaçöes detalhadas.

As transições são descritas como eventos que provocam a mudança do sistema para um determinado estado. Uma transição pode representar uma interação de um ator com o sistema, uma resposta do sistema a um ator ou um estímulo do sistema para uma interação de um ator. Uma transição entre estados é mostrada conectando um estado a outro através de uma reta. As setas na ponta de cada reta indicam a seqüência e ocorrência dos estados. As transições do fluxo principal são representadas 
por retas sólidas, enquanto que as transições do fluxo secundário possuem retas tracejadas em sua representação. Em uma cena completa o número de transições principais que saem de um estado inicial deve ser o mesmo das que nele chegam.

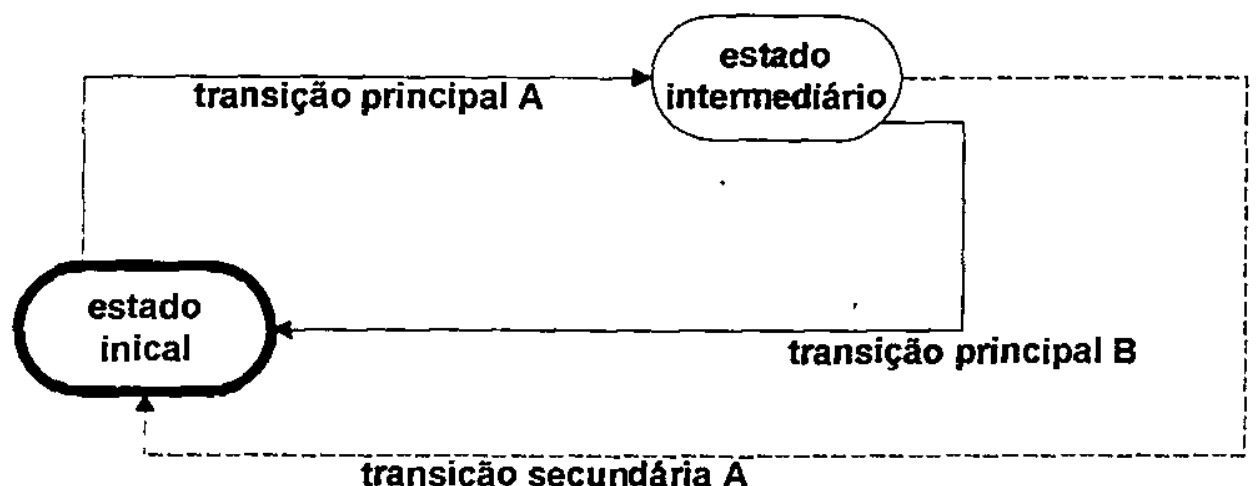

transiçâo secundária $A$

Figura 4.3 Diagrama Abstrato Detalhado

Durante a construção de um DAD a tarefa iterativa de unificação da terminologia do sistema é retomada. As informações coletadas nos DAD são armazenadas no glossário do sistema, que é expandido com dados sobre os contextos de início e término da cena, descrições sobre os estados e as transiçöes e os objetos do domínio utilizados durante o detalhamento da cena.

\subsubsection{Formalização}

A fase de formalização visa a aplicar um base formal matemática na fase de Modelagem dos Cenários com o objetivo de obter cenas mais precisas, suscetíveis a mudanças e mantendo o usuário envolvido no processo [10]. Nesta fase são gerados cenários para cada uma das cenas detalhadas no DAD. Esses cenários têm a forma de pequenos programas que são gerados a partir das especificações presentes no DAD.

Um DAD é um Diagrama baseado na notaçāo de uma máquina de estados finitos que representa uma visão $V$ de uma determinada cena, sob o ponto de vista de um ator. $\mathrm{Na}$ fase de formalização, essa máquina de estados de $\mathrm{V}$ é convertida em um conjunto de sentenças de uma linguagem regular $L v$, chamada Linguagem de Detalhamento (LD). A gramática de Lv, chamada de Gv, é uma gramática regular, definida por quádruplas (NT, T,P,S ), onde:

- NT é um conjunto finito chamado vocabulário não terminal que representa os estados do DAD para a visão $V$;

- T é um alfabeto finito, chamado vocabulário terminal que representa o conjunto de eventos do DAD;

- $\mathrm{P}$ é um conjunto finito de regras ou produções. Cada regra ou produção de $\mathrm{P}$ tem o formato $A \rightarrow B$ e as transições de $A$ para $B$ são resultado de um evento; $e$

- S é o axioma ou símbolo inicial de G. S é o nome da categoria sintática principal [20].

$\mathrm{Na}$ fase de formalização, para cada visão $\mathrm{V}$, o analista deve gerar cenários formais a partir da máquina de estado conceitual correspondente à visão (DAD). Esses 
cenários formais são escritos na forma de um programa utilizando a LD, a gramática reconhecedora desta linguagem é mostrada na figura 4.4. A validação de um programa escrito em uma determinada linguagem pode ser feita por um analisador de domínios, um subsistema responsável pela etapa de análise. Um programa gerado a partir de um DAD pode ser entäo validado por um analisador do domínio ERACE.

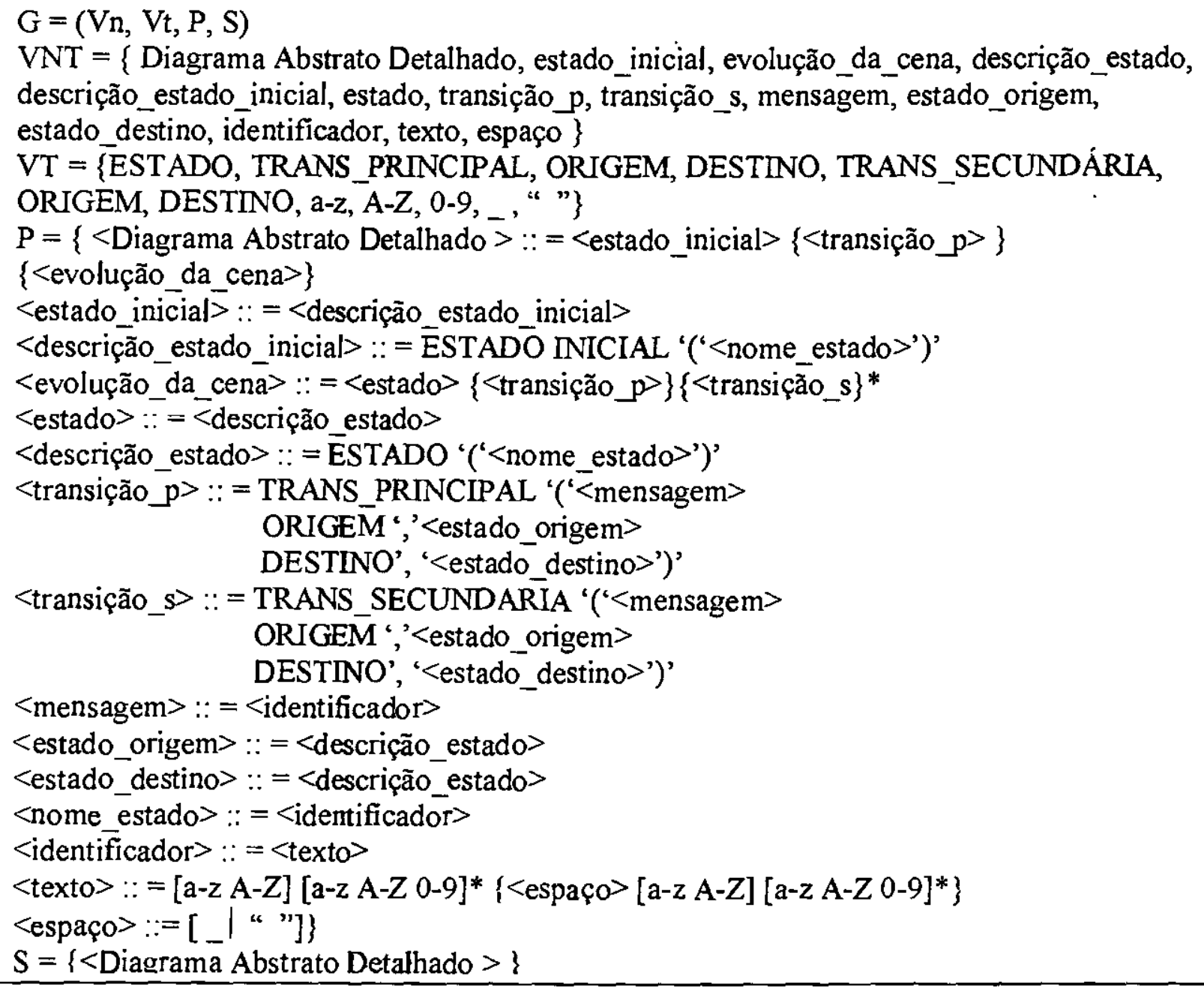

Figura 4.4-Gramática reconhecedora da Linguagem de Detalhamento

\subsubsection{Integração}

A Fase de integração visa a unificação dos modelos criados no processo ERACE e sua integração dentro do ciclo de vida do sistema. Essa fase consiste na unificação dos Diagramas Abstratos Detalhados pertencentes a uma mesma cena. Unificar os Diagramas Abstratos Detalhados de uma cena torna possivel uma visão geral e a execução da cena de uso identificada.

$\mathrm{Na}$ etapa de união dos DAD's, o primeiro passo é iniciar a integração, utilizando como base o Diagrama Abstrato Detalhado do ator principal daquela cena, os Diagramas Abstratos Detelhados dos outros atores participantes devem ser então "sobrepostos" seguindo descrições do próprio diagrama, pois como já foi dito, o estado inicial de um ator participante sempre faz referência a um estado intermediário presente no Diagrama Abstrato Detalhado do ator principal da mesma cena. Se um ator participa 
mais de uma vez em uma mesma cena existirão mais de estado em comum entre o ator participante e o principal, bastando então "sobrepor" todos os estados que se repetem nos dois diagramas. Esse diagrama chamado de Diagrama Unificado da Cena mostra a visão completa e sob todos os pontos de vista da cena descrita. A figura 4.5 ilustra um exemplo da criação de um DUC.

\subsubsection{Extensão dos Glossários}

Na fase de criação dos Diagramas Abstratos Detalhados o glossário que unifica a terminologia do sistema é estendido para descrever as novas informações especificadas neste diagramas. Novos glossánios que unificam as informações coletadas na fase de Modelagem dos Cenários são construidos com base nos Diagramas Abstratos Detalhados feitos para as várias cenas e atores do sistema. Cada Diagrama Abstrato Detalhado terá um glossário correspondente para descrever suas informações. Estes glossários são compostos pelas colunas nome, tipo, operação, argumento e descrição. $O$ nome é o identificador alfanumérico de um elemento presente no Diagrama Abstrato Detalhado. O tipo identifica se é um estado ou uma transição. A operação identifica a qual seqüência de estados pertencentes à cena está relacionado aquele elemento do Diagrama. Toda cena contém um conjunto de operações com o mesmo contexto de início e término que podem ser realizadas durante seu desenrolar. $O$ argumento identifica os objetos do dominio que são usados durante a operação. A descrição contém um texto livre e sucinto com as informações que descrevem o contexto e os objetivos de um estado ou uma transição do diagrama. O exemplo do formato de glossário construído na fase de Construção dos Cenários é mostrado na tabela 4.2 .

Tabela 4.2 Glossário do DAD

\begin{tabular}{||l|l|l|l|l|}
\hline NOME & TIPO & OPERAÇÃO & ARGUMENTO & DESCRIÇÃO \\
\hline Nome Estado Inicial & Estado Inicial & Operação 1 & Referência 1 & Descrição 1 \\
\hline Nome Estado 1 & Estado 1 & Operação 1 & Referência 2 & Descrição 2 \\
\hline Nome Transição 1 & $\begin{array}{l}\text { Transição } \\
\text { Principal 1 }\end{array}$ & Operação 1 & Referência 1 & Descrição 3 \\
\hline Nome Transição 2 & $\begin{array}{l}\text { Transição } \\
\text { Principal 1 }\end{array}$ & Operação 1 & Referência 2 & Descrição 4 \\
\hline
\end{tabular}

\subsection{Heurísticas para a passagem para o modelo de análise}

Uma vez que os modelos de requisitos do processo ERACE tenham sido elaborados, pode-se iniciar a fase de passagem para um modelo de análise. Os Diagramas DIC e DAD presentes no ERACE não coincidentemente são bastante semelhantes, respectivamente, aos Diagramas de casos de uso e Diagramas de estados descritos na Unified Modeling Language [21]. A notação aqui introduzida serve como processo que auxilia na construção dos modelos de análise da UML.. Esses diagramas são utilizados para representar diversos aspectos da estrutura do sistema. Para a produção dos modelos de análise devem ser aplicados ao modelo de requisitos produzido pelo ERACE um conjunto de heurísticas que ajudam a definir os componentes desses diagramas. 


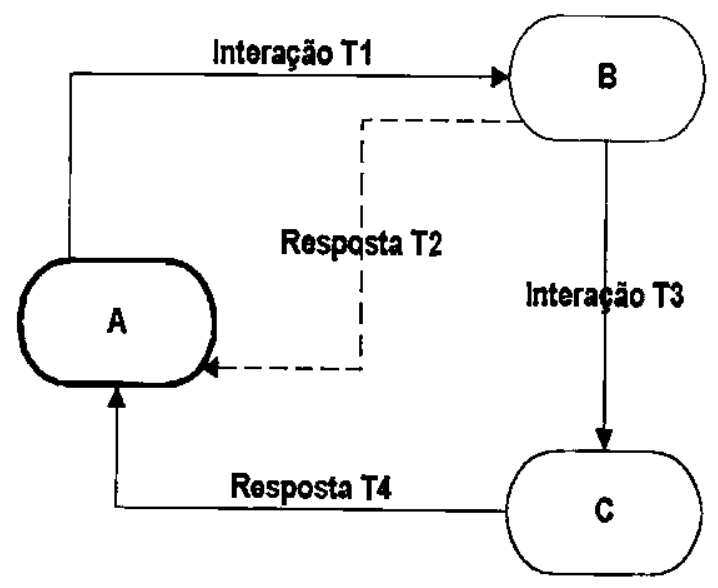

DAD - Ator Principal

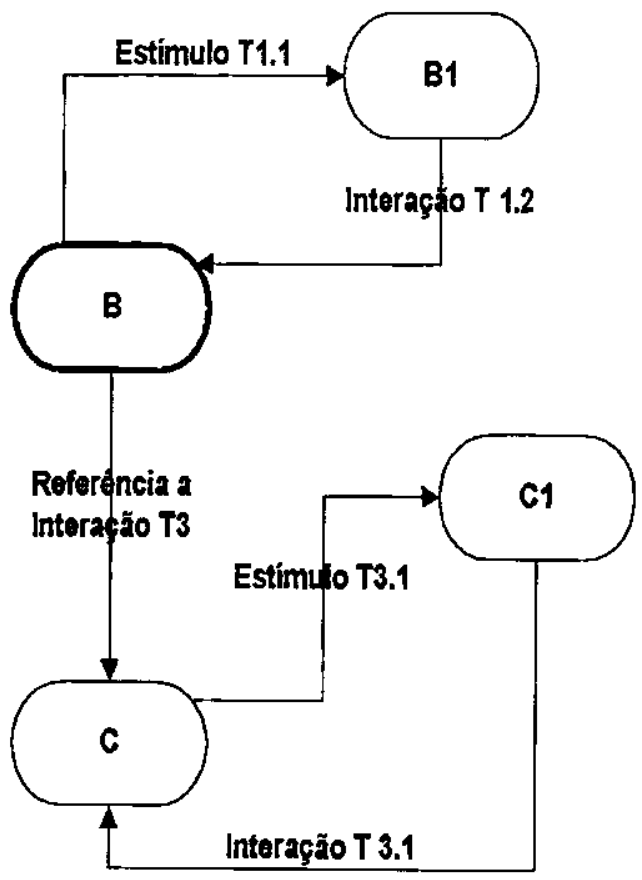

DAD - Ator Participante

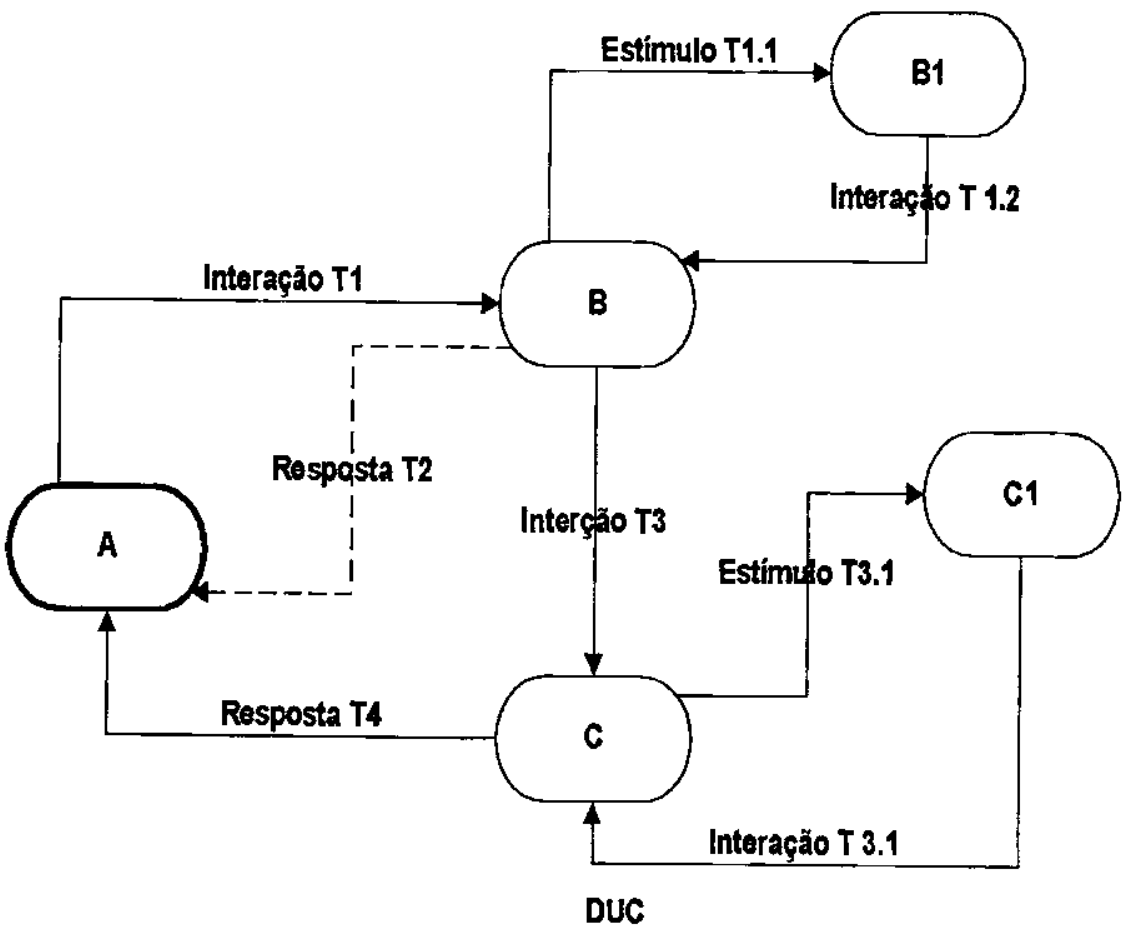

Figura 4.5 - Exemplo da criação de um DUC. $O$ ator participante colabora nos estados $B$ e $C$ do durante a interação do ator principal na cena. As interações do ator principal servem de estimulo para a interação do ator participante. 
Como principais heurísticas a serem aplicadas são identificadas as seguintes:

\subsubsection{Os Diagramas de Estados são construidos a partir dos Diagramas Abstratos Detalhados e dos Diagramas de Unificados das Cenas.}

Os Diagramas de Estados da UML podem ser obtidos a partir dos DAD's construídos para as cenas de uso identificadas no DIC. Para as cenas com a colaboração de mais de um ator a derivaçäo dos Diagramas de estados devem ser aplicadas com base no DUC da cena de uso em questão. A nomeação do diagrama de estados é a mesma usada nos DAD's, consultas ao glossário do DAD também facilitam a construção do Diagrama de Estados.

\subsubsection{Os Atores e os Argumentos são considerados candidatos a classes. Os métodos são as operaçőes.}

Baseado nos atores presentes no glossário do DIC e nos argumentos dos estados presentes no glossário do DAD são identificadas as classes candidatas do sistema. As operações presentes no glossário do DAD são indicativas dos métodos que compõem as classes. Praticamente todos os atores e argumentos podem dar origem a uma classe. Entretanto, para que seja incluído, o item deve estar relacionado a um conceito importante ao entendimento do domínio. Os métodos identificados com base nas operações são normalmente associados aos argumentos que mais aparecem na operação.

\subsubsection{As associações e as cardinalidades em geral são obtidas nos glossários.}

Com as informações registradas nos dois glossários construidos no processo ERACE são identificadas associações entre as classes candidatas. Cada associação está relacionada com os argumentos listados em cada cena. Consultas ao documento de requisitos e aos diagramas construidos também auxiliam na nomeação e na identificação das cardinalidades das associações. Se ao final da aplicação da terceira heurística restarem classes candidatas que não possuam associações, tais classes podem ser atributos de outras classes ou itens não relacionados a um conceito importante para o entendimento do domínio. Neste caso essa classe deverá ser excluida.

\subsubsection{O número de cenas sugere o número de submodelos de análise para a representação.}

As notações gráficas podem se tornar complicadas de entender caso os diagramas fiquem muito grandes e dispersos. A notação de um modelo de análise não é uma exceção a essa regra; para lidar com este problema, é possível dividir um diagrama em vários subdiagramas. A separação por assuntos pode ser utilizada para dividir um problema em partes coesas e independentes. A análise deve ser iniciada em um alto nível de abstração. Os detalhes somente devem ser acrescentados quando a estrutura global for considerada satisfatória. 0 modelo completo será simplesmente a união de todos os diagramas 


\subsubsection{Construção do Diagrama de Classes do Sistema.}

Com as informaçōes coletadas por intermédio das heurísticas 4.4 .2 e 4.4 .3 é iniciada a construção do Diagrama de Classes do Sistema, delimitando os limites do sistema e separando as classes e as associações que não são necessárias para a funcionalidade do sistema. Essa delimitação é feita com a aplicação de estereótipos às classes identificadas. Os estereótipos que podem ser utilizados são: de ator, substituem as classes candidatas que interagem com o sistema; de fronteira, usados para classes candidatas com função de comunicação ou manipulação (protocolos); de entidade, usados para modelar objetos de negócios e controle, usados para conectar objetos de fronteira com objetos de entidade e para manusear um seqüência de operações dentro do sistema.

\subsubsection{Os Diagramas de Seqüência e os Diagramas de Colaboração são construidos a partir das operaçōes identificadas no glossário do DAD.}

Os Diagramas de Seqüência são construídos a partir de cada operação presente nos glossários do DAD. Os objetos representados neste diagrama são identificados a partir das classes especificadas no Diagrama de Classes do Sistema construído com base na heurística 4.4.5. As mensagens são obtidas nas transições do DAD da operação especificada. Os rótulos são obtidos nas descrições dos estados e transiçöes da operação. Diagramas de Seqüência e Diagramas de Colaboração expressam uma informação semelhante, mas a apresentam de forma diferente. Os Diagramas de Seqüência estão focalizados sobre o tempo, e os de colaboração sobre o espaço [21]. Estes diagramas podem ser utilizados para ilustrar a execução de uma operação ou uma cena de uso do sistema. Os objetos que participam deste Diagrama são os mesmos utilizados na construção do Diagrama de seqüência. As ligaçōes são obtidas nas transições do DAD da operação especificada.

\subsection{Considerações Finais}

A partir da aplicação do processo ERACE e das heurísticas de passagem o engenheiro de software pode continuar a construção dos outros modelos que compõe a UML. Observa-se que boa parte da notação utilizada no processo ERACE abrange várias das notações sugeridas por Booch, Rumbaugth e Jacobson, em [21]: Diagramas de Casos de Uso, Diagramas de Atividades e Diagramas de Estados. E importante notar que a UML abrange uma linguagem de modelagem padrão, não um processo padrão. Através da UML é possivel aplicar o processo a um contexto, já que diferentes

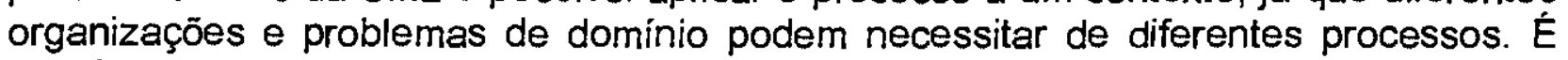
possivel então utilizar UML independentemente do processo. 
Capítulo 5 - Estudo de Caso 


\subsection{Considerações Iniciais}

Apresenta-se neste capítulo um estudo de caso de um sistema de auxílio a escrita de documentos técnicos com o objetivo de ilustrar a proposta apresentada no capítulo anterior. Para o desenvolvimento do estudo de caso utilizou-se o documento de requisitos do sistema SAPES que serviu como base para a elaboração do relatório técnico publicado por Turine e Masiero [23]. No anexo A apresenta-se a documento de requisitos completo desse sistema.

O Sistema SAPES tem como objetivo auxiliar a pesquisa bibliográfica. Os usuários deste sistema durante a sua a pesquisa podem ler publicações e armazenálas no sistema na forma de itens bibliográficos, construindo assim sua bibliografia pessoal. O usuário pode também utilizar o sistema durante a redação de textos científicos. A partir do documento editado pelo usuánio, o sistema reconhece e gera automaticamente a referência bibliográfica.

Na seção 5.2 é ilustrada a fase de Especificação de Requisitos do processo com a construção do Diagrama de Interação da Cenas e seu respectivo glossáno. Na seção 5.3 é ilustrada a fase de Criação de Cenários do processo com a construção dos Diagramas Abstratos Detaihados e seus respectivos glossários. São mostradas também as fases de formalização na qual são gerados cenários formais para cada Diagrama Abstrato Detalhado gerado e de integração, na qual são integradas as vários visões das diversas cenas detalhadas. Na seção 5.4 é mostrada a aplicação das heurísticas de passagem, que possibilitam a criação dos Modelos de Análise da UML a partir dos modelos criados no processo ERACE

\subsection{Fase de Especificação das Interações}

Esta fase permite especificar a colaboração entre os atores e as cenas de uso. Para a construção do Diagrama de Interação das Cenas relacionam-se os prováveis atores $e$ as cenas de uso encontradas no documento de requisitos e nos documentos produzidos/coletados na elicitação. No diagrama DIC-1 observa-se que o sistema foi subdividido em três cenas de uso independentes, contando com a interação de três atores. As cenas de uso representam as principais atividades do sistema. Uma cena uso é formada por várias operações relacionadas. O usuário do sistema pode desempenhar dois papéis no momento de interagir com o sistema: o de pesquisador $e$ o de escritor. Um terceiro ator foi identificado como sendo um subsistema "editor de textos", que é utilizado durante a inserção de referências bibliográficas em um artigo técnico.

Com o diagrama construído pode-se preparar o glossário que faz a descrição de todos os seus componentes. $\mathrm{O}$ glossário deve ser baseado no documento de requisitos que serviu como base para a criação do diagrama de interação das cenas e auxiliam no rastreamento das informações, possibilitando a validação dos requisitos analisados. A tabela 5.1 apresenta esse glossário. 


\subsection{Fase de Modelagem dos Cenários}

Esta fase permite especificar detalhadamente o comportamento de cada ator dentro das cenas identificadas. A partir de cada cena do DIC criado na seção anterior, são criados Diagramas Abstratos Detalhados para cada ator que participa da cena. Um DAD é descrito por estados, que representam as atividades realizadas pelas operações e por transiçōes, que representam as interaçōes de um ator com o sistema ou as respostas ou estímulos enviadas a um ator pelo.sistema.

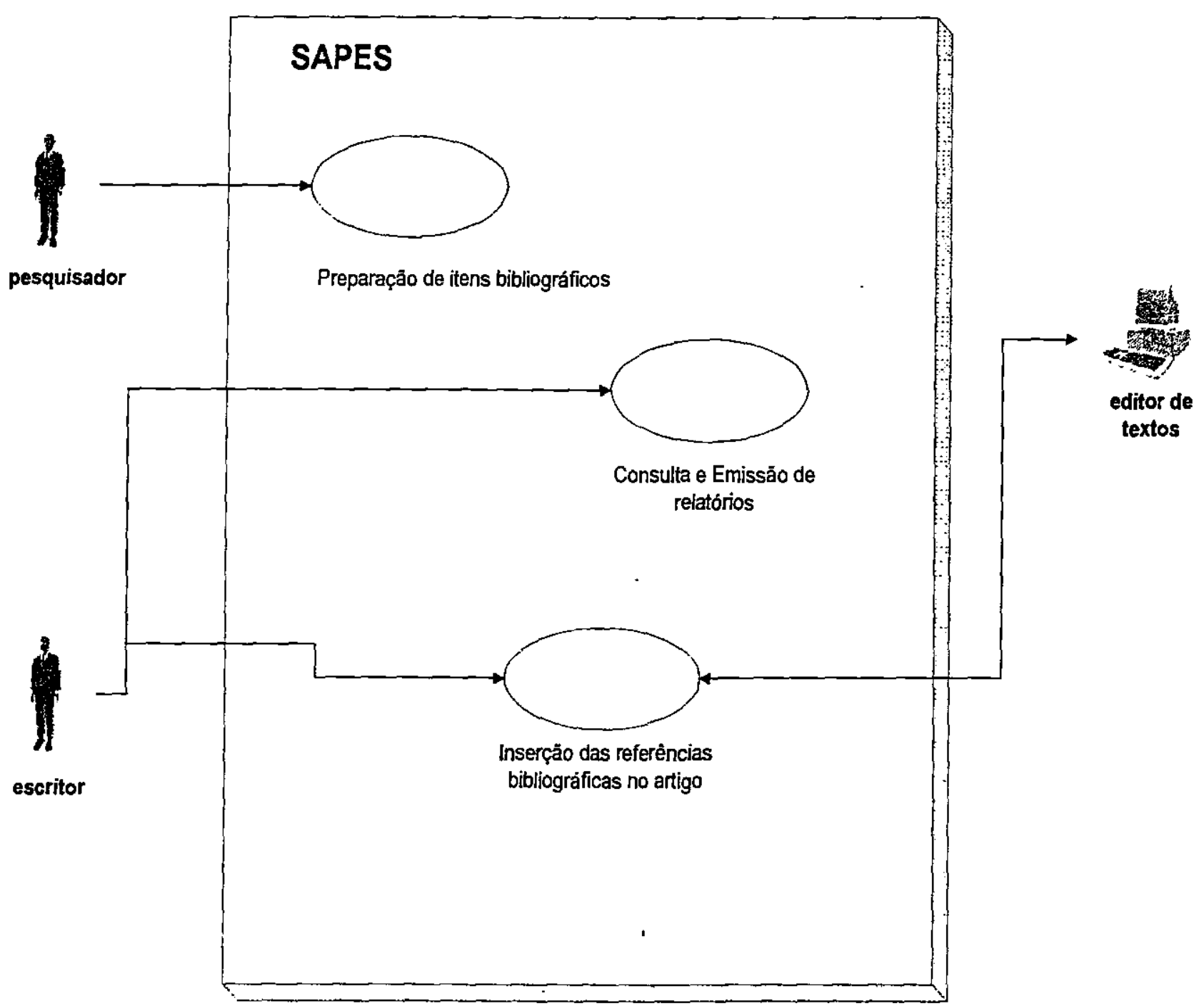

\section{DIC-1}

No DAD-1 são detalhadas as operações existentes na cena de uso "Preparação de Itens Bibliográfico". Todas as operaçōes agrupadas na cena iniciam e terminam no mesmo estado. As transiçōes entre os estados representam interações do atof principal dentro da cena ou respostas fornecidas pelo sistema. 
Tabela 5.1 - Glossário do DIC

\begin{tabular}{||l|c|l||}
\hline NOME & TIPO & DECRIÇÃO \\
\hline Pesquisador & Ator & $\begin{array}{l}\text { Pessoa que alimenta o sistema SAPES com o conjunto de itens } \\
\text { bibliográficos referentes a diversos artigos publicados }\end{array}$ \\
\hline Escritor & Ator & $\begin{array}{l}\text { Pessoa que utiliza o sistema SAPES e que está interessada na } \\
\text { obtenção de relatórios e manutenção automática de sua bibliografia }\end{array}$ \\
\hline $\begin{array}{l}\text { Consulta e } \\
\text { Emissão de } \\
\text { relatórios }\end{array}$ & Cena & $\begin{array}{l}\text { Conjunto de operações do sistema SAPES que descrevem a saida } \\
\text { de dados no sistema }\end{array}$ \\
\hline $\begin{array}{l}\text { Preparação de } \\
\text { itens bibliográficos }\end{array}$ & Cena & $\begin{array}{l}\text { Conjunto de operações do sistema SAPES que descrevem a } \\
\text { entrada de dados no sistema }\end{array}$ \\
\hline $\begin{array}{l}\text { Inserção de } \\
\text { referências } \\
\text { bibliográficas no } \\
\text { texto }\end{array}$ & Cena & $\begin{array}{l}\text { Conjunto de operações do sistema SAPES que descrevem a a } \\
\text { automatização da bibliografia }\end{array}$ \\
\hline $\begin{array}{l}\text { Editor de textos } \\
\text { Ator }\end{array}$ & $\begin{array}{l}\text { Subsistema utilizado pelo sistema SAPES para a produção de } \\
\text { referências bibliográficas }\end{array}$ \\
\hline
\end{tabular}

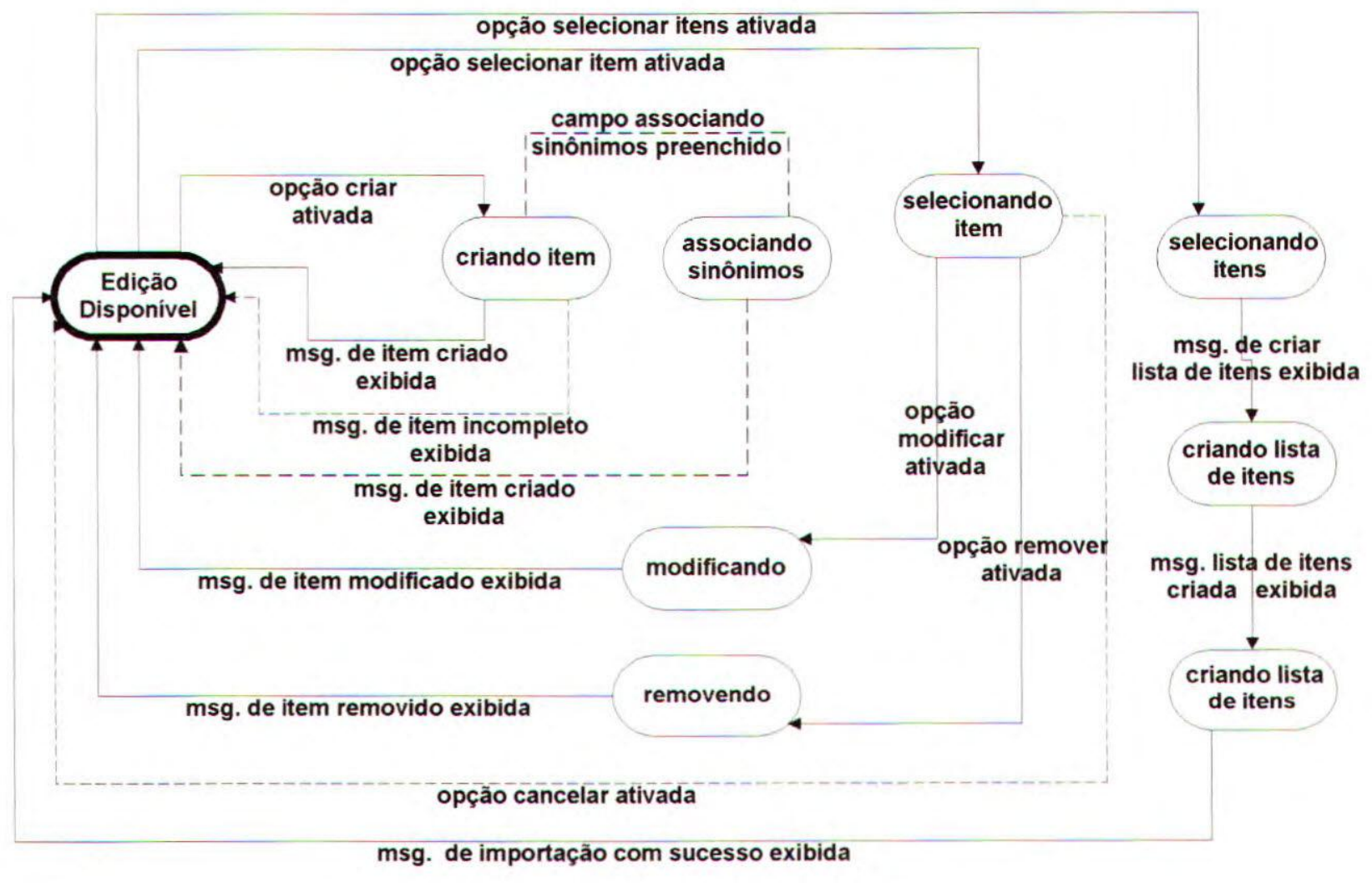

DAD-1 
No DAD-2 e DAD-3 são detaihadas as operações existentes na cena de uso "Inserção de Referências Bibliográficas". Como nesta cena existiu a interação de dois atores, ela possui dois DAD's em seu detalhamento. No DAD-2 é representado o detalhamento da interação do ator principal dentro da cena. No DAD-3 é representado o detalhamento da interação do ator participante. Em cenas com a colaboração de mais de um ator, os atores participantes iniciam sua colaboração em algum dos estados do DAD do ator principal. Por isso o estado inicial do DAD de um ator participante possui o mesmo nome do estado intermediário do ator principal, no qual o ator participante inicia a sua colaboração. Assim, se um ator participante colabora mais de um vez em uma mesma cena, cada colaboração deve sempre referênciar estados do DAD do ator principal.

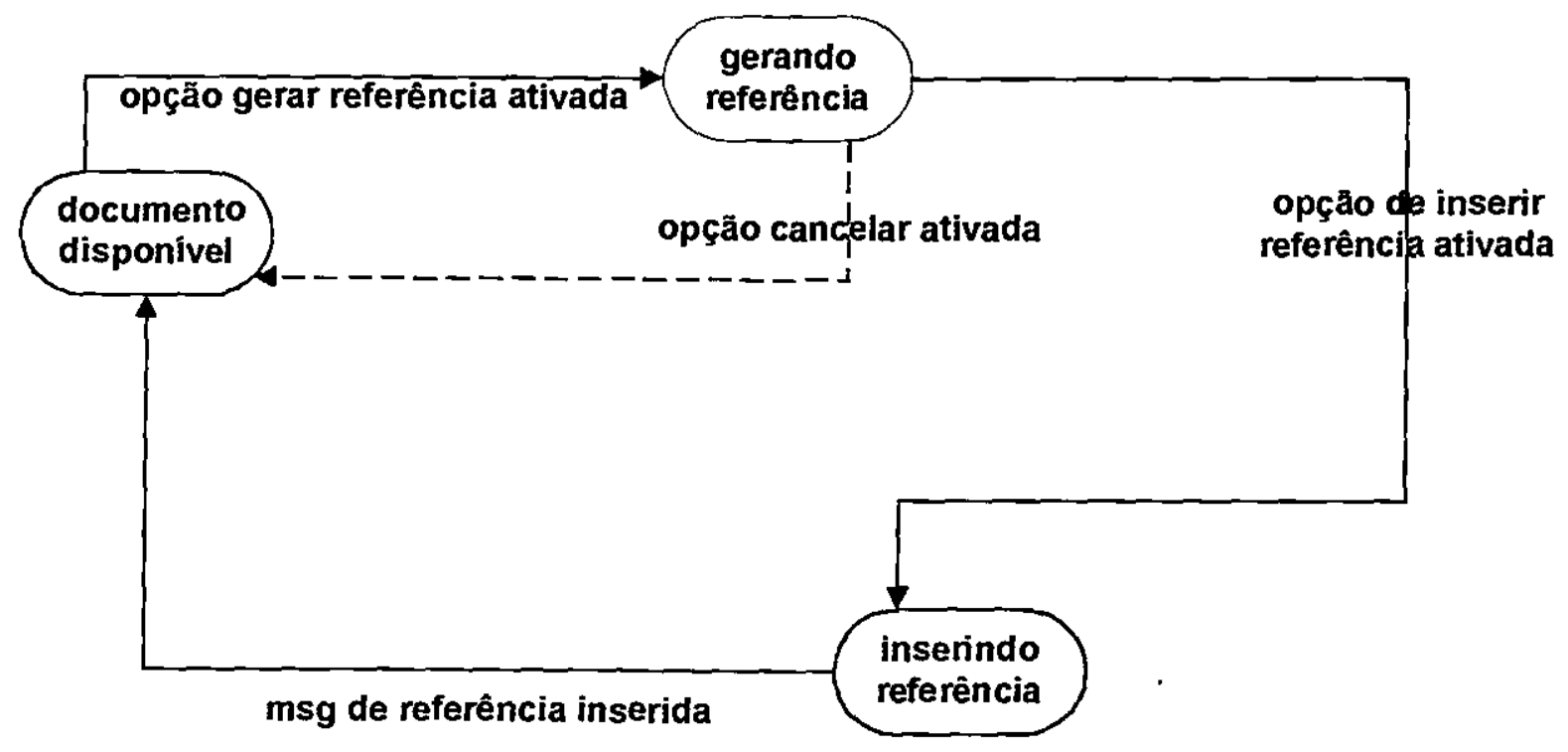

DAD-2

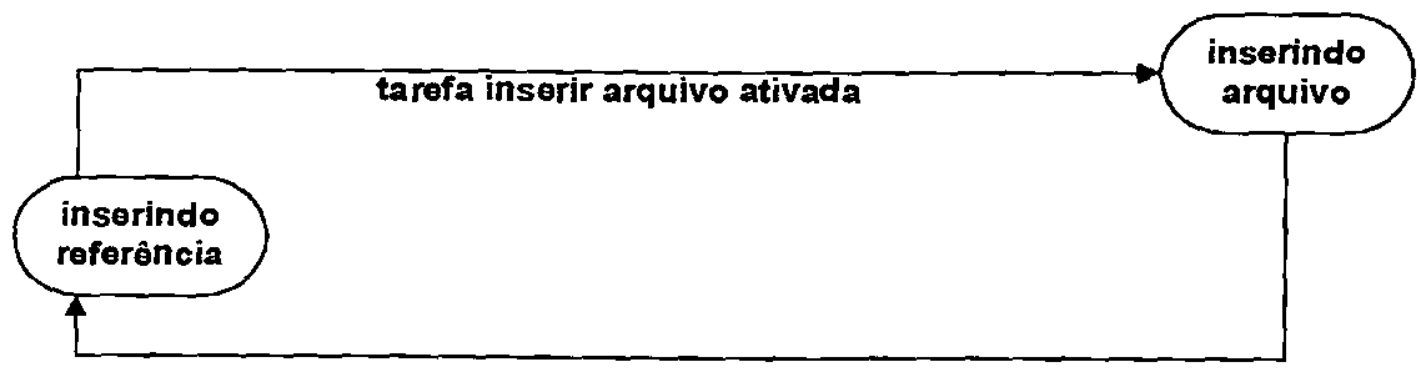

resp. arquivo inserido gerada

\section{DAD-3}

No DAD-4 são detalhadas as operações existentes na cena de uso "Consulta e Emissão de Relatórios". Como efeito ilustrativo, as várias operações que compõem a cena estão delimitadas por linhas grossas coloridas. As duas operações identificadas são agrupadas em uma mesma cena por iniciarem em um mesmo estado inicial e a ele retornarem no seu término. 


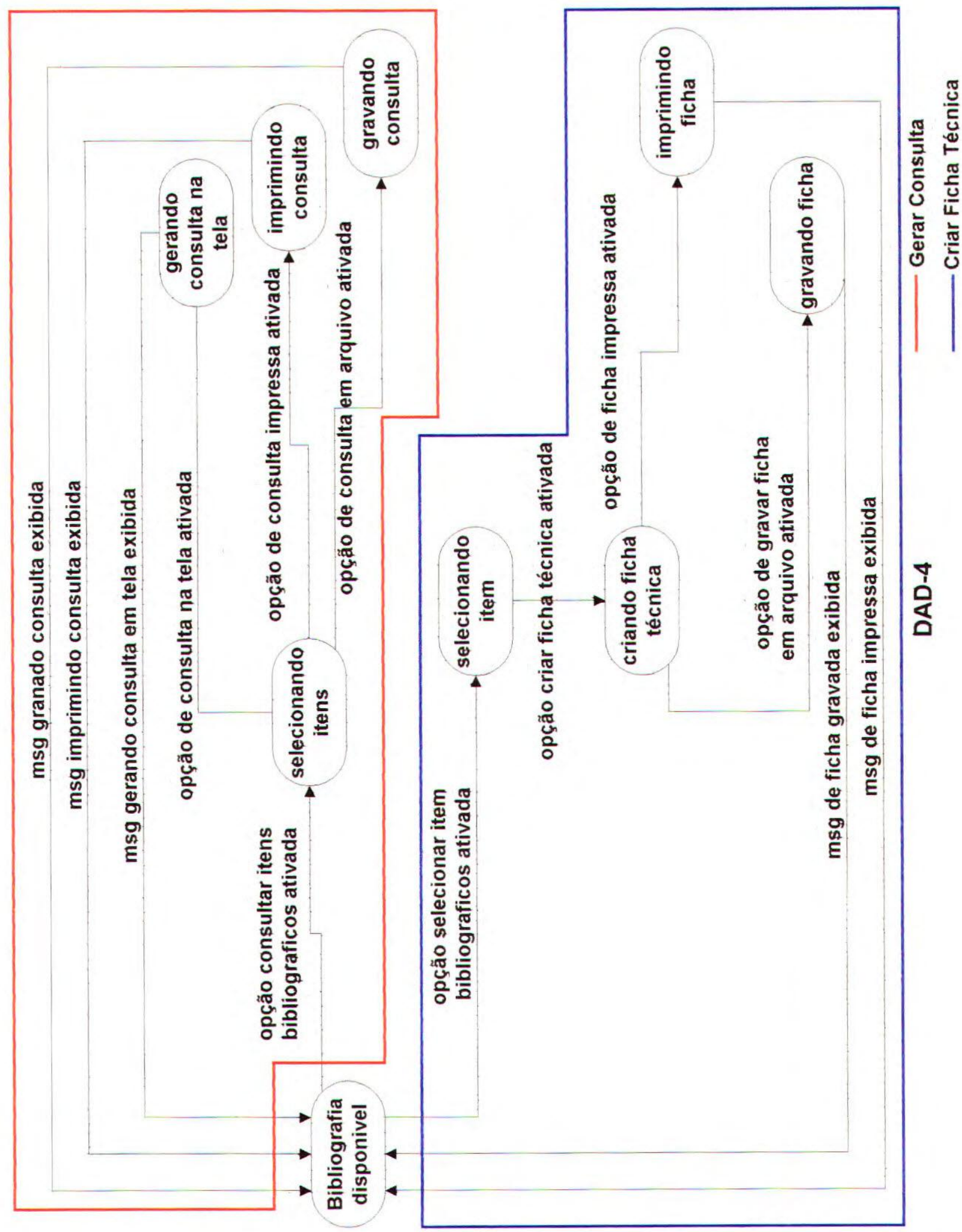




\subsubsection{Formalização}

TRANS_PRINCIPAL opçao criar item ativada ORIGEM edicao disponivel DESTINO criando item

TRANS_PRINCIPAL msg de item criado ORIGEM criando item DESTINO edicao disponivel

TRANS_SECUNDÁRIA msg de 'item incompleto exibida ORIGEM criando item DESTINO edicao disponivel

ESTADO associando sinonimo

TRANS_SECUNDÁRIA msg de item criado ORIGEM criando item DESTINO edicao disponivel

ESTADO Selecionando item

TRANS_PRINCIPAL opçao selecionar 'tem ativada ORIGEM edicao disponivel DESTINO Selecionando item

TRANS_PRINCIPAL msg de item selecionado ORIGEM Selecionado item DESTINO modificando

ESTADO modificando

TRANS_PRINCIPAL opção modificar ativada ORIGEM Selecionado item DESTINO removeñdo

TRANS_PRINCIPAL msg de item modificado exibida ORIGEM modificando DESTINO edicao disponivel

ESTADO removendo

TRANS_PRINCIPAL opção remover ativada ORIGEM Selecionado item DESTINO removendo

TRANS_PRINCIPAL msg de item removido exibida ORIGEM removendo DESTINO edicao dísponivel

ESTADO Selecionando itens

TRANS_PRINCIPAL opcao selecionar itens ativada ORIGEM edicao disponivel DESTINO Selecionando itens

TRANS_PRINCIPAL msg de item selecionado ORIGEM Selecionado itens DESTINO criando lista de itens disponivel

ESTADO Criando lista de itens

TRANS_PRINCIPAL msg de lista de itens criada exibida ORIGEM criando lista de itens DESTINO Importando itens

Estado Importando itens

TRANS_PRINCIPAL msg de importacão com sucesso exibida ORIGEM Importando itens

DESTINO edicao disponivel

\section{C-01}

Nesta fase cada Diagrama Abstrato Detalhado é convertido em um conjunto de sentenças de uma linguagem regular, chamada Linguagem de Detalhamento (LD), cada conjunto de sentenças equivale a um cenário formal que descreve os acontecimentos presentes na cena. A validação de um DAD pode ser realizada pela análise síntática de um programa escrito em $L D$ gerado a partir de um DAD. No cenário C-01 é apresentado o programa em LD gerado a partir do DAD-1, que detalha a 
interação principal na cena de "Preparação dos itens bibliográficos".

\subsubsection{Integração}

Nesta fase é realizada a unificaçăo dos modelos criados no processo ERACE. No caso das cenas que têm a participação de mais de um ator os Diagramas Abstratos Detalhados que compõe a cena são unificados, tornando possivel uma visão geral e a execução da cena de uso identificada. No diagrama DUC-01 é apresentada a unificação dos Diagramas Abstratos Detalhados da cena "Inserção de referências bibliográficas

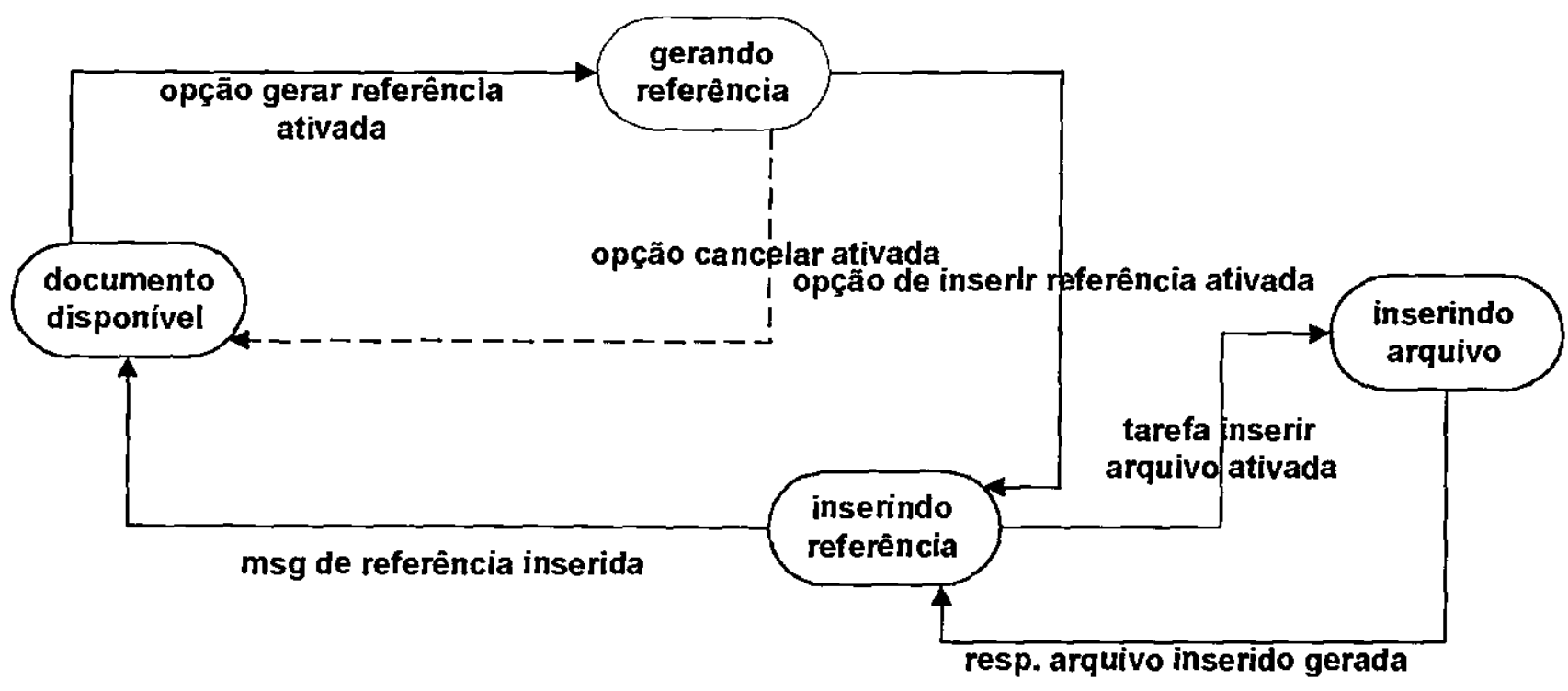

\subsubsection{Extensão dos glossários}

DUC-1

Com os a construção de todos os diagramas da fase de Criaçăo de Cenários pode-se preparar a extensão dos glossário que englobam descriçōes dos componentes dos Diagramas Abstratos Detalhados e Diagramas Unificados das Cenas. Todas as informações presentes na extensão aos glossários devem ser baseadas nos diagramas construídos na fase de Criação de Cenários. Tais informações serão úteis na aplicação das heurísticas de passagem para o Modelo de Análise. A tabela 5.2 ilustra o exemplo desse glossário para o DAD da cena "Preparaçăo de Itens Bibliográfico". O Anexo B contém uma versão mais completa das extensões dos glossários criadas para o estudo de caso.

\subsection{Aplicação das Heurísticas de passagem para o Modelo de Análise}


Baseado nos modelos (diagramas e glossários) de requisitos elaborados durante aplicação do processo ERACE, o engenheiro de software pode dar inicio às atividades relativas à fase de Especificação de Requisitos, aplicando as heurísticas de passagem, utilizando para isso notação dos Modelos de Especificaçāo de Requisitos da UML. A fase de análise tem como objetivo mostra a estrutura estática do modelo em particular os elementos que nele existem (tais como classes e tipos), sua estrutura interna e seus relacionamentos [31]. Segundo Eriksson e Penker em [24], em uma abordagem tradicional, os diagramas descritos na UML que melhor retratam as informaçōes a serem descritas na fase de análise são: de estados, de classes, de seqüência e de colaboração. As heurísticas descritas nesta seção ajudam na construção destes diagramas.

Tabela 5.2 - Glossário do DAD para a cena "Preparação de itens Bibliográficos"- Ator Principal"

\begin{tabular}{|c|c|c|c|c|}
\hline NOME & TIPO & OPERAÇÃO & ARGUMENTO & DESCRIÇÃO \\
\hline $\begin{array}{l}\text { Edição } \\
\text { Disponivel }\end{array}$ & $\begin{array}{l}\text { Estado } \\
\text { Inicial }\end{array}$ & & & $\begin{array}{l}\text { O sistema está } \\
\text { operando e inativo }\end{array}$ \\
\hline Criando Item & Estado & Criar item & $\begin{array}{l}\text { Bibliografia, } \\
\text { Item } \\
\text { bibliográfico }\end{array}$ & $\begin{array}{l}\text { Inserção de um novo } \\
\text { item bibliográfico na } \\
\text { bibliografia }\end{array}$ \\
\hline $\begin{array}{l}\text { Opção criar } \\
\text { item ativada }\end{array}$ & $\begin{array}{l}\text { Transição } \\
\text { Principal }\end{array}$ & Criar item & $\begin{array}{l}\text { Item } \\
\text { bibliográfico }\end{array}$ & $\begin{array}{l}\text { Interação que aciona a } \\
\text { criação de um item } \\
\end{array}$ \\
\hline $\begin{array}{l}\text { Msg. de item } \\
\text { criado exibida }\end{array}$ & $\begin{array}{l}\text { Transição } \\
\text { Principal }\end{array}$ & Criar item & $\begin{array}{l}\text { Item } \\
\text { bibliográfico }\end{array}$ & $\begin{array}{l}\text { Resposta de sucesso } \\
\text { para a operação criar } \\
\text { item }\end{array}$ \\
\hline $\begin{array}{l}\text { Msg de item } \\
\text { incompleto } \\
\text { exibida }\end{array}$ & $\begin{array}{l}\text { Transição } \\
\text { Secundária }\end{array}$ & Criar item & $\begin{array}{l}\text { Item } \\
\text { bibliográfico }\end{array}$ & $\begin{array}{l}\text { Resposta de falha para } \\
\text { a operação criar item }\end{array}$ \\
\hline $\begin{array}{l}\text { Campos de } \\
\text { sinônimos } \\
\text { preenchidos } \\
\end{array}$ & $\begin{array}{l}\text { Transição } \\
\text { Secundária }\end{array}$ & Criar item & $\begin{array}{l}\text { Item } \\
\text { bibliográfico }\end{array}$ & $\begin{array}{l}\text { Interação que inicia a } \\
\text { associação de } \\
\text { sinônimos }\end{array}$ \\
\hline $\begin{array}{l}\text { Msg. de item } \\
\text { criado exibida }\end{array}$ & $\begin{array}{l}\text { Transição } \\
\text { Secundária }\end{array}$ & Criar item & $\begin{array}{l}\text { Item } \\
\text { bibliográfico, } \\
\text { Sinônimos }\end{array}$ & $\begin{array}{l}\text { Resposta de sucesso } \\
\text { para a operação criar } \\
\text { item }\end{array}$ \\
\hline $\begin{array}{l}\text { Opção } \\
\text { cancelar } \\
\text { ativada }\end{array}$ & $\begin{array}{l}\text { Transição } \\
\text { Secundária }\end{array}$ & $\begin{array}{l}\text { Selecionar } \\
\text { item }\end{array}$ & $\begin{array}{l}\text { Item } \\
\text { bibliográfico }\end{array}$ & $\begin{array}{l}\text { Interação que cancela } \\
\text { a seleção de um item }\end{array}$ \\
\hline $\begin{array}{l}\text { Criando lista } \\
\text { de itens }\end{array}$ & Estado & $\begin{array}{l}\text { Importar } \\
\text { itens }\end{array}$ & $\begin{array}{l}\text { Item } \\
\text { bibliográfico, } \\
\text { Bibliografia }\end{array}$ & $\begin{array}{l}\text { Criação de uma lista de } \\
\text { itens bibliográficos } \\
\text { selecionados }\end{array}$ \\
\hline $\begin{array}{l}\text { Opção } \\
\text { selecionar item } \\
\text { ativada }\end{array}$ & $\begin{array}{l}\text { Transição } \\
\text { Principal }\end{array}$ & Criar item & $\begin{array}{l}\text { Item } \\
\text { bibliográfico }\end{array}$ & $\begin{array}{l}\text { Interação que aciona a } \\
\text { seleção de um item }\end{array}$ \\
\hline$\cdots$ & $\cdots$ & $\cdots$ & $\cdots$ & $\cdots$ \\
\hline
\end{tabular}




\subsubsection{Os Diagramas de Estados são construidos a partir dos diagramas de Abstratos Detalhados e do Diagrama Unificado das Cenas.}

Um Diagrama de Estados mostra a sucessão de estados pelos quais um objeto passa durante sua vida, em resposta aos eventos recebidos por ele. Os Diagramas de Estados da UML podem ser derivados a partir dos DAD's construídos para cada cena de uso identificada no Diagrama de Interação das Cenas. Para as cenas que contém a colaboração de mais de um ator, a derivação dos Diagramas de Estados deve ser aplicadas com base no DUC da cena de uso em questão. A figura 5.1 ilustra o Diagrama de Estados derivado a partir da cena de uso "Inserção de referências bibliográficas" o DUC desta cena de uso foi ilustrado na figura DUC-1. A nome dos estados é a mesma usada nos DAD's. A nomeação dos eventos deve ser derivada dos nomes das operações e das transições presentes no glossário da cena.

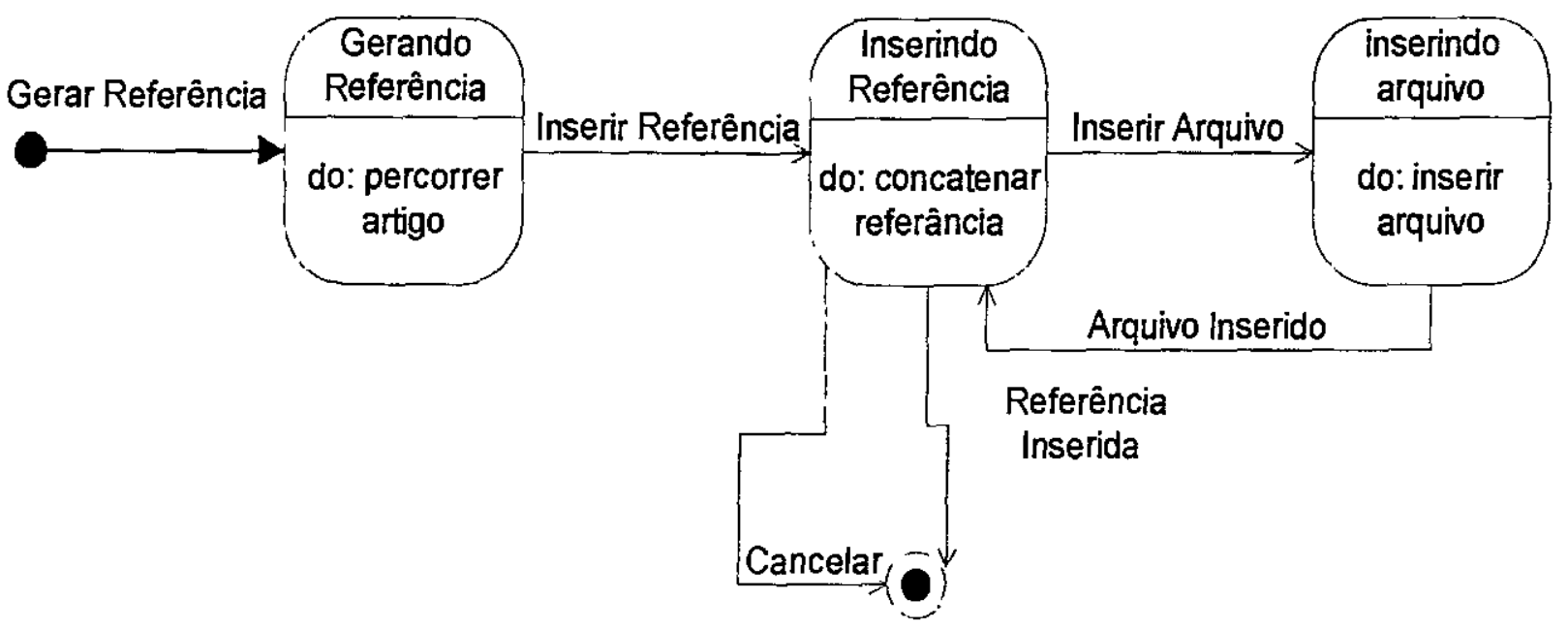

Figura 5.1 Diagrama de Estados para a cena "Inserção de referências bibliográficas"

Os Diagramas de Estados também podem ser derivados das operações pertencentes a uma cena. A figura 5.2 ilustra o Diagrama de Estados derivado a partir da operação "Criar ficha técnica" especificada na cena de uso "Consulta e Emissão derelatórios", o DAD desta cena de uso foi ilustrado na figura DAD-4.

\subsubsection{Os Atores e os Argumentos são considerados candidatos a classes. Os métodos são obtidos nas operações.}

A lista das classes candidatas é composta pelos atores identificados no glossário do DIC e pelos argumentos identificados no glossário do DAD. A Tabela 5.3 ilustra as classes candidatas. Os métodos candidatos identificados foram associados aos argumentos que mais aparecem na operação da qual foi obtido o método. O Anexo B contém a versão completa do glossário. 


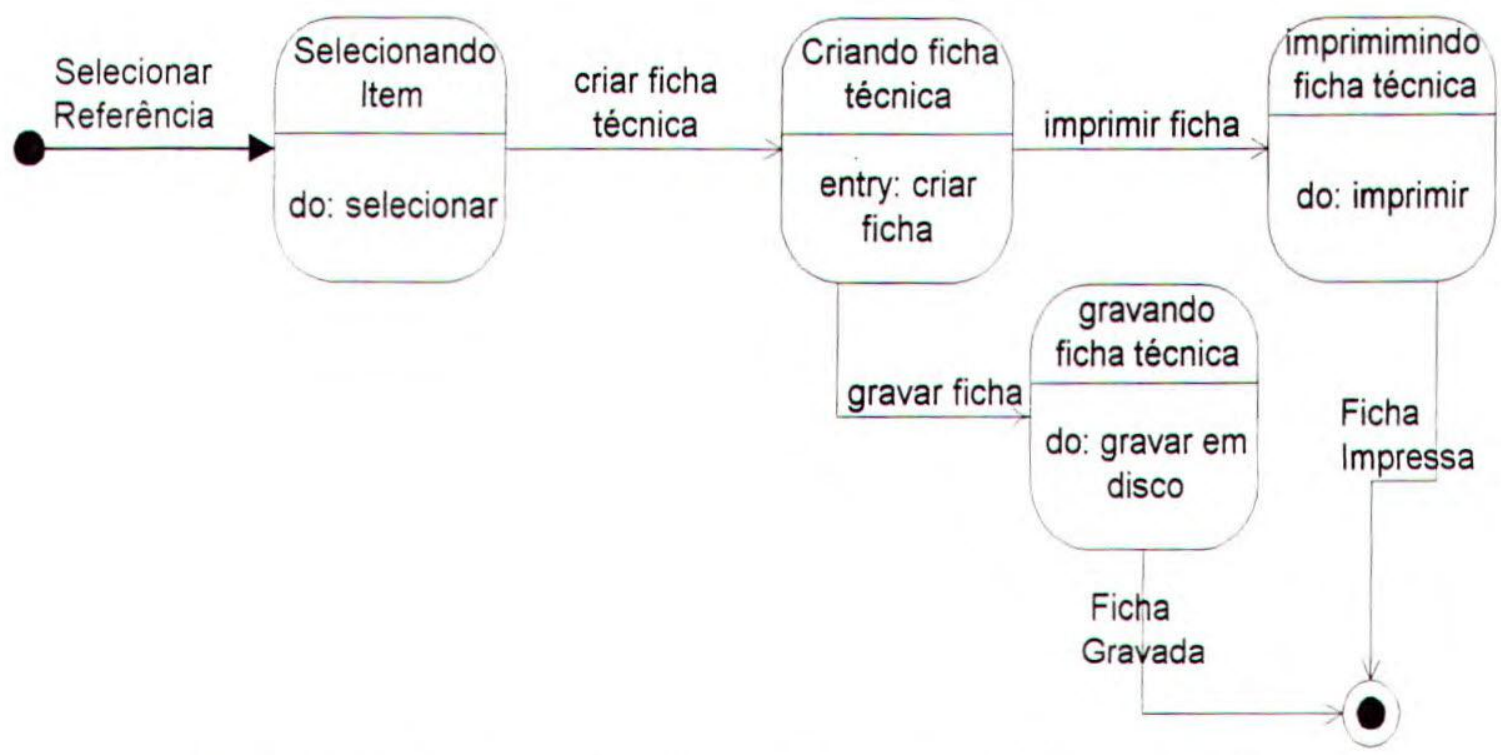

Figura 5.2 Diagrama de Estados para a operação "Criar ficha técnica"

\subsubsection{As associações e as cardinalidades em geral são obtidas nos glossários.}

Inicialmente devem ser identificadas as associações entre classes candidatas do tipo argumento (ARGUMENTO-ARGUMENTO). Dois ou mais argumentos presentes em um mesmo estado no glossário do DAD são uma indicativa de associação entre os mesmos. O tipo do relacionamento é identificado nas descrições do estado. Por exemplo, na tabela 5.4 os argumentos Bibliografia e Item Bibliográfico presentes no estado Criando Item sugerem uma associação. O campo descrição dá a idéia que item bibliográfico faz parte da bibliografia, o que indica uma associação de agregação. Outros tipos de associações entre argumentos podem ser obtidas diretamente das descrições. Por exemplo, as descrições das tabela 5.4 sugerem que um relatório pode ser do tipo consulta e do tipo ficha técnica, o que indica uma associação de generalização.

Tabela 5.3 - Classes e Métodos Candidatos

\begin{tabular}{||l|l||}
\hline \multicolumn{1}{|c||}{ Classes Candidatas } & \multicolumn{1}{c||}{ Métodos } \\
\hline Pesquisador & \\
\hline Escritor & \\
\hline Editor de Textos & Importar Bibliografia \\
\hline Bibliografia & $\begin{array}{l}\text { Criar Item, Modificar Item, Remover Item, Selecionar } \\
\text { Item }\end{array}$ \\
\hline Item Bibliográfico & Associar Sinônimo \\
\hline Sinônimo & Gerar Referência, Inserir Referência, Inserir_Referência \\
\hline Referência Bibliográfica & \\
\hline Artigo & Gerar Consulta \\
\hline Relatório de Consulta & Criar Ficha Técnica \\
\hline Ficha Técnica &
\end{tabular}


Tabela 5.4 - Fragmento do glossário "Preparação de itens bibliográficos - Ator Principal"

\begin{tabular}{||c|l|l|l|l||}
\hline \hline NOME & \multicolumn{1}{|c||}{ TIPO } & OPERAÇÃO & ARGUMENTO & DESCRIÇÃO \\
\hline Criando Item & Estado & Criar item & $\begin{array}{l}\text { Bibliografia, } \\
\text { Item } \\
\text { bibliográfico }\end{array}$ & $\begin{array}{l}\text { Inserção de um novo } \\
\text { item bibliográfico na } \\
\text { bibliografia }\end{array}$ \\
\hline
\end{tabular}

Associações entre classes candidatas do tipo ator e argumento (ATORARGUMENTO) são obtidas a partir das descrições das transições dos glossários do $\mathrm{DAD}$ em que o ator colabora. As associações são normalmente entre o ator do DAD e o argumento da transição. Na tabela 5.5, por exemplo, a descrição da transição Opção criar item ativada sugere uma associação entre 0 ator do DAD (no caso o pesquisador) e item bibliográfico.

Tabela 5.4 - Fragmento do glossário "Consulta e Emissão de Relatórios - Ator Principal"

\begin{tabular}{||l|l|l|l|l||}
\hline \multicolumn{1}{|c|}{ NOME } & \multicolumn{1}{|c|}{ TIPO } & OPERAÇÃO & ARGUMENTO & DESCRIÇÃO \\
\hline $\begin{array}{l}\text { Imprimindo } \\
\text { consulta }\end{array}$ & Estado & Gerar Consulta & $\begin{array}{l}\text { Relatório de } \\
\text { Consulta, Itens } \\
\text { bibliográficos }\end{array}$ & $\begin{array}{l}\text { Gera na impressora um } \\
\text { relatório do tipo consulta } \\
\text { selecionado por intermédio } \\
\text { da combinação de um ou } \\
\text { mais itens de informação }\end{array}$ \\
\hline $\begin{array}{l}\text { Imprimindo } \\
\text { Ficha Técnica }\end{array}$ & Estado & $\begin{array}{l}\text { Criar Ficha } \\
\text { Técnica }\end{array}$ & Ficha Técnica & $\begin{array}{l}\text { Gera na impressora um } \\
\text { relatório do tipo ficha técnica } \\
\text { de um item bibliográfico }\end{array}$ \\
\hline
\end{tabular}

Tabela 5.5 - Fragmento do glossário "Preparação de itens bibliográficos - Ator Principal"

\begin{tabular}{||l|l|l|l|l||}
\hline \multicolumn{1}{|c|}{ NOME } & \multicolumn{1}{|c|}{ TIPO } & OPERAÇÃO & ARGUMENTO & DESCRIÇÃO \\
\hline $\begin{array}{l}\text { Opção criar item } \\
\text { ativada }\end{array}$ & $\begin{array}{l}\text { Transição } \\
\text { Principal }\end{array}$ & Criar item & Item bibliográfico & $\begin{array}{l}\text { Interação que aciona a } \\
\text { criação de um item }\end{array}$ \\
\hline
\end{tabular}

As cardinalidade para todas as associações devem ser obtidas nas descrições dos glossários ou no próprio documento de requisitos do sistema. Consultas ao documento de requisitos e aos diagramas construídos também auxiliam na nomeação das associações. Classes candidatas que ao final da aplicação da heurística 5.4.3 não possuírem nenhum tipo de associação podem ser: atributos de outras classes (esta checagem deve ser feita nos campos de descrições do DAD) ou itens não relacionados a um conceito importante ao entendimento do domínio, neste caso tal classe deverá ser excluida. Por exemplo, neste estudo de caso a classe candidata item de informação não foi associada a nehuma outra classe. Verificando a descrição do 
estado na qual esta classe é um argumento, notou-se que um item de informação é um dos atributos da classe candidata item bibliográfico (Ver Anexo B).

\subsubsection{Um Diagrama de Classes pode ser subdivido em vários subdiagramas. 0 número de cenas sugere o número de submodelos de análise para a representação.}

Para o caso dos diagramas ficarem muito grandes é possivel dividir um diagrama em vários subdiagramas. As figuras 5.3, 5.4 e 5.5 mostram as classes e seus relacionamentos divididos de acordo com as cenas identificadas para Diagrama de Interação das Cenas. O modelo completo pode ser obtido simplesmente pela união de todos os subdiagramas

\subsubsection{Construção do Diàgrama de Clàsses do Sistema}

Com as informações coletadas por intermédio das outras heurísticas é iniciada a construção do Diagrama de Classes do Sistema. Nesta heurística são especificadòs estereótipos para as classes do Diagrama de Classes, a fim de especificar limites e separar as classes e as associações que não são necessárias para a funcionalidade do sistema.. A figura 5.6 ilustra o diagrama de objetos completo do sistema após a aplicação de todas as heurísticas. Os estereótipos utilizados são: de ator, substituem as classes candidatas que interagem com o sistema; de fronteira, usados para classes candidatas com função de comunicação ou manipulação (protocolos); de entidade, usados para modelar objetos de negócios e controle, usados para conectar objetos de fronteira com objetos de entidade e para manusear um seqüência de operações dentro do sistema.

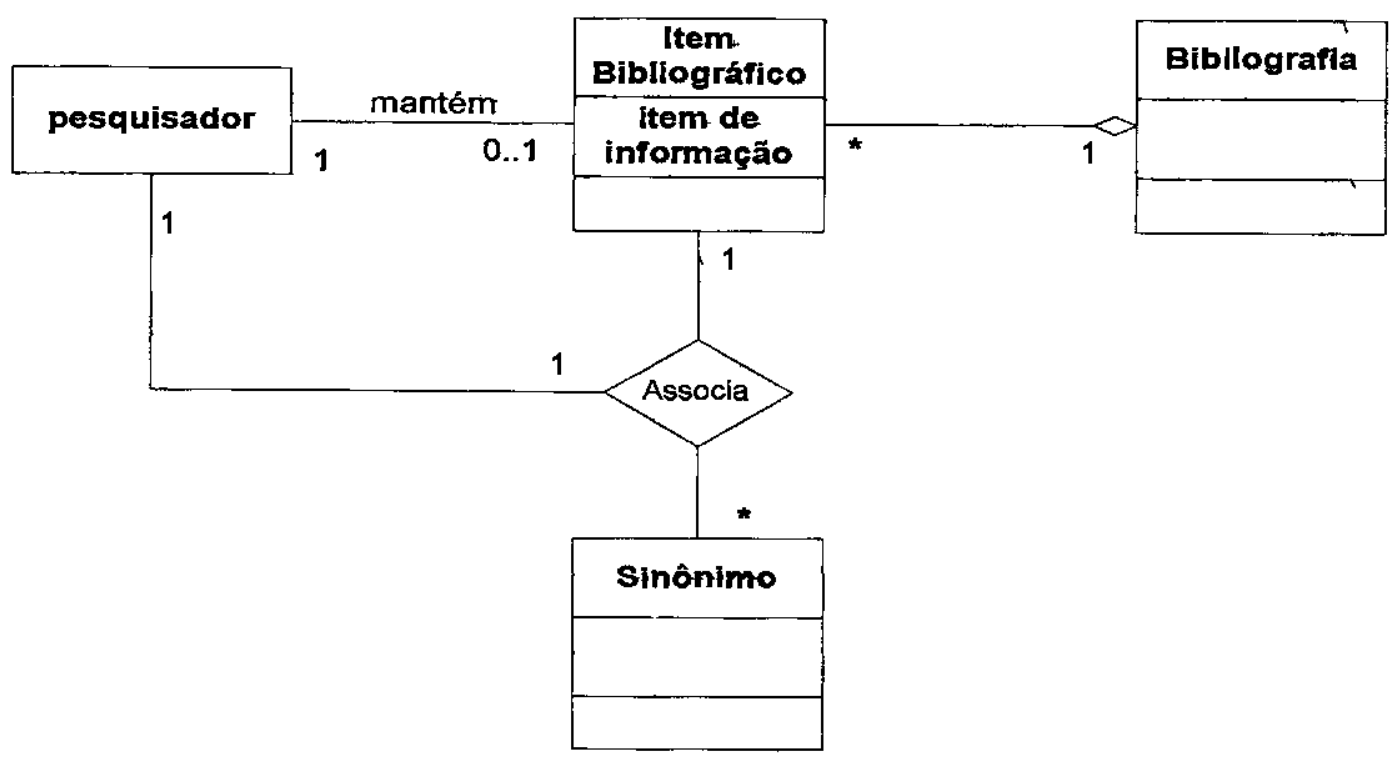

5.3 Subdiagrama de Classes para a cena "Preparação de itens bibliográficos" 
Capitulo $5 \quad-76-$

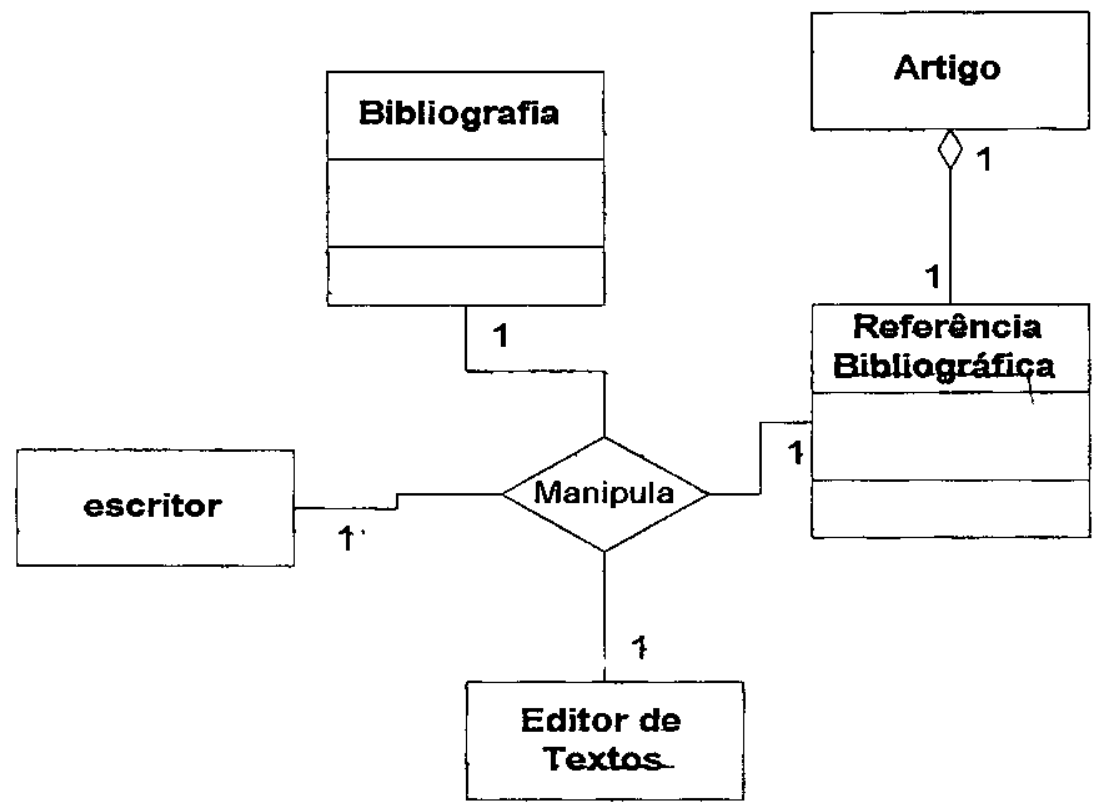

5.4 Subdiagrama de Classes para a cena "Inserção de Referência Bibliográfica no Texto"

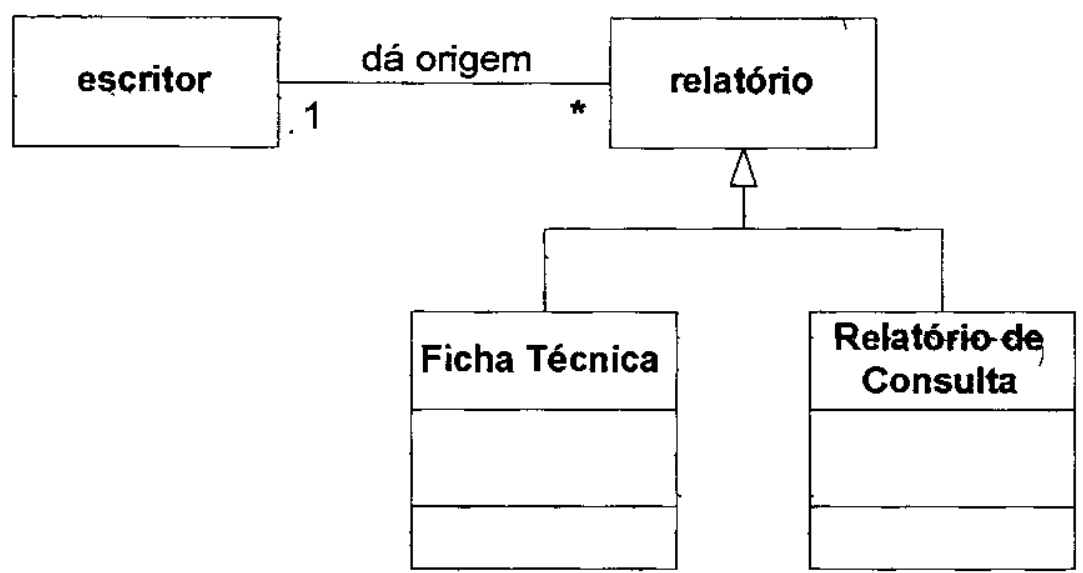

5.5 Subdiagrama de Clàsses para a cena "Consultà e Emińssão de Rèlatórīos" 


\subsubsection{Os Diagramas de Seqüência e os Diagramas de Colaboração são construidos a partir das operações identificadas no glossário do DAD.}

Um Diagrama de Seqüência mostra interações entre objetos organizadas seqüencialmente no tempo. Os Diagramas de Seqüência devem ser construidos a partir das operações identificadas nos glossários. Os objetos que participam do diagrama são identificados a partir das classes especificadas no Diagrama de Classes do Sistema construído na heurística 5.4.5. As mensagens säo obtidas nas transições do DAD da operação especificada. Os rótulos podem ser obtidos nas descriçōes dos estados e transiçōes da operação. A figura 5.7 ilustra o Diagrama de Seqüência construído para a operação Criar Item da cena de uso "Preparação de itens bibliográficos", o.DAD desta cena de uso foi ilustrado na figura DAD-1. O diagrama de seqüência deve abranger todos os estados da cena sejam eles do fluxo principal ou secundário. Neste exemplo o objeto Sinónimos que faz parte do fluxo secundário da operação Criar Item é especificado no diagrama de seqüência

Os Diagramas de Seqüência podem ser construídos a partir de operações relacionadas de uma mesma cena. A figura 5.8 ilustra a Diagrama de Seqüência construído para as operação "Gerar referência bibliográfica" e "Inserir referência bibliográfica" da cena de uso "Inserção de referências bibliográficos no texto".

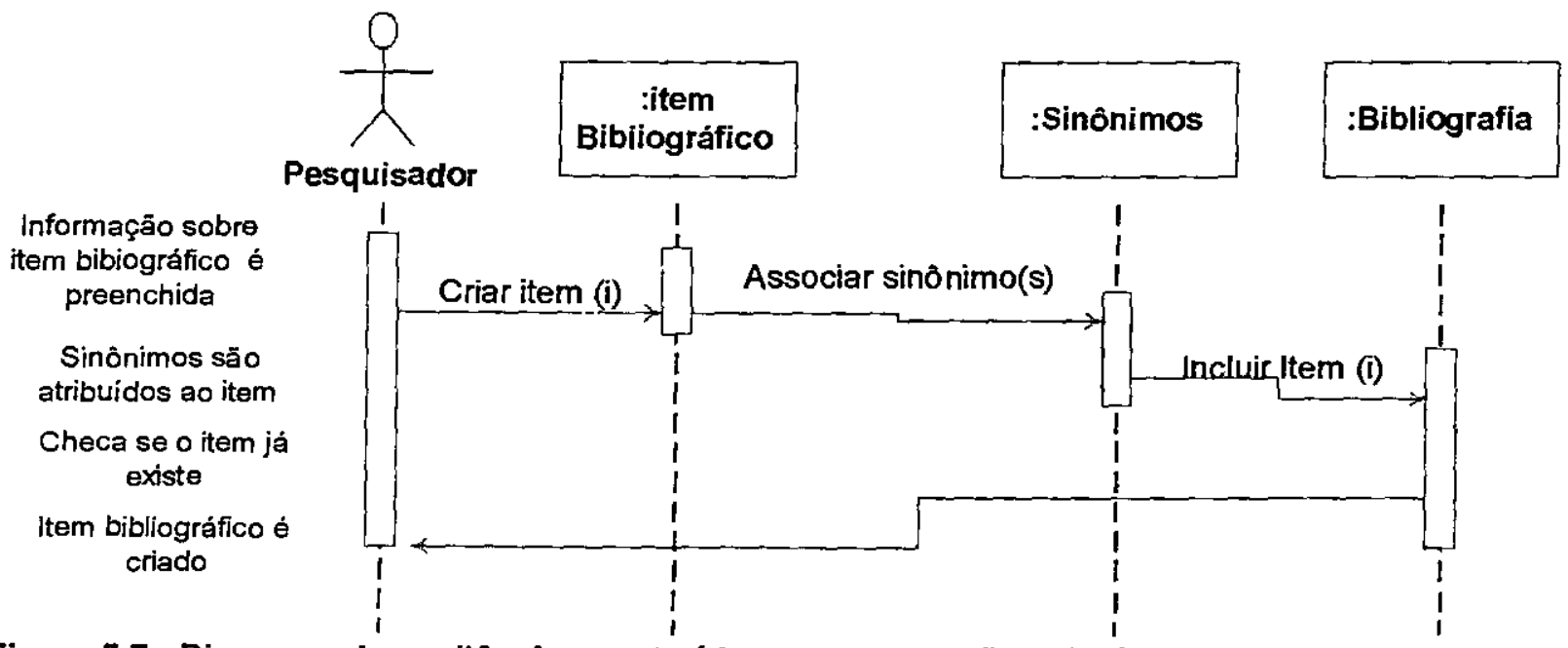

Figura 5.7 - Diagrama de seqüência construido para a operação Criar ltem da cena de uso "Preparação de itens bibliográficos"

Um Diagrama de Colaboração mostra as interaçōes de objetos organizadas entre os objetos e seus vínculos. Os diagramas de colaboração podem ser utilizados para ilustrar a execução de uma operação ou uma cena de uso do sistema. Os objetos que participam deste diagrama também são os mesmos identificados na heurística 5.4.5. As ligações devem ser obtidas a partir das transições do DAD da operação especificada. A figura 5.9 ilustra o Diagrama de Colaboração construido para a operação "Criar Item" da cena de uso "Preparação de itens bibliográficos" 


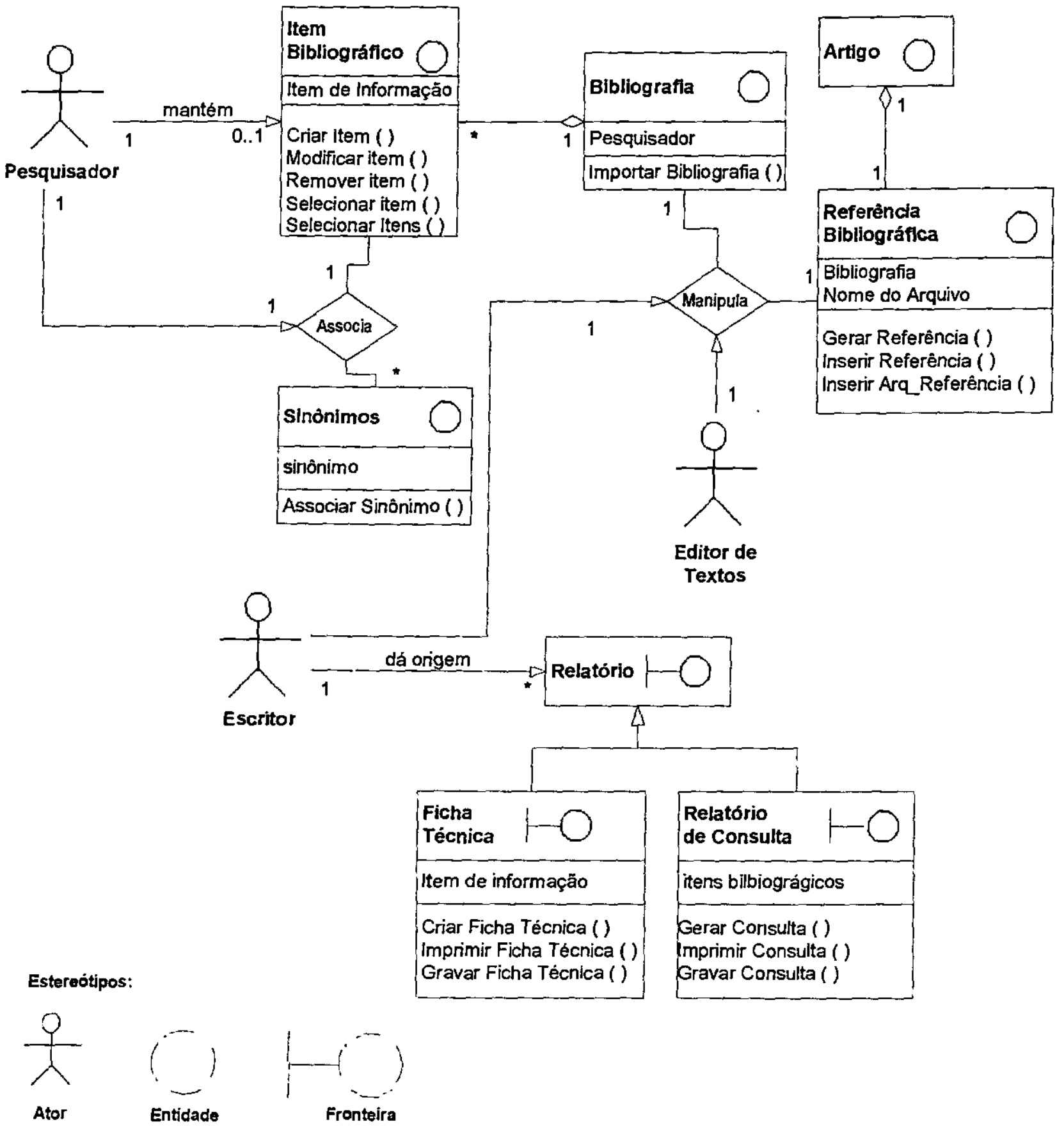

Figura 5.6 Diagrama de Classes do Sistema. 


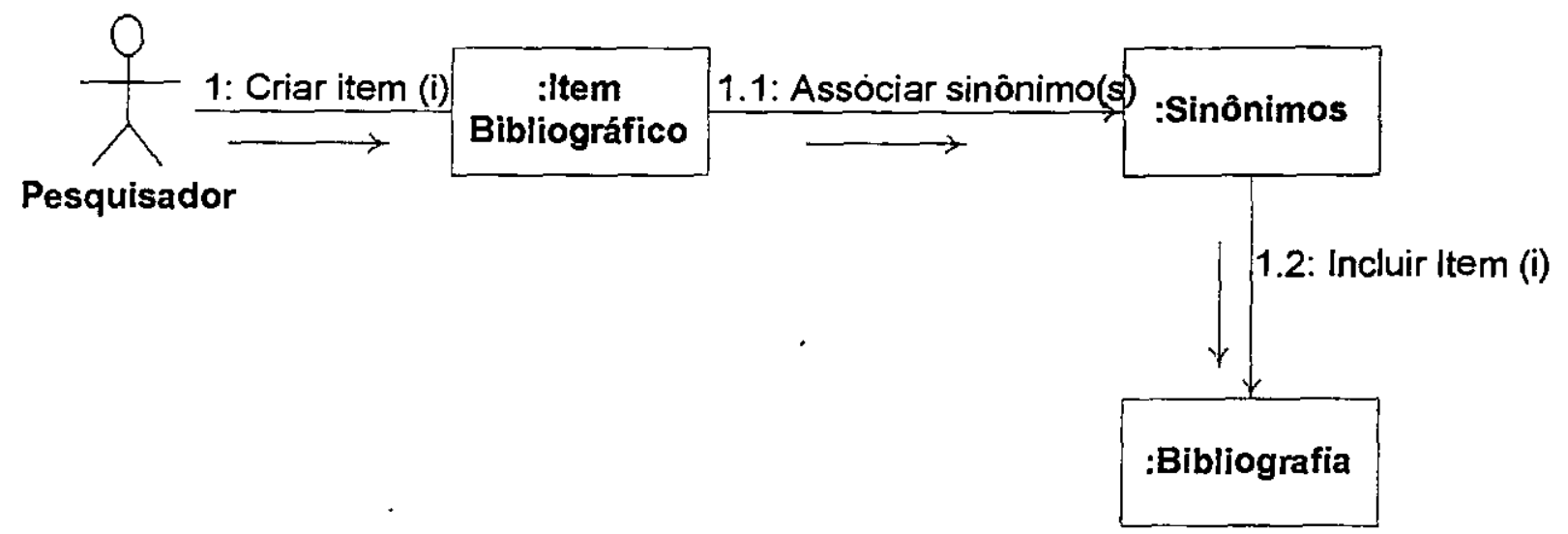

Figura 5.8 - Diagrama de sequiência construído para as operaçôes "Gerar referência bibliográfica" e "Inserir referência bibliográfica"

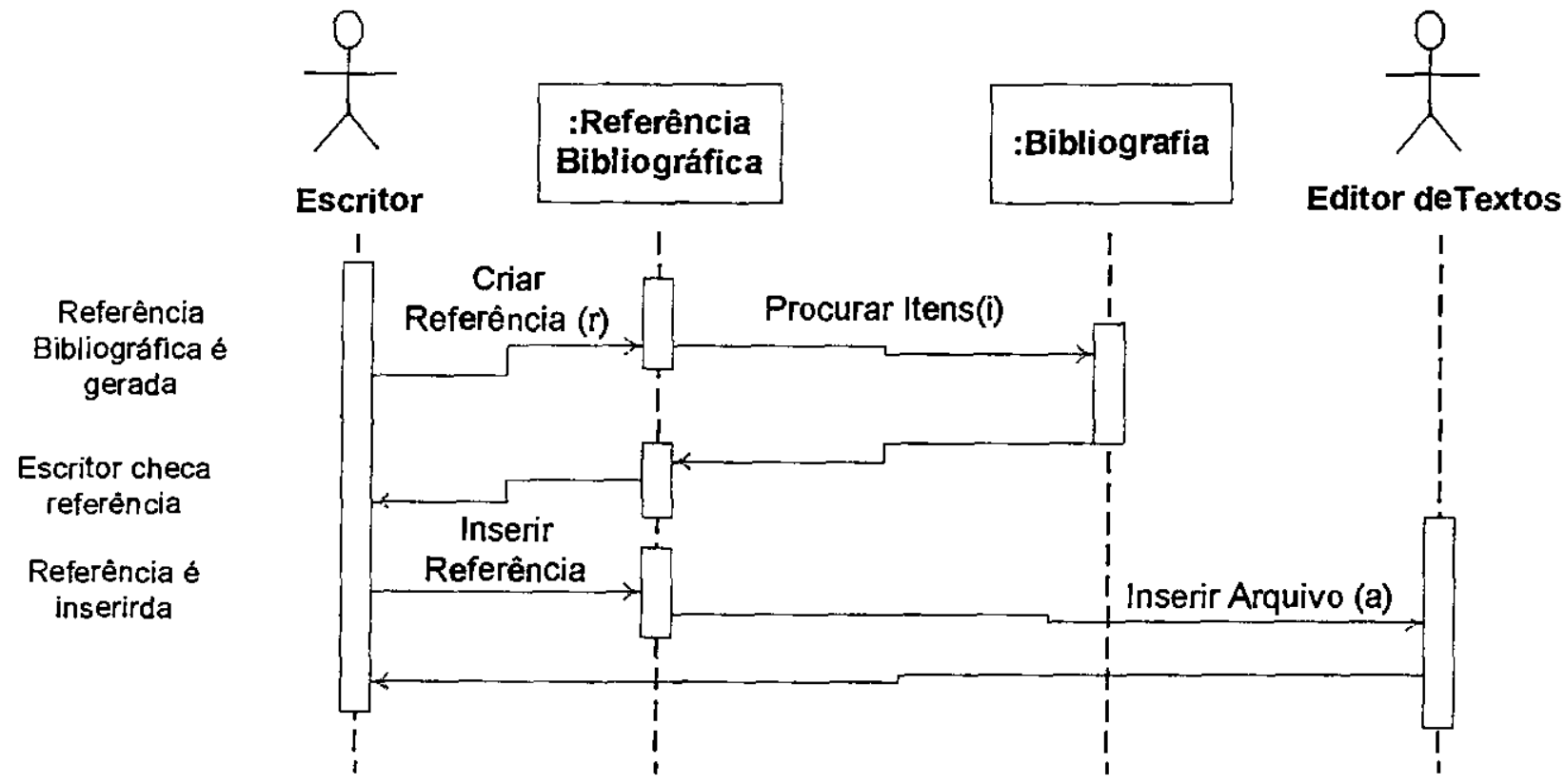

Figura 5.9 - Diagrama de colaboração construído para a operação Criar Item da cena de uso "Preparação de itens bibliográficos"

A figura 5.10 ilustra o Diagrama de Colaboração construído para as operação "Gerar referência bibliográfica" e "Inserir referência bibliográfica" da cena de uso "Inserção de referências bibliográficos no texto". 


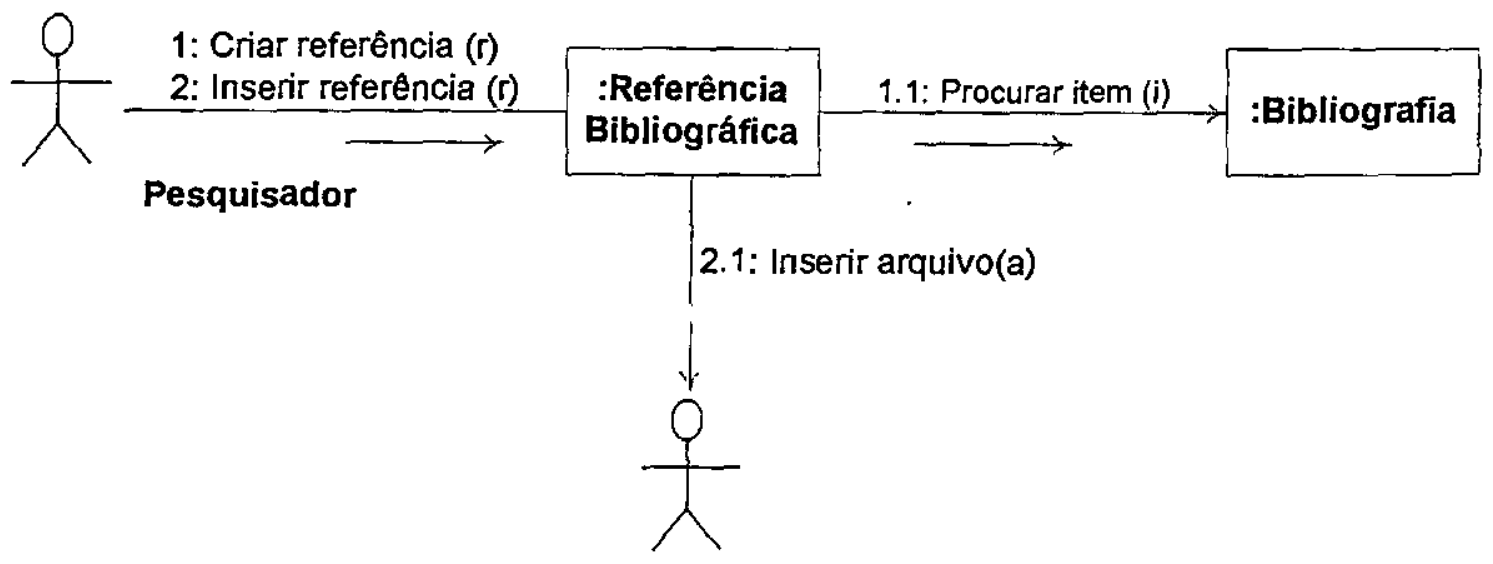

Editor deTextos

Figura 5.10 - Diagrama de colaboração construido para as operaçăo "Gerar referéncia bibllográfica" e "Inserir referência bibliográfica"

\subsection{Considerações Finais}

A aplicação do processo ERACE apresentada propicia uma melhor compreensão dos requisitos do software desejado pelo usuário, por se tratar de uma técnica que utiliza diagramas e descrições textuais organizadas em glossários, garantindo uma boa documentação do problema, de tal forma que, tanto o usuário quanto o desenvolvedor, podem trocar informaçōes e compreendê-las sob diversos pontos de vista.

A construção dos diversos glossários impõe um processo de documentação mais sistemático, procurando apresentar com maior precisão os significados e as descrições dos termos presentes no contexto da aplicação. Além disso, todos os modelos do processo (diagramas e glossários) respeitam a organização proposta pelo documento de requisitos, facilitando a verificação dos requisitos do sistema.

A criação de cenários formais (representações em LD para os DAD's), impõe uma maior formalidade na criação dos modelos, permitindo avaliar a corretitude da modificação de um determinado requisito. $E$, finalmente, a partir dos modelos criados e com aplicação das heurísticas de passagem, pode-se mais facilmente construir o Modelo de Análise do Sistema. 
Capítulo 6 - A Ferramenta ERACE 


\subsection{Considerações Iniciais}

A principal função da engenharia de requisitos é gerar especificações que descrevam de forma não ambígua, consistente e completa o comportamento do universo do domínio de um problema. Criar ferramentas que apoiem tal fase é uma forma de apoiar algumas atividades da engenharia de requisitos, o que contribui para aumentar a produtividade e a qualidade dos sistemas produzidos.

Para que uma ferramenta suporte com êxito a fase de engenharia de requisitos, ela deve considerar que as especificaçōes de requisitos são geradas a partir da análise das necessidades do sistema após consultas ao usuário e da redação de um documento de requisitos. A satisfação dos requisitos especificados pelo usuário é précondição básica para o sucesso de um software. A Erace-Tool é uma ferramenta baseada no método ERACE, que utiliza um conjunto de diagramas para retratar, a partir da visão do usuário, os caminhos possíveis na utilização do sistema. A ferramenta apóia a criação de:

- diagramas de interação das cenas;

- diagramas abstratos de detalhamento das cenas;

- glossário do domínio do problema.

\subsection{Arquitetura ERACE}

A arquitetura ERACE compõe-se de: um gerente de objetos, uma base de dados e um interface gráfica. A definição e a representação das cenas de uso e seus detalhamento são construídas a partir da interface gráfica e os componentes desses diagramas são organizados pelo gerente de objetos e armazenados na base de dados.

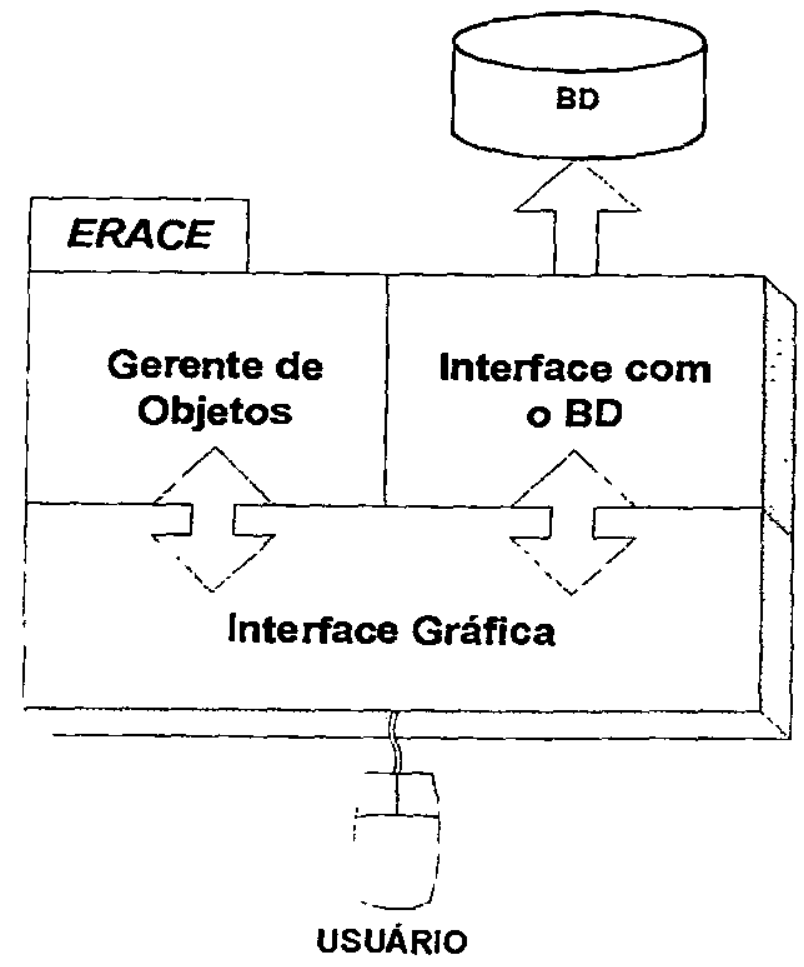

6.1 Arquitetura da ferramenta ERACE 


\subsection{Implementação}

A ERACE está implementada em Delphi, versão 3.0. A ferramenta requer o sistema operacional Windows 95 ou Windows NT 4.0, e recomenda-se que 0 equipamento seja, no mínimo, um Pentium $100 \mathrm{MHz}$, com 16 Mbytes de memória RAM. Para sua instalação completa, são necessários 1 Mbytes de espaço em disco. Em sua totalidade a ferramenta ERACE tem atualmente 2.823 linhas de código Delphi.

A ferramenta ERACE usa os aplicativos de banco de dados da linguagem Delphi. O Delphi faz interface com o Borland Database Engine [28], que têm acesso a diversas fontes de dados, incluindo Dbase, Paradox e tabelas ASCll (por meio de drivers apropriados). A ERACE faz o armazenamento de seu banco de dados em um arquivo único no formato ASCII.

A ferramenta ERACE provê uma interface gráfica, para a modelagem dos diagramas do processo ERACE. A interface gráfica da ferramenta apoia também a construção dos glossários e a validação dos Diagramas Abstratos Detalhados nela construídos. A fase de validação da ferramenta utiliza um domínio próprio construído no sistema DRACO-PUC [22], [27], que é um sistema transformacional que propõe o desenvolvimento de software por intermédio da criação e da reutilização de domínios, num alto nivel de abstração.

\subsection{Editor do Diagrama de Interação das Cenas (DIC)}

A ferramenta ERACE apóia o processo ERACE na fase de construção de um Diagrama de Interação das Cenas disponibilizando as seguintes funções: identificação dos atores; identificação de cenas de uso; identificação de relacionamentos entre atores e cenas de uso e identificação das dependências entre as cenas de uso. $\mathrm{Na}$ figura 6.2 é ilustrado um DIC construído com o apoio da ferramenta ERACE para o estudo de caso apresentado no capitulo cinco.

A ferramenta ERACE, durante a construção do DIC, apoia a coleta de informação sobre o diagrama. Essas informações são inseridas em um glossário que armazena a descrição de todos os componentes editados no DIC. A figura 6.3 ilustra o glossário construído a partir da figura 6.3 referente ao estudo de caso.

\subsection{Editor do Diagrama Abstrato Detalhado (DAD)}

A ferramenta ERACE permite especificar detalhadamente o comportamento de cada ator dentro do sistema. A partir de cada cena do DIC criado na seção anterior, podem ser criados DAD's para cada ator que participa de um determinada cena. A edição de um DAD só possivel se existir um DIC previamente editado. Na figura 6.4 é ilustrado um DAD construido na ferramenta ERACE para a cena "Preparação de itens bibliográficos" apresentada no capitulo cinco.

Em cenas com a colaboração de mais de um ator, a ferramenta ERACE permite, a criação de mais de um DAD para a mesma cena (conforme o número de atores participante). No DAD de um ator participante pelo menos um item do diagrama (o estado principal) deve ter o mesmo nome de um dos itens do DAD do ator principal. 


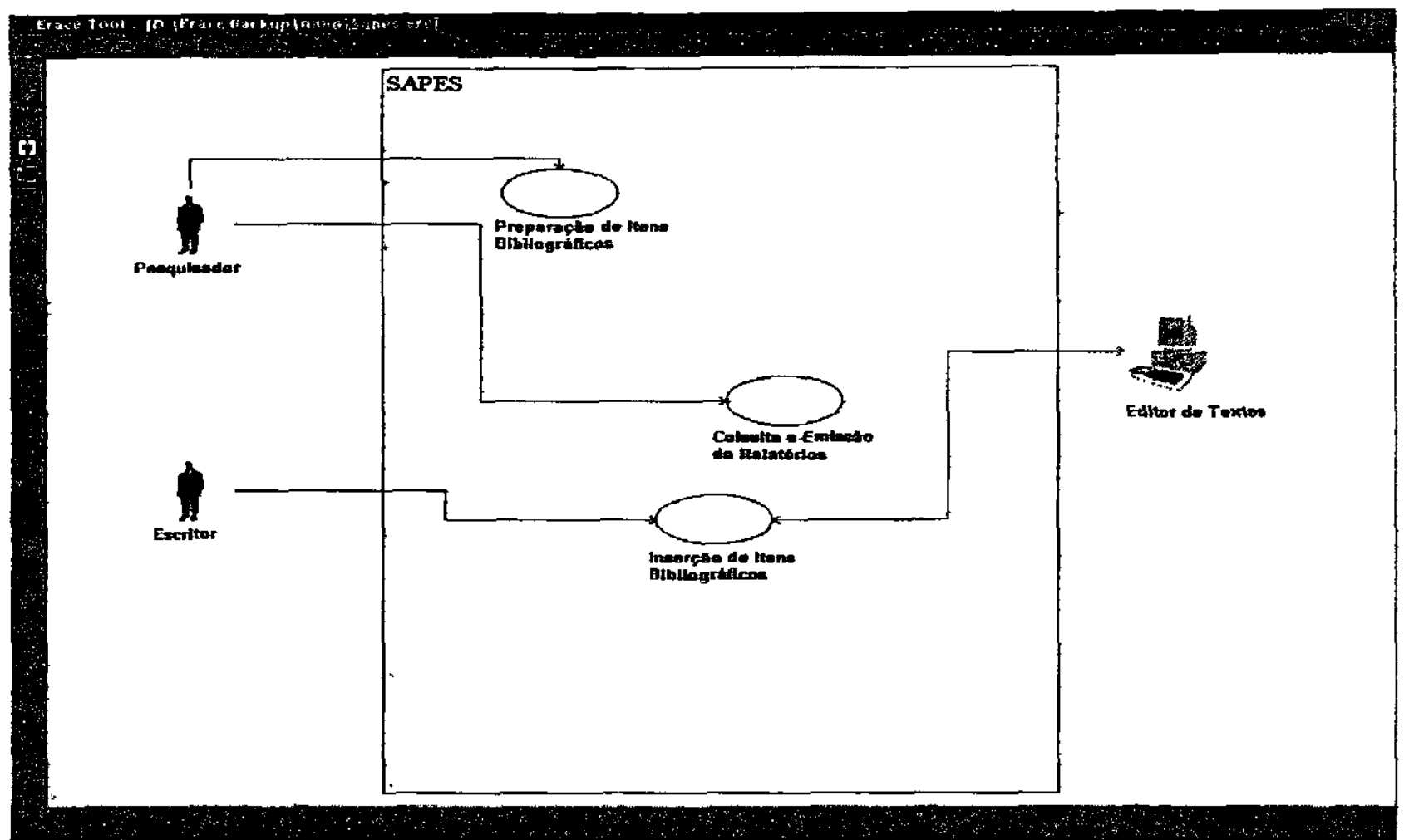

\subsection{Tela de ediçăo de um DIC}

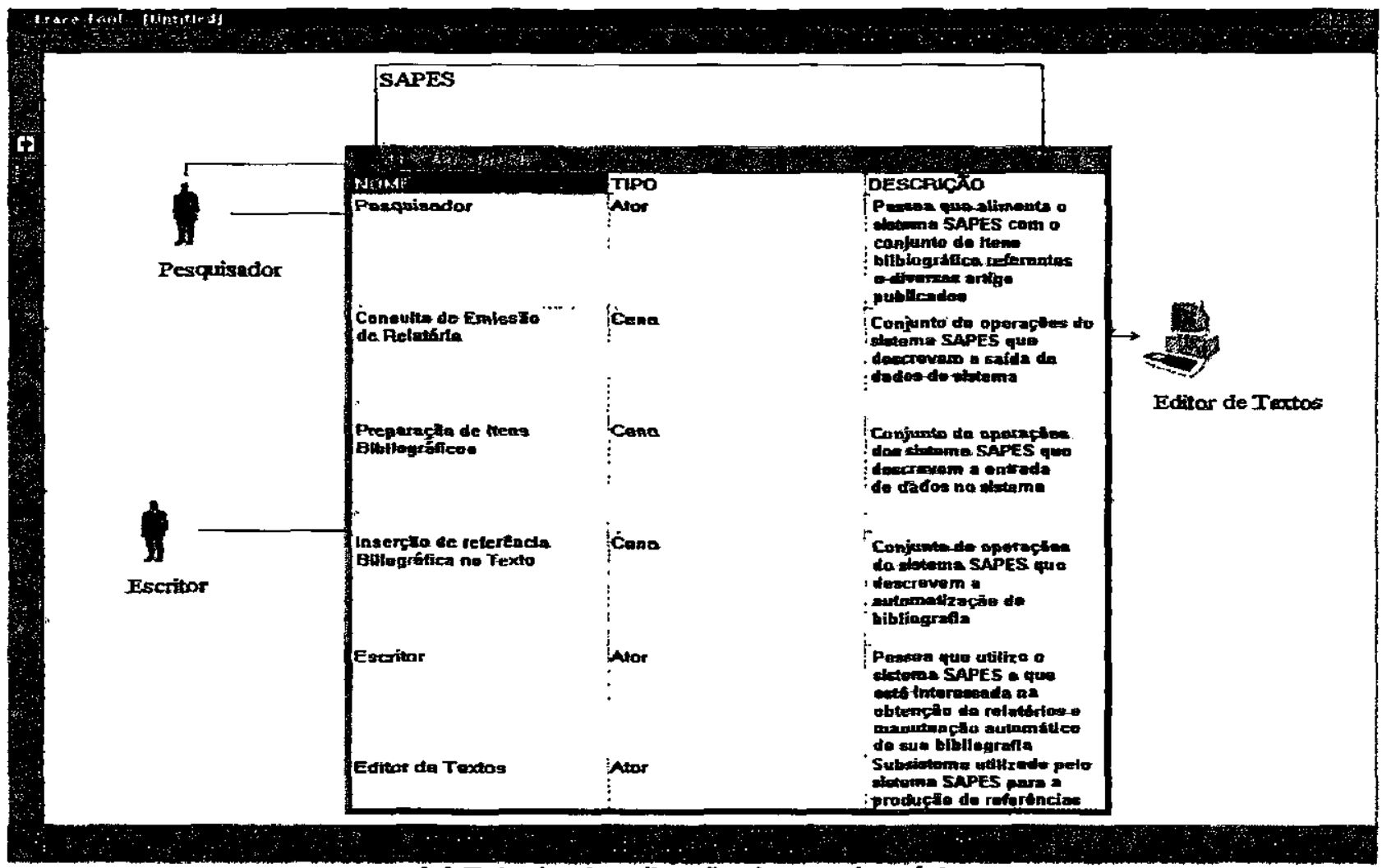

\subsection{Tela de visualização de um glossário}




\subsection{Validação dos Diagramas abstratos}

$\mathrm{Na}$ Erace tool os diagramas abstratos de detalhamento, após construídos, podem ser validados por um parser, um subsistema responsável pela etapa de análise. Cada parser de domínio é responsável pela análise de programas escritos em sua linguagem. A ferramenta Erace produz uma descrição textual do detalhamento, que é um pequeno programa escrito na linguagem gerada a partir da gramática de construção dos DAD's, a Linguagem de Detalhamento (LD).Este programa é validado por um parser de domínio Erace gerado na máquina DRACO-PUC [22].

\subsubsection{Máquina DRACO PUC}

A Máquina DRACO-PUC [22], [27] é um sistema de software que tem como objetivo principal implementar o paradigma Draco [25]. O paradigma está baseado na reutilização de componentes, onde estes estão agrupados em domínios, os quais oferecem uma linguagem própria como interface. A máquina permite validar as idéias do paradigma Draco, suportando não somennte a construção de domínios, mas também as principais etapas do processo de desenvolvimento de software, ao longo do seu ciclo de vida.

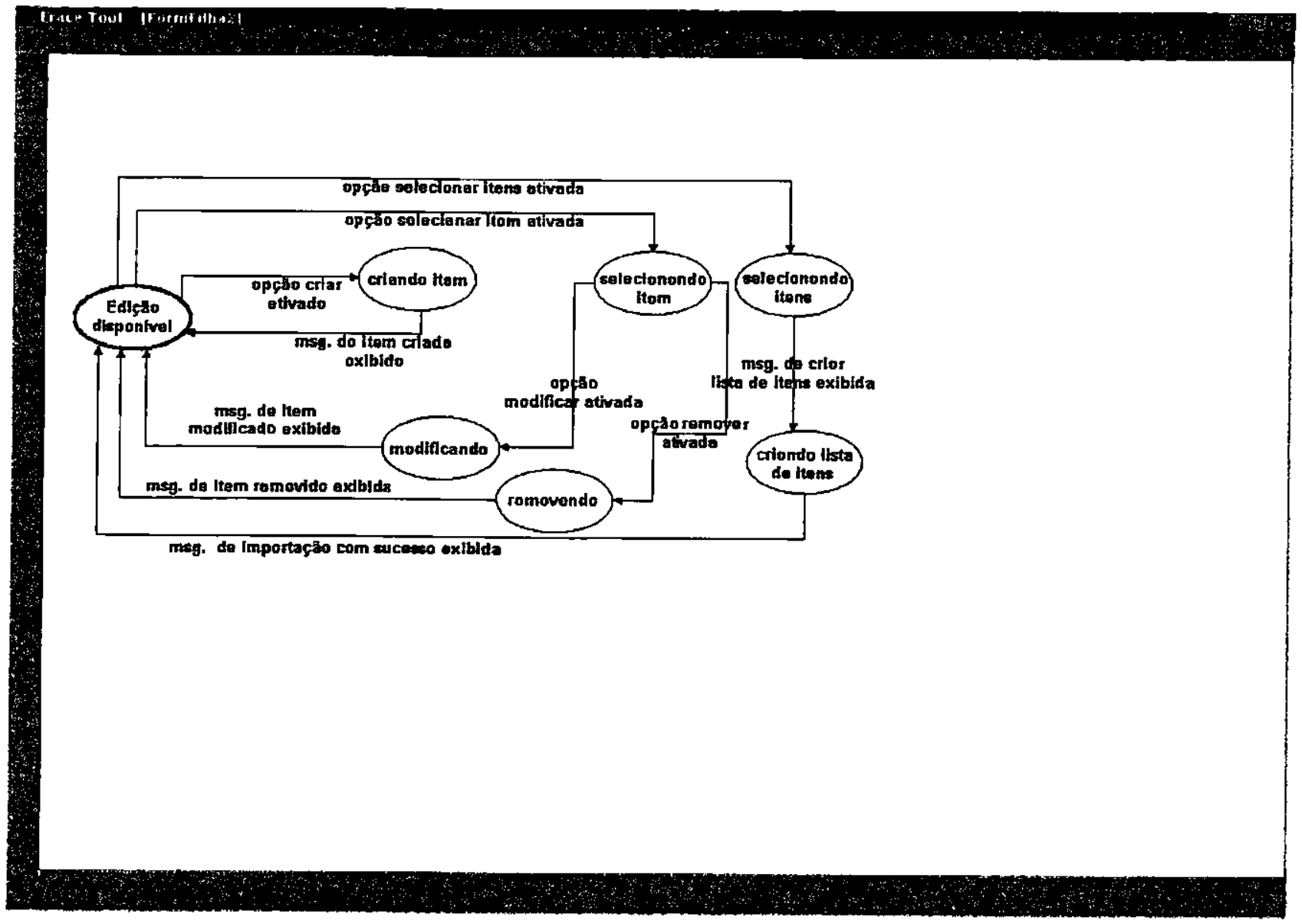


O ambiente DRACO é um sistema transformacional orientado a domínios, na qual as especificações de software em linguagens de alto nivel podem ser mapeadas automaticamente para linguagens executáveis. Um domínio para o Draco é constituído:

- Uma linguagem, cuja sintaxe é definida para permitir a escrita de programas de domínio. Para analisar os programas constroi-se um parser a partir da definição da gramática da linguagem, a qual tem associada açōes semânticas para a geração de uma árvore de sintaxe abstrata (AST) das aplicaçōes escritas no domínio. Essa AST particular è chamada Draco AST (DAST). Para que um programa possa ser manipulado pela máquina Draco é necessário que ele esteja representado na forma interna. Para auxiliar na criação do parser existe um subsistema gerador de parser chamado pargem.

- bibliotecas de transformações. As transformações que mapeiam estruturas de uma linguagem em estruturas dessa mesma linguagem são chamadas horizontais (intra-domínios), ao passo que as transformações que mapeiem estruturas de uma linguagem em estruturas de uma outra linguagem são chamadas verticais (inter-domínios). Cada regra de transformaçăo definida possui basicamente duas partes: o Left hand side (Lhs), que descreve o padrão a ser encontrado nas descrições, e o Right hand side (Rhs), que descreve o padrão de reescrita que substituirá a parte da descrição instanciada a partir do Lhs;

- Pretty Printer, que é um unparser responsável por mapear repesentaçб̄es em sintaxe abstrata para a sintaxe concreta da linguagem, ou seja, que exibe a DAST da aplicação na linguagem de domínio.

A máquina Draco, possibilita a produção automática de um programa executável a partir da especificação na linguagem do domínio da aplicação. Dada uma aplicação, - processo para sua transformação é iniciado pela verificação de suas sintaxe pelo parser domínio. A ferramenta ERACE utiliza as aplicações de análise do ambiente Draco, para validar os programas produzidos com base nos diagramas. As aplicaçöes de transformação não são usadas na ferramenta ERACE, no entanto abrem uma gama muito grande de opções de integração desta proposta com outros trabalhos, o qual foi o aspecto mais relevante para a integração da ferramenta ERACE com a máquina DRACO-PUC. As propostas de trabalhos futuros serão discutidas mais detalhadamente no capitulo sete.

\subsubsection{Etapas da validação}

Na ferramenta ERACE a fase de validação de uma DAD é formada pelas seguintes etapas:

\section{- Geração do programa em LD para o DAD editado}

Nesta etapa a ferramenta gera um programa em LD gerado com base na gramática de construção apresentada na figura 4.4. O algoritmo que gera o programa em LD percorre a base de dados do diagrama em edição criando em memória sua representação formal. O programa gerado é apresentado para o usuário para que o 
mesmo possa checar a representação formal da cena de uso especificada, na figura 6.5 é ilustrada a tela de visualização da cena de uso "Inserção de itens bibliográficos". Assim que o usuário pressiona o botão direito do mouse na opção $\langle\mathrm{OK}\rangle$, o programa é gravado em um arquivo que recebe o nome da cena detalhada e a extensão .dsc; este será o arquivo submetido ao parser de domínio ERACE.

\section{- Validação do programa pelo parser de domínio ERACE}

Nesta etapa o programa gerado a partir da cena em edição é submetido à análise do parser ERACE gerado na máquina DRACO-PUC. A resposta da análise é apresentada ao usuário por meio de uma mensagem que reporta o êxito ou o erro da operação (figura 6.6 ).

A etapa de validaçãa executada com apoio da máquina DRACO permite verificar entre outras opções que:

- Todos os estados de um DAD válido possuem pelo menos uma transição para os outros estados. Significa que um estado de um sistema não poderá mudar sem a acorrência de algum evento.

- Os DAD's, após validados, possuem apenas um estado inicial e um estado final e eles são os mesmos. Garante a completitude do DAD, o que reduz a complexidade das cenas especificadas.

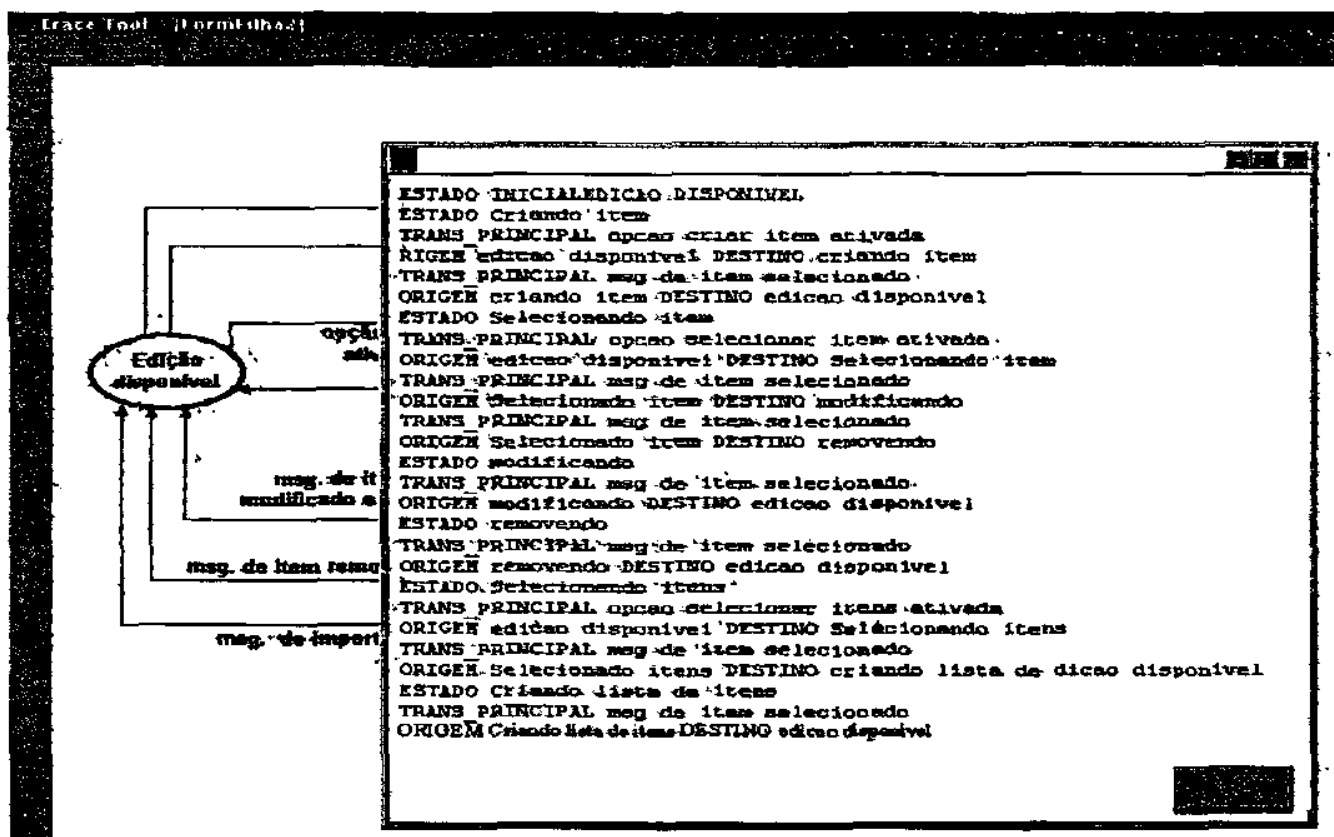

6.5 Tela de vlsualização de programa em LD 


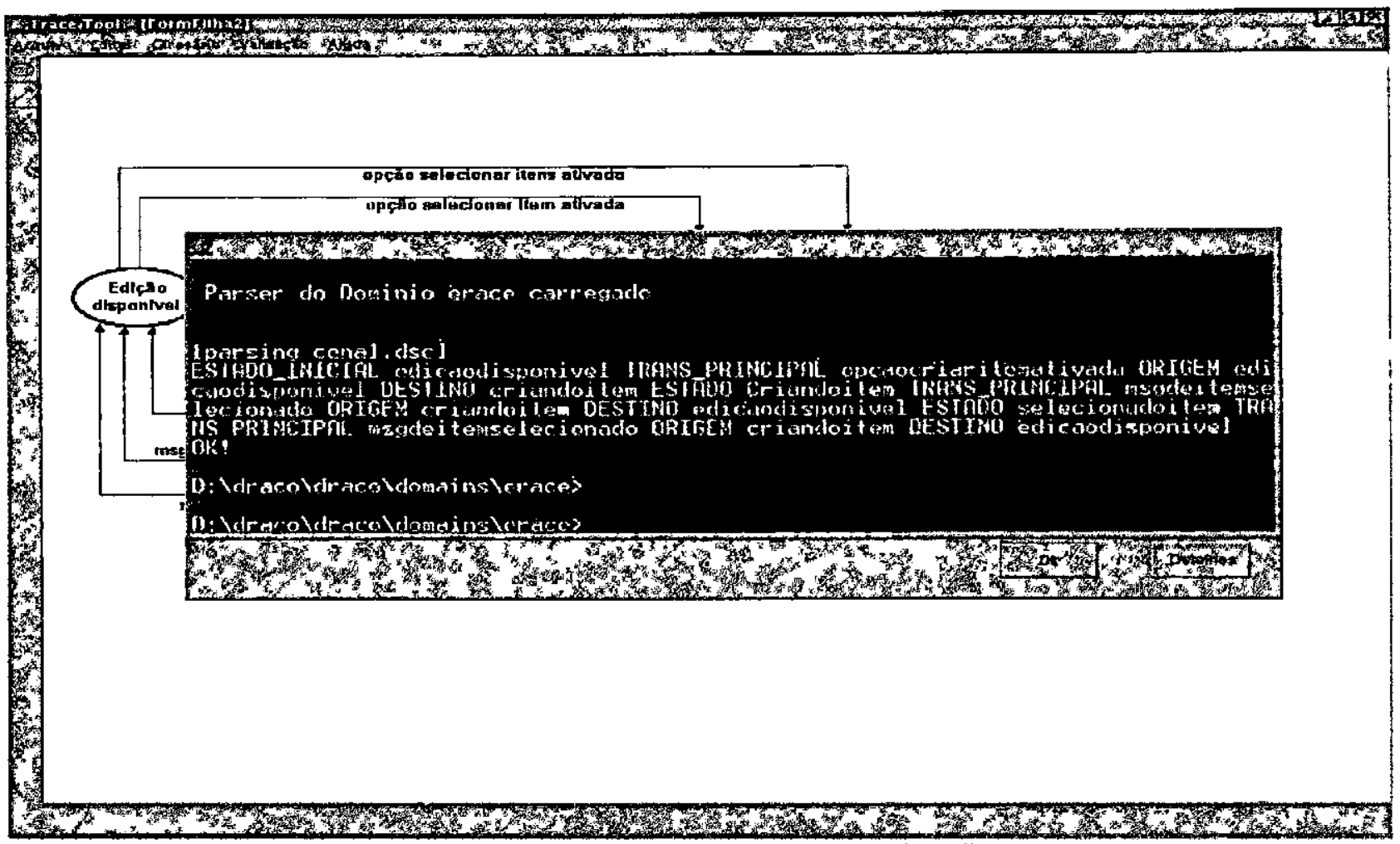

\subsection{Tela de resposta da operaçāo de validação}

Quando uma descrição em LD, ou seja, um programa escrito na linguagem de domínio ERACE gerada no DRACO é analisada, o parser gera automaticamente a DAST correspondente. Esta documentação mostra a árvore sintática do DAD em questão, e pode ser muito útil na fase de teste de um sistema, servindo como uma verificação futura dos documentos de requisitos.

(*DOMAIN* draco root (_SYSTEM_S1 __MODULE_ cena1.dsc __OBJECT_O 01 (*DOMAIN* erace root (dac1 (estado_inicial1 (descricao_estado_inicial1 (nome1 ledicaodisponivel| )))(Ist1_transicao_p (transicao_p1 (nome $\overline{1}$ |opcaocriaritemativadal )(nome1 ledicaodisponivel| )(nome1 |criandoitem| )))(Ist1_evolucao_cena (evolucao_cena1 (Ist1_rule1 (rule11 (estado1 (descricao_estado1 (nome1 |Criandoitem| )))(transicao_p1 (nome1 Imsgdeitemselecionadol )(nome1 [criandoitem] )(nome1 ledicaodisponivel| ))_sto_transicao_s )(rule11 (estado1 (descricao_estado1 (nome1 |selecionadoitem| )))(transicao_p1 (nome1 |msgdeitemselecionadol )(nome1 (criandoitem| )(nome1 (edicaodisponivel| ))_(st0_transicao_s ))))))) )))

6.7 Exemplo de um fragmento da DAST gerada pelo DRACO para a cena "Preparação de itens bibliográficos"

\subsection{Considerações Finais}

A ERACE oferece um ambiente gráfico e simples para construção do DIC e DAD's de um sistema na fase de modelagem de seus requisitos. Todos os glossários criados durante a modelagem podem ser obtidos na forma de relatórios, o que fornece 
uma documentação para outras fases do sistema modelado. Além disso, a ERACE respeita a organização de todos os modelos do processo (diagramas e glossários), facilitando a verificação dos requisitos do sistema.

A validação dos cenários formais impõe uma maior formalidade na criação dos modelos, permitindo avaliar a corretitude e completitude de possíveis modificações nos requisitos. A validação ainda possibilita a produção de cenários formais completos e fornece informações úteis em outras fases do ciclo de vida de desenvolvimento de software. 
Capítulo 7 - Conclusão 


\subsection{Considerações Iniciais}

Este trabalho teve como objetivos estudar as propostas de análise de requisitos encontradas na literatura pesquisada, apresentar uma proposta de um método para a fase de engenharia de requisitos e a construção de uma ferramenta que apoia 0 método proposto. Foram estudadas diversas técnicas e métodos para análise de requisitos, tanto aqueles dirigidos ao processo de desenvolvimento tradicional, como aqueles dirigidos ao desenvolvimento orientado a objetos. Após o estudo dos métodos orientados a objetos, técnicas de análise de requisitos e ciclo de vida onientado a objetos, iniciou-se o desenvolvimento de uma proposta de um método que atenda os pontos críticos das fases de engenharia de requisitos dos principais métodos que utilizam a técnica de construção de cenários. Este processo, conforme ilustrado na Figura 3.1, é composto de uma fase de Especificação de Interações e uma fase de Modelagem dos Cenários. Foram propostas ainda uma série de heurísticas de passagem para a fase de análise adaptadas à notação da UML. Por fim, foi construída uma ferramenta de interface gráfica que apoia a construção e validação dos modelos propostos pelo método.

As técnicas e métodos estudados utilizam cenários como uma ferramenta para a construção do modelo de requisitos. Todas as abordagens revisadas são normalmente compostas por uma descrição diagramática e textual. Esse tipo de abordagem direcionou o esforço para o desenvolvimento de uma proposta de um método que incluisse a construção de diagramas e glossários para representar informações dos requisitos de sistema. A notação dos cenários proposta no método OOSE foi aproveitada em sua maior parte, acrescentando-se algumas notações novas e criandose uma parte descritiva que descreve os cenários. Assim, o método ERACE é composto por um diagrama de interação construído a partir do documento de requisitos, máquinas de estados construídas a partir do diagrama de interação e um conjunto de glossários que documenta os modelos criados pelo método.

Após a construção dos modelos propostos pelo ERACE inicia-se a aplicação de um conjunto de heurísticas de passagem para a construção dos modelos de análise, mais especificamente os propostos pelo notação da UML. A aplicação das heuristicas tem como objetivo identificar os prováveis objetos do sistema e descrever seus comportamentos. Essa atividade permite que durante a análise seja identificada a estrutura do modelo, em particular os elementos que nele existem (tais como classes e tipos), sua estrutura interna e seus relacionamentos.

A proposta de passagem do método ERACE para os modelos de análise da UML faz a ligação entre os vários modelos construídos, mantendo a rastreabilidade das informações entre os glossánios, diagramas e o documento de requisitos. Durante a fase de passagem os principais diagramas da notação da UML são desenvolvidos de forma integrada e compativel. 


\subsection{Contribuiçōes deste Trabalho}

Capítulo 7 - $93-$

Como visto na seção anterior, a proposta do método ERACE para elicitação e modelagem de requisitos é composta por várias etapas combinadas de forma integrada entre si. O diagrama de interação das cenas baseado na técnica de casos de uso do método OOSE foi ligeiramente modificado, se comparados com a proposta original, de forma a permitir melhorias nas semânticas dos atores, das cenas de uso e seus relacionamentos, aplicação de uma visão única da cena para cada ator e Identificação de contextos para as cenas de uso. A busca da integração e compatibilidade entre os diagramas propostos pelo método e a notação da UML propiciou inúmeras vantagens durante a construção do madelo de análise. Algumas dessas vantagens são: redução da atividade de construção do diagrama de classes, melhor apoio para a construção dos diagramas de classes do sistema, do diagrama de estados, diagrama de seqüência e diagrama de colaboração. A proposta do método de elicitação de requisitos foi desenvolvida na expectativa de atender à fase de engenharia de requisitos de uma forma bem definida e, diante dos resultados obtidos até o momento, espera-se que traga reais benefícios no processo de desenvolvimento de software orientado a objetos.

A construção de glossários para as vários modelos construídos pelo ERACE é uma boa solução para evitar alguns problemas típicos em descrições de requisitos que utilizem linguagem natural. Nos glossários são detalhados termos usados na descrição dos requisitos. Com a formação do léxico do domínio, todo o vocabulário usado nas especificações e detalhamentos das cenas de uso é sintetizado e unificado, facilitando o entendimento do elementos do domínio.

A utilização de máquinas de estados para o detalhamento das cenas de uso propiciou uma maior formalização na construção do modelo de requisitos. Os conceitos relativos a cenas de uso e operaçōes ajudam a reduzir a complexidade na representação dos requisitos e organizam as várias atividades do sistema em seções distintas. A abordagem utilizada nos diagramas de detalhamento gera uma documentação sobre a interface do sistema, que pode ser utilizada de forma muito útil nas fases de projeto e implementação de um sistema.

A construção da ferramenta proporcionou não somente uma interface para a construção dos modelos propostos no método, mas um ambiente computacional para a validação e integração destes vários modelos. Além disso, a ferramenta utiliza em sua atividade de validação o sistema transformacional DRACO-PUC, que abriu uma gama de possibilidades quanto à tradução entre o domínio construido para a ferramenta $e$ outros linguagens de domínio. A integração com o DRACO-PUC ainda garantiu uma série de informações adicionais que aumentam a formalidade da descrição das cenas de uso, dando origem a documentos que podem ser utilizados na fase de testes do sistema.

Com o método proposto consegue-se uma boa integração entre os modelos da fase de engenharia de requisitos e os modelos da fase de análise orientada a objetos propostos pela UML. Assim, o método ERACE pode ser utilizado como processo para a obtenção do modelo de análise da UML. O método também possibilita uma 
Capítulo 7 - $94-$

compreensão mais rápida dos requisitos e da funcionalidade do sistema.

\subsection{Futuras Pesquisas}

A partir deste trabalho será possivel realizar pesquisas que avaliam o uso das informaçőes coletadas durante a aplicação do método ERACE em outras fases do ciclo de vida do sistema. Como a UML não propõe um método padrão para emprego de sua notação, vários métodos conhecidos poderiam ser aplicados e um estudo comparativo poderia ser realizado com base em um estudo de caso. Alguns métodos orientados a objetos que podem ser avaliados para a elaboração dessa comparação são: Booch [26], OBA [10], FUSION [15], OMT [11] e OOSE [6].

Um trabalho interessante que poderia ser desenvolvido é a possibilidade da simulação dos diagramas abstratos detalhados no ambiente STATSIM desenvolvido pelo grupo de engenharia de software do ICMSC-USP São Carlos. Este trabalho poderia ser realizado utilizando a máquina DRACO-PUC e o aproveitando a domínio ERACE construído para a mesma. Assim poderia ser construído um domínio STASIM (a qual possui uma gramática utilizada em seu editor gráfico) e serem realizadas traduçães entre estes dominios para que um diagrama abstrato de detalhado pudesse ser visualizado no ambiente STASIM.

Finalmente, outro estudo que pode ser desenvolvido é a extensão da ferramenta ERACE afim de incorporar a criação de modelos de análise. A dificuldade para a realização desse tipo de trabalho será a adaptaçäo das heuristicas de passagem para a ferramenta, pois tal tarefa não poderia se dar de maneira automática, mas sim acomparthadia passo a passo pelo projetista. 


\section{Bibliografia}

[1] VERMULAPALLI, C. A use case FAQ (Frequently Asked Questions). Contributions Proposed To The First Workshop On Use Cases, Austin, Texas, 15 de Outubro de 1995, http:// www. unantes. univ.nantes.fr/usecase/RootEXTENSION.html, [Acesso em 4/3/1996]

[2] BERARD, V. E. Be careful with "use cases". The Objecty Agency, Inc, http:Ilwww.TOA.com/pub/html/use_case.html, [Acesso em 28/4/1996].

[3] LEITE, C. J. Engenharia de requisitos: notas de aula. Particular do Autor, Janeiro, 1994.

[4] NEIGHBORS, M. J. An assessment reuse technology after ten years. In: INTERNATIONAL WORKSHOP ON SOFTWARE REUSABILITY, 3., IEEE Computer Society Press, 1994 . Proceedings. p. 6-13,

[5] KAUFMAN, D. L. Scenario selection and implementation techniques for scenario-based rapid prototyping. SERC-TR-19-F, Computer and Information Sciences Department, University of Florida, 1988.

[6] JACOBSON, I., et al. Object-oriented software engeneering. A Use Case Driven Approach", Addison-Wesley, 1992.

[7] RUBIN, S. K. ; Goldberg, A. Object behavior analysis. Communications of the ACM, 1992. V. 35, n.9, p. $48-62$

[8] HOLBROOK, $\mathrm{H}$. A scenario-based methodology for conducting requirements elicitation. Software Engeneering Notes, 1990. v.15, n.1, p.95-104

[9] MALHOTRA, A.; CARROL, J.M.; THOMAS, J.C.; MILLER, L.A. Cognitive processes in design. International Journal of Man-Machine Studies, 1987. n. 12, p. $119-140$

[10] HSIA, P.; SAMUEL, J.; GAO, J,; KUNG, D. Formal approach to scenario analysis. IEEE Software, 1994. p.33-41

[11] RUMBAUGH, J. Object-oriented modeling design. New Jersey: Prentice-Hall, Englewood Cliffs, 1991.

[12] REGNELL, B.; KLIMBER, K; WESSLÉN, A. Improving the use case driven approach to requirements engeneering. In: INTERNATIONAL SYMPOSIUM ON REQUIREMENTS ENGINEERING, 2., IEEE, Março, 1995. p.40-47

[13] ARMOUR, F.; BOYD, L.; SOOD M. Use case modeling concepts for large business system development. First Workshop On Use Cases, Austin, Texas, outubro, 1995, http://www.unantes. univ.nantes.fr/usecase/RootEXTENSION.html, [Acesso em 4/3/1996] 
[14] JENKINS, M.; NAUMANN, J.; WETHERBE, J. Empirical invetigation of systems development practices and results. Information and Management, 1994. v.7

[15] COLEMAN, D., et al. Object oriented development: the fusion method. U.S.A., Prentice Hall, 1994.

[16] JACKSON, M. Problems and requirements: In: INTERNATIONAL SYMPOSIUM ON REQUIREMENTS ENGINEERING, 2., IEEE, Março, 1995. p.40-47

[17] RIBEIRO, L. A. Semântica de uma ferramenta para o SADT. Dissertação de Mestrado, Instituto de Informática - UFRGS, Outubro, 1991.

[18] FORTES, R.P.M. Uma ferramenta de apoio à utilização de Statecharts para a especificação do comportamento de sistemas de tempo-real complexos. Dissertação de Mestrado, Instituto de Ciências Matemáticas de São Carlos - USP, Abril, 1991.

[19] HAREL, D. STATECHARTS: a visual formalism to complex systems. Science of Computer Programing, 1987. n.8, p.231-274

[20] RODRIGUES, S. Introdução a Gramática e Linguagens. Notas do ICMSC, Série Computação, número 10.

[21] RATIONAL SOFTWARE CORPORATION, Notation Guide Version 1.0 http://www.rational.com/UML, [Acesso em 12/2/1998]

[22] PRADO A. F. Estratégia de Re-Engenharia Orientada a Domínios. Tese de Doutorado, Pontíficia Universidade Católica do Rio de Janeiro, 1992

[23] TURINE, M.;MASIERO P.C. Especificação de Requisitos: Uma introdução. Relatório técnico do ICMSC, Série Computação, Março,1996.

[24] ERIKSSON, H.;MAGNUS, P. UML Toolkit, Ed. Wiley Computer Publishing, 1998

[25] NEIGHBORS, J. Software Constructing Using Components. Tese de Doutorado, UCLA Irvine, 1980

[26] BOOCH, G. Object Oriented Analysis and Design with Aplications, Second Edition, the Benjamin/Cummings Publishing Company, Inc, Santa Clara, 1994

[27] LEITE, J. C. S. P.; PRADO, A F., SAN'TANA, M.; FREITAS F. O Uso do Paradigma Transformacional no Porte de Programas Cobol. IX Simpósio Brasileiro de Engenharia de Software -SBES, Recife, 1995

[28] CANTÚ M. Dominando o Delphi 2.0, Ed. Makron Books, 1997

[29] COLEMAN, D.; MALAN, R.; LETSINGER, R. Object Oriented at Work, Prentice Hall, 1996 
[30] PRADO A. F. Desenvolvimento de Software Orientado a Objetos: Notas de Aula, 1997.

[31] RATIONAL SOFTWARE CORPORATION Rational Objectory Process 4.1 http://www.rational.com/UML/Process/, [Acesso em 12/2/1998]

[32] RATIONAL SOFTWARE CORPORATION - UML Frequently Asked Questions http://www.rational.com/UML/FAQ/, [Acesso em 12/2/1998]

[33] RATIONAL SOFTWARE CORPORATION UML Glossary http://www.rational.com/UML/Others/, [Acesso em 12/2/1998]

[34] PRADO, A F., COUTO, A. A.; LIMA, V. M.;SILVA T. E. ToolRC: Ferramenta CASE Orientada a Objetos. XI Simpósio Brasileiro de Engenharia de Software -SBES, Fortaleza, 1997 
Anexo A 


\section{Visão Geral do Sistema}

Anexo A - $99-$

O Sistema de Apoio à Escrita (SAPES) tem como objetivo principal auxiliar a pesquisa bibliográfica. Os usuários deste sistema são, principalmente, pesquisadores que durante a sua pesquisa bibliográfica podem ler publicações (por exemplo; artigos, livros e periódicos) e armazená-las no sistema através de itens bibliográficos, construindo, assim, a sua bibliografia pessoal. Esta bibliografia pode ser alterada e consultada conforme a necessidade do pesquisador, além da possibilidade de fornecer diferentes tipos de relatório. $O$ pesquisador pode também utilizar o sistema durante a redação de textos científicos. Através do documento produzido pelo pesquisador, o sistema reconhece as citações e gera automaticamente a referência bibliográfica.

\section{Requisitos Funcionais}

\subsection{Preparação e Manutenção dos Itens Bibliográficos}

1. O sistema deve permitir a inserção, alteração e exclusão de itens bibliográficos, mantendo uma bibliografia.

2. O sistema deve solicitar ao pesquisador os itens de informação necessários para inserir um itens bibliográfico na bibliografia. Os itens de informação são: título, autor(es), data(mês/ano), local, resumo da publicação, assunto, numeração física, editora, periódico (volume, numero, páginas), congresso e forma de citação.

3. O sistema deve fornecer mensagens de erro quando itens bibliográficos incompletos forem inseridos. Tais mensagens interrogam o pesquisador se deseja cancelar a operação de inserção, completar as informações incompletas ou concluir a inserção assim mesmo.

4. O sistema deve, no caso de ocorrer a tentativa de inserção de um item bibliográfico já existente, comunicar ao pesquisador a existência deste item bibliográfico na bibliografia. Se, neste caso, o pesquisador confirmar a operação de inserção, o sistema deve informar que tal operação irá alterar o item bibliográfico existente.

5. O sistema deve gerar automaticamente a forma de citação (código de citação) seguindo o padrão ABNT (Associação Brasileira de Normas Técnicas) quando o pesquisador inserir um item bibliográfico na bibliografia. 
6 O sistema deve fornecer facilidades para a criação e manutenção de uma lista de sinônimos, para os seguintes itens de informação do item bibliográfico: autor, editora, periódico e congresso.

7 O sistema deve permitir a alteração dos itens de informação de um item bibliográfico da bibliografia, com exceção do código de citação que é gerado automaticamente pelo sistema. O pesquisador pode acessar/recuperar um item bibliográfico pêlos itens de informação: autor, título e pêlos sinônimos de autor e título, respectivamente.

8 O sistema deve permitir a exclusão de um item bibliográfico se este item existe na bibliografia. O pesquisador pode acessar/recuperar um item bibliográfico a ser exciuído pêlos itens de informação: autor, titulo e pêlos sinônimos de autor e título, respectivamente.

9 O sistema deve permitir a inserção de itens bibliográficos importados de bibliografias de outros pesquisadores, através dos itens de informação autor e titulo e também pêlos sinônimos de autor e título, respectivamente. O operação de inserção pode exigir ou não confirmação. A importação de itens pode ser total (todo a bibliografia do pesquisador) ou parcial (somente alguns itens bibliográfico).

10. O sistema não deve permitir a alteração da bibliografia pôr parte de pesquisadores não autorizados (Segurança de Acesso).

\subsection{Consultas Gerais e Emissão de Relatórios}

11. O sistema deve permitir consulta a itens bibliográficos existentes na bibliografia. A busca destes itens bibliográficos pode ser realizada a partir dos seguintes itens de informação ou combinação destes: autor, assunto, editora, periódico, local e ano de publicação. Assim, o sistema apresenta para o pesquisador todos o(s) itens(s) bibliográficos que satisfazem o critério de busca. 
12. O sistema deve, durante o processo de consulta, averiguar com o pesquisador quais itens de informação ele deseja recuperar. Assim, o sistema pode recuperar itens bibliográficos totais ou parciais.

13. 0 sistema deve solicitar ao pesquivador 7 no momento da consulta o tipo do relatório a ser gerado. $O$ relatório contém itens de informação relativos aos itens bibliográficos selecionados pelo pesquisador durante o processo de consulta. Os relatórios podem ser impressos (na tela ou na impressora) ou podem ser gravados em arquivos para posterior análise.

14. Osistema deve ordenar os itens bibliográficos dos relatórios de acordo com a preferência do pesquisador utilizando as alternativas pelos Itens de informação: autor, titulo e pelos sinônimos 5 de autor e título, respectivamente.

15. Osistema deve fornecer recursos para a criação e impressão de ficha técnica a partir das informações que o sistema possui sobre os itens bibliográficos. Uma vez geradas as ficha técnicas, o pesquisador pode optar pôr relatório impresso ou gravação em arquivos. As fichas técnicas contêm além dos itens de informação do item bibliográfico, de forma parcial ou total, anotações do pesquisador a respeito do item bibliográfico.

\subsection{Uso dos Itens Bibliográficos durante a redação de um texto cientifico.}

16. 0 sistema deve percorrer o documento produzido pelo pesquisador a fim de identificar todas as citaçōes encontradas. A partir destas citaçōes o sistema deve gerar automaticamente a referência bibliográfica seguindo o padrão $A B N T$, e que posteriormente será anexada ao documento. As citações no documento devem estar na forma $A B N T$.

170 sistema deve permitir ao pesquisador ordenar as referência das referências bibliográficas em ordem alfabética por autor ou pela ocorrência da sua respectiva citação no documento. 
18. Caso o sistema encontre uma citação na documentação que não esteja na bibliografia, o sistema deverá fornecer uma mensagem adequada ao pesquisador alertando a ocorrência de uma possivel citaçäo incorreta.

19.0 sistema não deve permitir que o pesquisador altere as informações geradas automaticamente pelo sistema. Caso o pesquisador deseje alterar os itens de informação de uma referência das referências bibliográficas por erro ou por não estar completa, ou deseje inserir um item bibliográfico não encontrado pelo sistema, este deve proceder com as alterações desejadas na bibliografia e em seguida o sistema deve percorrer novamente o documento gerando uma nova bibliografia. Caso não deseje fazer alterações na bibliografia, deverá então fazer correções diretamente no documento.

\section{Requisitos de Qualidade}

\subsection{Confiabilidade}

20. O sistema deve ter capacidade para recuperar os dados perdidos da última operação que realizou em caso de falha.

21.0 sistema deve fornecer facilidades para a realização de backups dos arquivos do sistema.

\subsection{Eficiência}

22. O tempo de processamento de uma operação de consuita não deve exceder três segundos para uma quantidade inferior a 10 itens bibliográficos.

23. 0 tempo de resposta para as operações de inserção, alteração e exclusão não deve exceder a três segundos.

\subsection{Portabilidade}

24.0 sistema deve rodar em microcomputadores da linha IBM PC que possuam microprocessador 486 DX ou superior, memória RAM mínima de 8Mbytes e rodam sob Windows 95.

25. O sistema deve ser facilmente portável para o UNIX. 
Anexo B 


\section{GLOSSÁRIO DO DIC}

\begin{tabular}{||l|l|l|}
\hline NOME & TIPO & DECRIÇÃO \\
\hline Pesquisador & Ator & $\begin{array}{l}\text { Pessoa que alimenta o sistema } \\
\text { SAPES com o conjunto de itens } \\
\text { bibliográficos referentes a } \\
\text { diversos artigos publicados }\end{array}$ \\
\hline Escritor & Ator & $\begin{array}{l}\text { Pessoa que utiliza o sistema } \\
\text { SAPES e que está interessada na } \\
\text { manutenção automática de sua } \\
\text { bibliografia }\end{array}$ \\
\hline Consulta e Emissão de relatórios & Cena & $\begin{array}{l}\text { Conjunto de operações do sistema } \\
\text { SAPES que descrevem a saida de } \\
\text { dados no sistema }\end{array}$ \\
\hline $\begin{array}{l}\text { Preparação de itens } \\
\text { bibliográficos }\end{array}$ & $\begin{array}{l}\text { Conjunto de operações do sistema } \\
\text { SAPES que descrevem o entrada } \\
\text { de dados no sistema }\end{array}$ \\
\hline $\begin{array}{l}\text { Inserção de referências } \\
\text { bibliográficas no texto }\end{array}$ & Cena & $\begin{array}{l}\text { Conjunto de operações do sistema } \\
\text { SAPES que descrevem o } \\
\text { automatização da bibliografia }\end{array}$ \\
\hline Editor de texto & $\begin{array}{l}\text { Subsistema utilizado pelo sistema } \\
\text { SAPES para a produção de } \\
\text { referências bibliográficas }\end{array}$ \\
\hline
\end{tabular}

\section{GLOSSÁRIO DA CENA “ PREPARAÇÃO DE ITENS BIBLIOGRÁFICO”}

\begin{tabular}{||l|l|l|l|l||}
\hline NOME & TIPO & OPERAÇÃO & ARGUMENTO & DESCRIÇÃO \\
\hline $\begin{array}{l}\text { Edição } \\
\text { Disponivel }\end{array}$ & Estado Inicial & & $\begin{array}{l}\text { O sistema está operando e } \\
\text { inativo }\end{array}$ \\
\hline Criando Item & Estado & Criar item & $\begin{array}{l}\text { Item } \\
\text { Bibliográfico, } \\
\text { Bibliografia }\end{array}$ & $\begin{array}{l}\text { Inserção de um novo item } \\
\text { bibliográfico na } \\
\text { bibliografia }\end{array}$ \\
\hline $\begin{array}{l}\text { Opção criar item } \\
\text { ativada }\end{array}$ & $\begin{array}{l}\text { Transição } \\
\text { Principal }\end{array}$ & Criar item & $\begin{array}{l}\text { Item } \\
\text { bibliográfico }\end{array}$ & $\begin{array}{l}\text { Interação que inicia a } \\
\text { criação de um item }\end{array}$ \\
\hline $\begin{array}{l}\text { Msg. de item } \\
\text { criado exibida }\end{array}$ & $\begin{array}{l}\text { Transição } \\
\text { Principal }\end{array}$ & Criar item & $\begin{array}{l}\text { Item } \\
\text { bibliográfico }\end{array}$ & $\begin{array}{l}\text { Mensagem de sucesso } \\
\text { para a operação criar item }\end{array}$ \\
\hline $\begin{array}{l}\text { Msg de item } \\
\text { incompleto } \\
\text { exibida }\end{array}$ & $\begin{array}{l}\text { Transição } \\
\text { Secundária }\end{array}$ & Criar item & $\begin{array}{l}\text { Item } \\
\text { bibliográfico }\end{array}$ & $\begin{array}{l}\text { Mensagem de falha para a } \\
\text { operação criar item }\end{array}$ \\
\hline $\begin{array}{l}\text { Campos de } \\
\text { sinônimos } \\
\text { preenchido }\end{array}$ & $\begin{array}{l}\text { Transição } \\
\text { Secundária }\end{array}$ & Criar item & $\begin{array}{l}\text { Item } \\
\text { bibliográfico }\end{array}$ & $\begin{array}{l}\text { Interação que inicia a } \\
\text { associação de sinônimos }\end{array}$ \\
\hline $\begin{array}{l}\text { Associando } \\
\text { sinônimos }\end{array}$ & Estado & Criar item & $\begin{array}{l}\text { Item } \\
\text { Bibliográfico, } \\
\text { sinônimos }\end{array}$ & $\begin{array}{l}\text { Associação de sinônimos } \\
\text { para um item } \\
\text { bibliográfico }\end{array}$ \\
\hline
\end{tabular}




\begin{tabular}{|c|c|c|c|c|}
\hline $\begin{array}{l}\text { Msg. de item } \\
\text { criado exibida }\end{array}$ & $\begin{array}{l}\text { Transição } \\
\text { Secundária }\end{array}$ & Criar item & $\begin{array}{l}\text { Item } \\
\text { bibliográfico }\end{array}$ & $\begin{array}{l}\text { Mensagem de sucesso } \\
\text { para a operação de } \\
\text { associar sinônimos }\end{array}$ \\
\hline $\begin{array}{l}\text { Opção } \\
\text { selecionar item } \\
\text { ativada }\end{array}$ & $\begin{array}{l}\text { Transição } \\
\text { Principal }\end{array}$ & Criar item & $\begin{array}{l}\text { Item } \\
\text { bibliográfico }\end{array}$ & $\begin{array}{l}\text { Interação que inicia a } \\
\text { seleção de um item }\end{array}$ \\
\hline $\begin{array}{l}\text { Selecionando } \\
\text { item }\end{array}$ & Estado & $\begin{array}{l}\text { Selecionar } \\
\text { item, } \\
\text { Modificar } \\
\text { item, } \\
\text { Remover item } \\
\end{array}$ & $\begin{array}{l}\text { Item } \\
\text { bibliográfico }\end{array}$ & $\begin{array}{l}\text { Seleção de um único item } \\
\text { bibliográfico através da } \\
\text { combinação de um ou } \\
\text { mais atributos }\end{array}$ \\
\hline $\begin{array}{l}\text { Opção remover } \\
\text { ativada }\end{array}$ & \begin{tabular}{|l|} 
Transição \\
Principal \\
\end{tabular} & Remover item & $\begin{array}{l}\text { Item } \\
\text { bibliográfico }\end{array}$ & $\begin{array}{l}\text { Interação que inicia a } \\
\text { remoção de um item }\end{array}$ \\
\hline $\begin{array}{l}\text { Opção cancelar } \\
\text { ativada }\end{array}$ & $\begin{array}{l}\text { Transição } \\
\text { Secundária }\end{array}$ & $\begin{array}{l}\text { Selecionar } \\
\text { item }\end{array}$ & $\begin{array}{l}\text { Item } \\
\text { bibliográfico }\end{array}$ & $\begin{array}{l}\text { Interação que cancela a } \\
\text { seleção de itens }\end{array}$ \\
\hline Removendo & Estado & Remover item & \begin{tabular}{|l|} 
Item \\
bibliográfico \\
Bibliografia \\
\end{tabular} & $\begin{array}{l}\text { Remoção de um item } \\
\text { bibliográfico selecionado } \\
\text { da Bibliografia } \\
\end{array}$ \\
\hline $\begin{array}{l}\text { Opção modificar } \\
\text { item ativada }\end{array}$ & \begin{tabular}{|l|} 
Transição \\
Principal \\
\end{tabular} & $\begin{array}{l}\text { Modificar } \\
\text { item }\end{array}$ & $\begin{array}{l}\text { Item } \\
\text { bibliográfico }\end{array}$ & $\begin{array}{l}\text { Interação que inicia a } \\
\text { modificação de um item }\end{array}$ \\
\hline Modificando & Estado & $\begin{array}{l}\text { Modificar } \\
\text { item }\end{array}$ & $\begin{array}{l}\text { Item } \\
\text { bibliográfico } \\
\text { Bibliografia }\end{array}$ & $\begin{array}{l}\text { Modificação de um item } \\
\text { bibliográfico selecionado } \\
\text { da Bibliografia }\end{array}$ \\
\hline $\begin{array}{l}\text { Opção cancelar } \\
\text { ativada }\end{array}$ & $\begin{array}{l}\text { Transição } \\
\text { Secundária }\end{array}$ & \begin{tabular}{|l|} 
Selecionar \\
item
\end{tabular} & $\begin{array}{l}\text { Item } \\
\text { bibliográfico }\end{array}$ & $\begin{array}{l}\text { Interação que cancela a } \\
\text { seleção de um item }\end{array}$ \\
\hline $\begin{array}{l}\text { Opção } \\
\text { selecionar itens } \\
\text { ativada }\end{array}$ & $\begin{array}{l}\text { Transição } \\
\text { Principal }\end{array}$ & Importar itens & $\begin{array}{l}\text { Item } \\
\text { bibliográfico }\end{array}$ & $\begin{array}{l}\text { Interação que inicia a } \\
\text { seleção de vários itens }\end{array}$ \\
\hline $\begin{array}{l}\text { Selecionando } \\
\text { itens }\end{array}$ & Estado & $\begin{array}{l}\text { Selecionar } \\
\text { itens, Importar } \\
\text { itens }\end{array}$ & Bibliografia & $\begin{array}{l}\text { Seleção de vários itens } \\
\text { bibliográfico através da } \\
\text { combinação de um ou } \\
\text { mais atributos } \\
\end{array}$ \\
\hline $\begin{array}{l}\text { Msg. de criar } \\
\text { lista de itens } \\
\text { exibida }\end{array}$ & $\begin{array}{l}\text { Transição } \\
\text { Principal }\end{array}$ & Importar itens & $\begin{array}{l}\text { Item } \\
\text { bibliográfico }\end{array}$ & $\begin{array}{l}\text { Resposta de sucesso para } \\
\text { a operação selecionar } \\
\text { itens } \\
\end{array}$ \\
\hline $\begin{array}{l}\text { Criando lista de } \\
\text { itens }\end{array}$ & Estado & Importar itens & \begin{tabular}{|l|} 
Item \\
bibliográfico, \\
Bibliografia \\
\end{tabular} & \begin{tabular}{|l|} 
Criação de uma lista de \\
itens bibliográficos \\
selecionados \\
\end{tabular} \\
\hline $\begin{array}{l}\text { Msg. lista de } \\
\text { itens criada } \\
\text { exibida }\end{array}$ & $\begin{array}{l}\text { Transição } \\
\text { Principal }\end{array}$ & Importar itens & $\begin{array}{l}\text { Item } \\
\text { bibliográfico }\end{array}$ & $\begin{array}{l}\text { Mensagem de sucesso } \\
\text { para a operação criar lista } \\
\text { de itens }\end{array}$ \\
\hline $\begin{array}{l}\text { Importando } \\
\text { Lista de Itens } \\
\text { Bibliográficos } \\
\end{array}$ & Estado & Importar itens & $\begin{array}{l}\text { Itens } \\
\text { Bibliográficos, } \\
\text { Bibliografia } \\
\end{array}$ & $\begin{array}{l}\text { Importação da lista de } \\
\text { itens criada }\end{array}$ \\
\hline $\begin{array}{l}\text { Msg. de } \\
\text { importação com } \\
\text { sucesso exibida } \\
\end{array}$ & $\begin{array}{l}\text { Transição } \\
\text { Principal }\end{array}$ & Importar itens & $\begin{array}{l}\text { Item } \\
\text { bibliográfico }\end{array}$ & $\begin{array}{l}\text { Mensagem de sucesso } \\
\text { para a operação criar itens } \\
\text { Bibliográficos } \\
\end{array}$ \\
\hline
\end{tabular}


3. GLOSSÁRIO DA CENA “INSERÇÃO DAS REFERÊNCIAS BIBLIOGRÁFICAS NO TEXTO - ATOR: ESCRITOR"

\begin{tabular}{|l|l|l|l|l||}
\hline NOME & TIPO & OPERAÇÃO & ARGUMENTO & DESCRIÇÃO \\
\hline $\begin{array}{l}\text { Documento } \\
\text { Disponivel }\end{array}$ & Estado Inicial & documento está aberto \\
\hline $\begin{array}{l}\text { Gerando } \\
\text { referência }\end{array}$ & Estado & $\begin{array}{l}\text { Inserir } \\
\text { referência }\end{array}$ & $\begin{array}{l}\text { Referências } \\
\text { Bibliográfica }\end{array}$ & $\begin{array}{l}\text { Criação de referências para } \\
\text { os itens bibliográficos, } \\
\text { gerando um arquivo de } \\
\text { referências }\end{array}$ \\
\hline $\begin{array}{l}\text { Opção gerar } \\
\text { referência } \\
\text { ativada }\end{array}$ & $\begin{array}{l}\text { Transição } \\
\text { Principal }\end{array}$ & $\begin{array}{l}\text { Inserir } \\
\text { referência }\end{array}$ & $\begin{array}{l}\text { Referências } \\
\text { Bibliográfica }\end{array}$ & $\begin{array}{l}\text { Interação que inicia a } \\
\text { geração de referências }\end{array}$ \\
\hline $\begin{array}{l}\text { Opção cancelar } \\
\text { ativada }\end{array}$ & $\begin{array}{l}\text { Transição } \\
\text { Secundária }\end{array}$ & $\begin{array}{l}\text { Inserir } \\
\text { referência }\end{array}$ & $\begin{array}{l}\text { Referências } \\
\text { Bibliográfica }\end{array}$ & $\begin{array}{l}\text { Interação que cancela a } \\
\text { geração de referências }\end{array}$ \\
\hline $\begin{array}{l}\text { Opção de } \\
\text { inserir } \\
\text { referência } \\
\text { ativada }\end{array}$ & $\begin{array}{l}\text { Transição } \\
\text { Principal }\end{array}$ & $\begin{array}{l}\text { Inserir } \\
\text { referência }\end{array}$ & $\begin{array}{l}\text { Referências } \\
\text { Bibliográfica }\end{array}$ & $\begin{array}{l}\text { Interação que inicia a } \\
\text { inserção de referências no } \\
\text { Artigo }\end{array}$ \\
\hline $\begin{array}{l}\text { Inserindo } \\
\text { referência } \\
\text { Bibliográfica }\end{array}$ & Estado & $\begin{array}{l}\text { Inserir } \\
\text { referência }\end{array}$ & $\begin{array}{l}\text { Referência } \\
\text { Bibliográfica, } \\
\text { Artigo }\end{array}$ & $\begin{array}{l}\text { Inserção da referências } \\
\text { bibliográficas no fim do } \\
\text { artigo em edição. }\end{array}$ \\
\hline \hline
\end{tabular}

\section{GLOSSÁRIO DA CENA “INSERÇÃO DAS REFERÊNCIAS BIBLIOGRÁFICAS NO TEXTO - ATOR: EDITOR DE TEXTOS"}

\begin{tabular}{||l|l|l|l|l||}
\hline NOME & TIPO & OPERAÇÃO & ARGUMENTO & DESCRIÇÃO \\
\hline $\begin{array}{l}\text { Inserindo } \\
\text { Referência }\end{array}$ & Estado Inicial & $\begin{array}{l}\text { Inserir } \\
\text { arquivo }\end{array}$ & $\begin{array}{l}\text { Referências } \\
\text { Bibliográfica }\end{array}$ & $\begin{array}{l}\text { A Referência bibliográfica } \\
\text { foi gerada }\end{array}$ \\
\hline $\begin{array}{l}\text { Inserindo } \\
\text { arquivo }\end{array}$ & Estado & $\begin{array}{l}\text { Inserir } \\
\text { arquivo }\end{array}$ & $\begin{array}{l}\text { Artigo, } \\
\text { Referência } \\
\text { Bibliográfica }\end{array}$ & $\begin{array}{l}\text { Inserção de referência } \\
\text { bibliográfica no artigo } \\
\text { aberto }\end{array}$ \\
\hline $\begin{array}{l}\text { Tarefa inserir } \\
\text { arquivo ativada }\end{array}$ & $\begin{array}{l}\text { Transição } \\
\text { Principal }\end{array}$ & $\begin{array}{l}\text { Inserir } \\
\text { arquivo }\end{array}$ & $\begin{array}{l}\text { Referência } \\
\text { Bibliográfica }\end{array}$ & $\begin{array}{l}\text { Estímulo que inicia a } \\
\text { inserção do arquivo de } \\
\text { referèncias }\end{array}$ \\
\hline $\begin{array}{l}\text { Resposta } \\
\text { arquivo } \\
\text { inserido gerada }\end{array}$ & $\begin{array}{l}\text { Transição } \\
\text { Principal }\end{array}$ & $\begin{array}{l}\text { Inserir } \\
\text { arquivo }\end{array}$ & $\begin{array}{l}\text { Referência } \\
\text { Bibliográfica }\end{array}$ & $\begin{array}{l}\text { Resposta de sucesso para a } \\
\text { inserção do arquivo de } \\
\text { referências }\end{array}$ \\
\hline
\end{tabular}

\section{GLOSSÁRIO DA CENA “CONSULTA E EMISSÃO DE RELATÓRIOS”}

\begin{tabular}{||l|l|l|l|l||}
\hline NOME & TIPO & OPERAÇÃO & ARGUMENTO & DESCRIÇÃO \\
\hline $\begin{array}{l}\text { Bibliografia } \\
\text { Disponivel }\end{array}$ & Estado Inicial & $\begin{array}{l}\text { Gerar } \\
\text { Consulta }\end{array}$ & $\begin{array}{l}\text { Uma bibliografia já foi } \\
\text { criada e está disponivel }\end{array}$ \\
\hline $\begin{array}{l}\text { Opção } \\
\text { consultar itens } \\
\text { bibliográficos } \\
\text { ativada }\end{array}$ & $\begin{array}{l}\text { Transição } \\
\text { Principal }\end{array}$ & $\begin{array}{l}\text { Gerar } \\
\text { Consulta }\end{array}$ & $\begin{array}{l}\text { Itens de } \\
\text { Informação }\end{array}$ & $\begin{array}{l}\text { Interação que inicia a } \\
\text { seleção de itens de } \\
\text { informação para consulta }\end{array}$ \\
\hline
\end{tabular}




\begin{tabular}{|c|c|c|c|c|}
\hline $\begin{array}{l}\text { Selecionando } \\
\text { itens de } \\
\text { informação }\end{array}$ & Estado & $\begin{array}{l}\text { Gerar } \\
\text { Consulta }\end{array}$ & $\begin{array}{l}\text { Itens de } \\
\text { Informação }\end{array}$ & $\begin{array}{l}\text { Seleção de um ou mais } \\
\text { itens de informação de um } \\
\text { item bibliográfico para um } \\
\text { relatório de consulta }\end{array}$ \\
\hline $\begin{array}{l}\text { Opção de } \\
\text { consulta na tela } \\
\text { ativada }\end{array}$ & $\begin{array}{l}\text { Transição } \\
\text { Principal }\end{array}$ & $\begin{array}{l}\text { Gerar } \\
\text { Consulta }\end{array}$ & \begin{tabular}{|l} 
Itens de \\
Informação
\end{tabular} & $\begin{array}{l}\text { Interação que inicia a } \\
\text { geração de relatório de } \\
\text { consulta em tela }\end{array}$ \\
\hline $\begin{array}{l}\text { Gerando } \\
\text { consulta na tela }\end{array}$ & Estado & $\begin{array}{l}\text { Gerar } \\
\text { Consulta }\end{array}$ & $\begin{array}{l}\text { Relatório de } \\
\text { Consulta }\end{array}$ & $\begin{array}{l}\text { Gera na tela um relatório de } \\
\text { consultas de itens } \\
\text { bibliográficos selecionados } \\
\text { através da combinação de } \\
\text { um ou mais itens de } \\
\text { informação }\end{array}$ \\
\hline $\begin{array}{l}\text { Msg gerando } \\
\text { consulta em } \\
\text { tela exibida }\end{array}$ & $\begin{array}{l}\text { Transição } \\
\text { Principal }\end{array}$ & $\begin{array}{l}\text { Gerar } \\
\text { Consulta }\end{array}$ & $\begin{array}{l}\text { Relatório de } \\
\text { Consulta }\end{array}$ & $\begin{array}{l}\text { Mensagem de sucesso na } \\
\text { geração de consulta em tela }\end{array}$ \\
\hline $\begin{array}{l}\text { Opção de } \\
\text { consulta } \\
\text { impressa } \\
\text { ativada }\end{array}$ & $\begin{array}{l}\text { Transição } \\
\text { Principal }\end{array}$ & $\begin{array}{l}\text { Imprimir } \\
\text { Consulta }\end{array}$ & $\begin{array}{l}\text { Relatório de } \\
\text { Consulta }\end{array}$ & $\begin{array}{l}\text { Interação que inicia a } \\
\text { geração de consulta na } \\
\text { impressora }\end{array}$ \\
\hline $\begin{array}{l}\text { Imprimindo } \\
\text { consulta }\end{array}$ & Estado & $\begin{array}{l}\text { Imprimir } \\
\text { Consulta }\end{array}$ & $\begin{array}{l}\text { Relatório de } \\
\text { Consulta, Itens } \\
\text { Bibliográficos }\end{array}$ & $\begin{array}{l}\text { Gera na impressora um } \\
\text { relatório do tipo consulta } \\
\text { selecionados por } \\
\text { intermédio da combinação } \\
\text { de um ou mais itens de } \\
\text { informação }\end{array}$ \\
\hline $\begin{array}{l}\text { Msg } \\
\text { imprimindo } \\
\text { consulta } \\
\text { exibida }\end{array}$ & $\begin{array}{l}\text { Transição } \\
\text { Principal }\end{array}$ & $\begin{array}{l}\text { Imprimir } \\
\text { Consulta }\end{array}$ & $\begin{array}{l}\text { Relatório de } \\
\text { Consulta }\end{array}$ & $\begin{array}{l}\text { Mensagem de sucesso na } \\
\text { impressão de consulta }\end{array}$ \\
\hline $\begin{array}{l}\text { Opção de } \\
\text { consulta } \\
\text { gravada em } \\
\text { arquivo }\end{array}$ & $\begin{array}{l}\text { Transição } \\
\text { Principal }\end{array}$ & $\begin{array}{l}\text { Gravar } \\
\text { Consulta }\end{array}$ & $\begin{array}{l}\text { Relatório de } \\
\text { Consulta }\end{array}$ & $\begin{array}{l}\text { Interação que inicia a } \\
\text { geração de consulta } \\
\text { gravada em arquivo }\end{array}$ \\
\hline $\begin{array}{l}\text { Gravando } \\
\text { consulta }\end{array}$ & Estado & $\begin{array}{l}\text { Gravar } \\
\text { Consulta }\end{array}$ & $\begin{array}{l}\text { Relatório de } \\
\text { Consulta }\end{array}$ & $\begin{array}{l}\text { Gera em disco um arquivo } \\
\text { com o relatório de consulta } \\
\text { de itens bibliográficos, } \\
\text { selecionados através da } \\
\text { combinação de um ou mais } \\
\text { itens de informação }\end{array}$ \\
\hline $\begin{array}{l}\text { Msg gravando } \\
\text { consulta } \\
\text { exibida }\end{array}$ & $\begin{array}{l}\text { Transição } \\
\text { Principal }\end{array}$ & $\begin{array}{l}\text { Gravar } \\
\text { Consulta }\end{array}$ & $\begin{array}{l}\text { Relatório de } \\
\text { Consulta }\end{array}$ & $\begin{array}{l}\text { Mensagem de sucesso na } \\
\text { gravação de consulta em } \\
\text { disco }\end{array}$ \\
\hline $\begin{array}{l}\text { Opção } \\
\text { selecionar item } \\
\text { bibliográfico } \\
\text { ativada }\end{array}$ & $\begin{array}{l}\text { Transição } \\
\text { Principal }\end{array}$ & $\begin{array}{l}\text { Criar Ficha } \\
\text { Técnica }\end{array}$ & $\begin{array}{l}\text { Item } \\
\text { Bibliográfico }\end{array}$ & $\begin{array}{l}\text { Interação que inicia a } \\
\text { seleção de um item } \\
\text { bibliográfico para a criação } \\
\text { de ficha técnica ou } \\
\text { anotação }\end{array}$ \\
\hline
\end{tabular}




\begin{tabular}{|l|l|l|l|l|}
\hline $\begin{array}{l}\text { Selecionando } \\
\text { item }\end{array}$ & Estado & $\begin{array}{l}\text { Criar Ficha } \\
\text { Técnica }\end{array}$ & $\begin{array}{l}\text { Item } \\
\text { Bibliográfico }\end{array}$ & $\begin{array}{l}\text { Seleção de um único item } \\
\text { biblográfico através da } \\
\text { combinação de um ou mais } \\
\text { atributos. }\end{array}$ \\
\hline $\begin{array}{l}\text { Opção criar } \\
\text { ficha técnica } \\
\text { ativada }\end{array}$ & $\begin{array}{l}\text { Transição } \\
\text { Principal }\end{array}$ & $\begin{array}{l}\text { Criar Ficha } \\
\text { Técnica }\end{array}$ & Ficha Técnica & $\begin{array}{l}\text { Interação que inicia a } \\
\text { criação de uma ficha } \\
\text { técnica }\end{array}$ \\
\hline $\begin{array}{l}\text { Criando Ficha } \\
\text { Técnica }\end{array}$ & Estado & $\begin{array}{l}\text { Criar Ficha } \\
\text { Técnica }\end{array}$ & Ficha Técnica & $\begin{array}{l}\text { Criação de ficha técnica } \\
\text { contendo itens de } \\
\text { informações e anotações } \\
\text { sobre o item bibliográfico }\end{array}$ \\
\hline $\begin{array}{l}\text { Opção de ficha } \\
\text { impressa }\end{array}$ & $\begin{array}{l}\text { Transição } \\
\text { Principal }\end{array}$ & $\begin{array}{l}\text { Imprimir } \\
\text { Ficha } \\
\text { Técnica }\end{array}$ & Ficha Técnica & $\begin{array}{l}\text { Interação que inicia a } \\
\text { impressão de uma ficha } \\
\text { técnica }\end{array}$ \\
\hline $\begin{array}{l}\text { Imprimindo } \\
\text { Ficha Técnica }\end{array}$ & Estado & $\begin{array}{l}\text { Imprimir } \\
\text { Ficha } \\
\text { Técnica }\end{array}$ & Ficha Técnica & $\begin{array}{l}\text { Gera na impressora um } \\
\text { relatório do tipo ficha } \\
\text { técnica }\end{array}$ \\
\hline $\begin{array}{l}\text { Msg } \\
\text { imprimindo } \\
\text { ficha exibida }\end{array}$ & $\begin{array}{l}\text { Transição } \\
\text { Principal }\end{array}$ & $\begin{array}{l}\text { Imprimir } \\
\text { Ficha } \\
\text { Técnica }\end{array}$ & Ficha Técnica & $\begin{array}{l}\text { Mensagem de sucesso na } \\
\text { impressão de ficha técnica }\end{array}$ \\
\hline $\begin{array}{l}\text { Opção de } \\
\text { gravar ficha em } \\
\text { arquivo ativada }\end{array}$ & $\begin{array}{l}\text { Transição } \\
\text { Principal }\end{array}$ & $\begin{array}{l}\text { Gravar Ficha } \\
\text { Técnica }\end{array}$ & Ficha Técnica & $\begin{array}{l}\text { Interação que inicia a } \\
\text { gravação de uma ficha } \\
\text { técnica }\end{array}$ \\
\hline $\begin{array}{l}\text { Gravando } \\
\text { Ficha Técnica }\end{array}$ & Estado & $\begin{array}{l}\text { Gravar Ficha } \\
\text { Técnica }\end{array}$ & Ficha Técnica & $\begin{array}{l}\text { Gera em disco um relatório } \\
\text { do tipo ficha técnica }\end{array}$ \\
\hline $\begin{array}{l}\text { Msg Gravando } \\
\text { ficha técnica } \\
\text { exibida }\end{array}$ & $\begin{array}{l}\text { Transição } \\
\text { Principal }\end{array}$ & $\begin{array}{l}\text { Gravar Ficha } \\
\text { Técnica }\end{array}$ & Ficha Técnica & $\begin{array}{l}\text { Mensagem de sucesso na } \\
\text { gravação de ficha técnica }\end{array}$ \\
\hline
\end{tabular}


Anexo C 


\section{Integração da Ferramenta ERACE com o Sistema Draco}

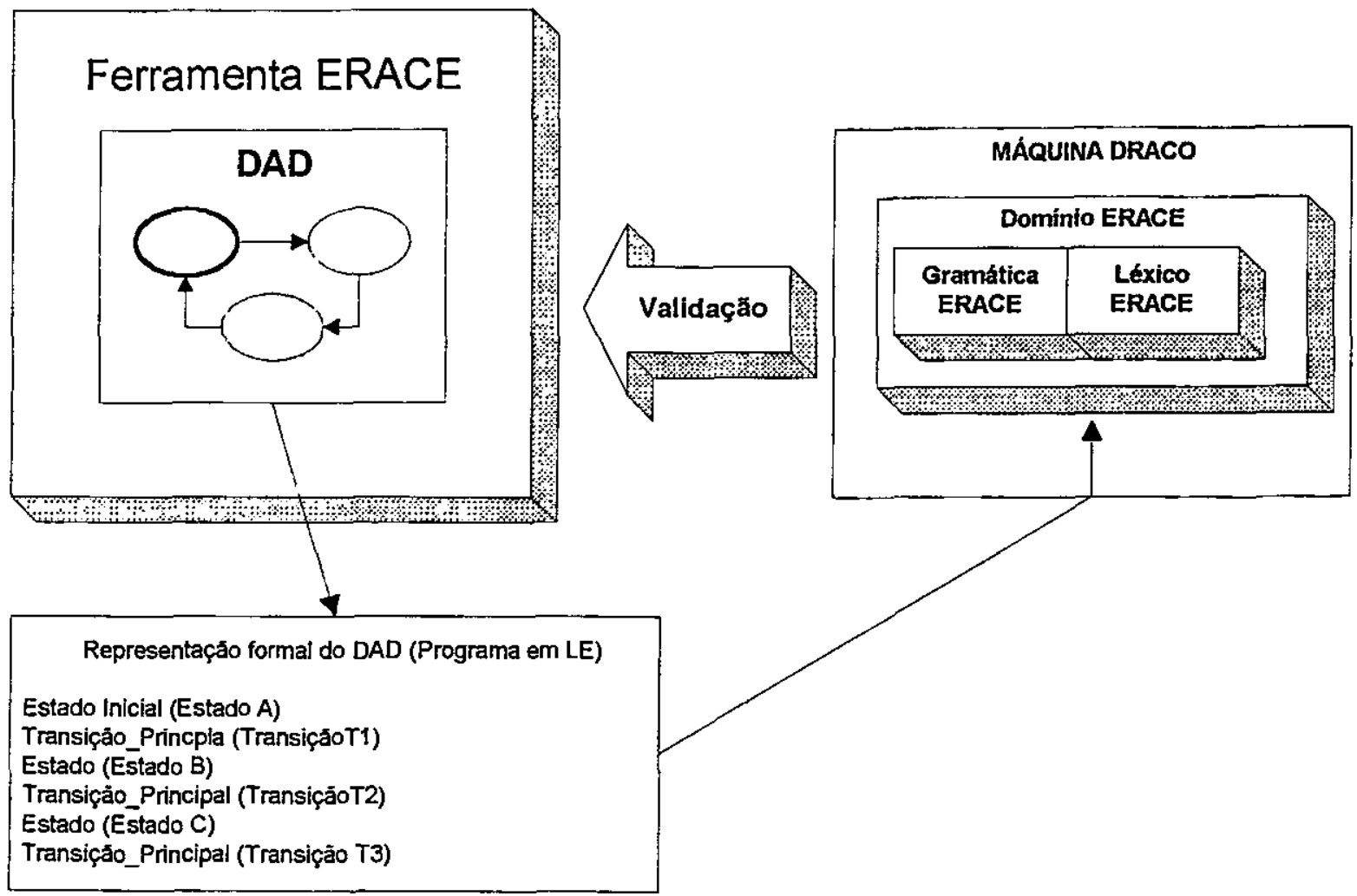

\section{Gramática ERACE definida para o sistema Draco}

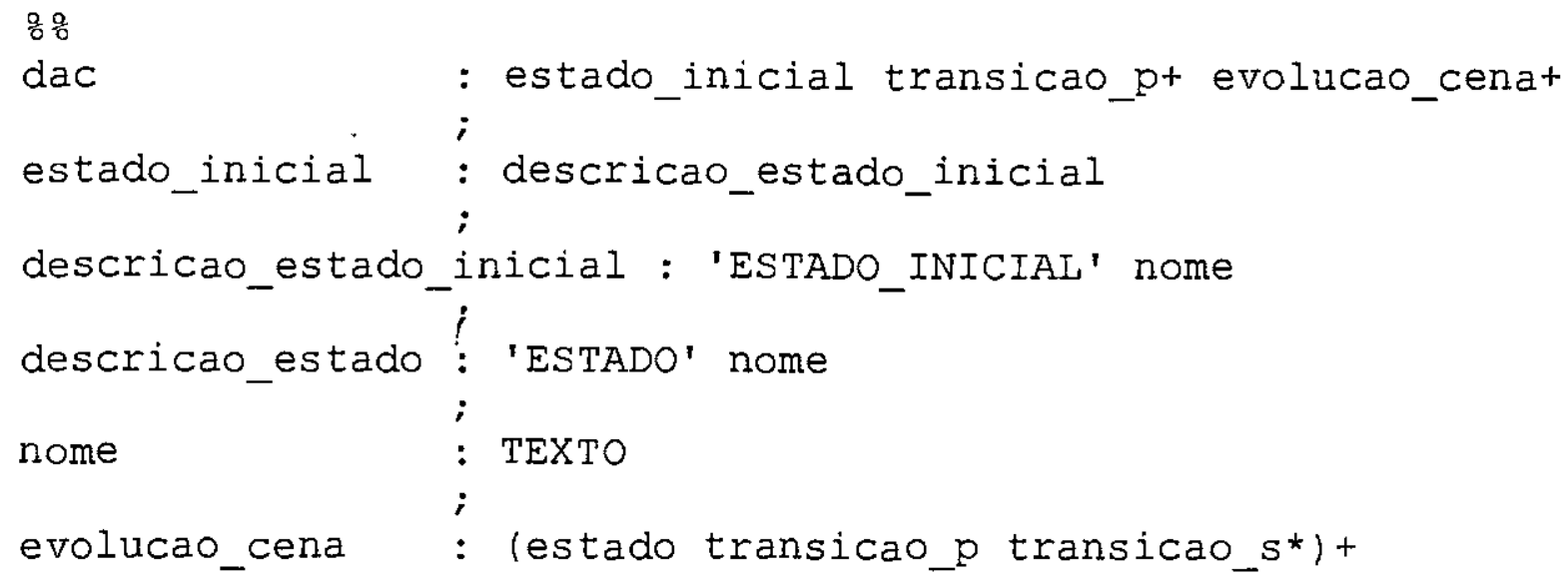




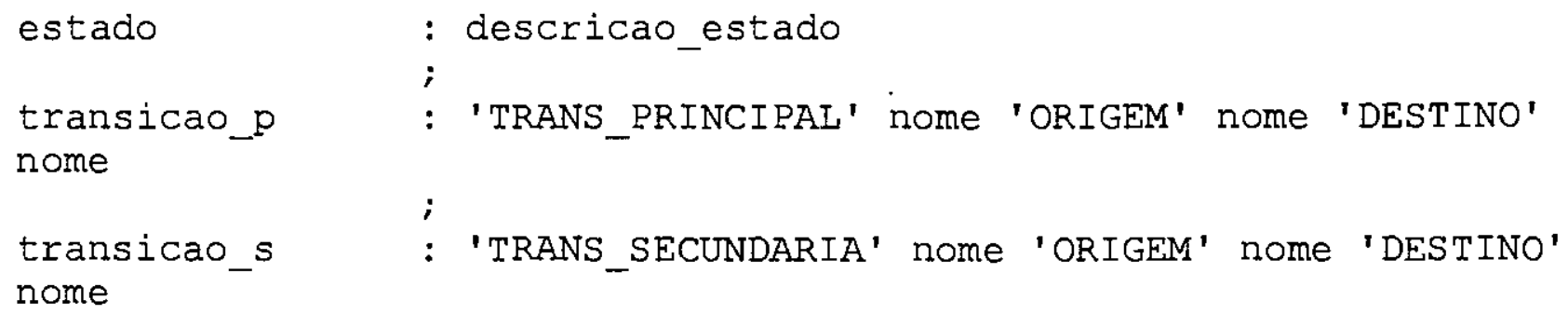

\section{Léxico ERACE definido para o sistema Draco}

81

\#include <string.h>

\#include <ctype.h>

\#include <stdio.h>

char* PutDelimiters();

char* strupper();

int 1 ineno $=0$;

char linebuf [500];

int tokenpos $=0$;

\#define store line() [ strcpy(linebut, yytext+1); lineno++; showlineno (); Eokenpos=0; yyless (1); )

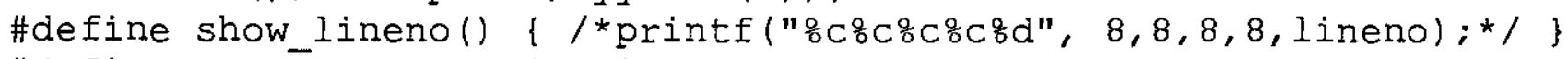

\#define ECHO

\{ printf("oss ",yytext); fflush(stdout); \}

\#define return_token(X) \{ ECHO; yylval.lc=PutDelimiters (yytext); tokenpos+=yyleng; return $(\mathrm{X})$;

\#define return_empty $(X)\{y y l v a l . l c="$; return $(X) ;\}$

\#define return_special(X) \{ECHO; yylval.lc=strdup (yytext);

tokenpost=yyleng; return $(X) ;\}$

\#define return_user_val(X) \{ECHO; tokenpos t=yyleng; return(X); \}

\#define signal_err $(\overline{)}\{\}$

\#define debug $(\bar{X})$

$\{$ printf(X); fflush(stdout); \}
옹
garray
SPACES $\quad[\backslash n \backslash t]+$
LETTER $\quad[\mathrm{A}-\mathrm{Za}-\mathrm{z}]$
ALNUM $\quad[a-z A-Z 0-9]$
NAME $\{$ LETTER\} (\{ALNUM\} $\}\{$ LETTER $\})$ * 


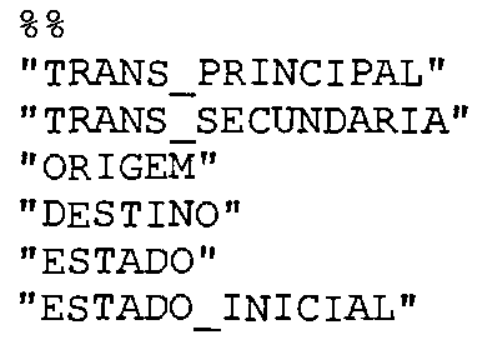

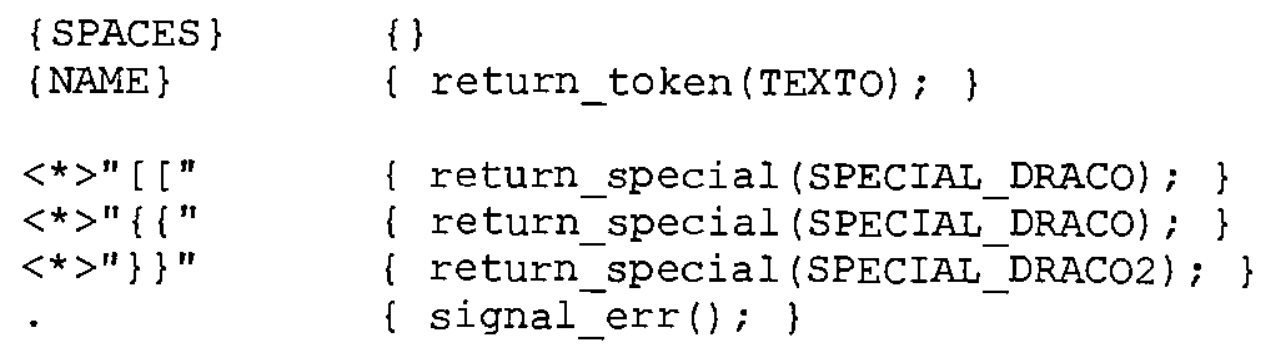

응움

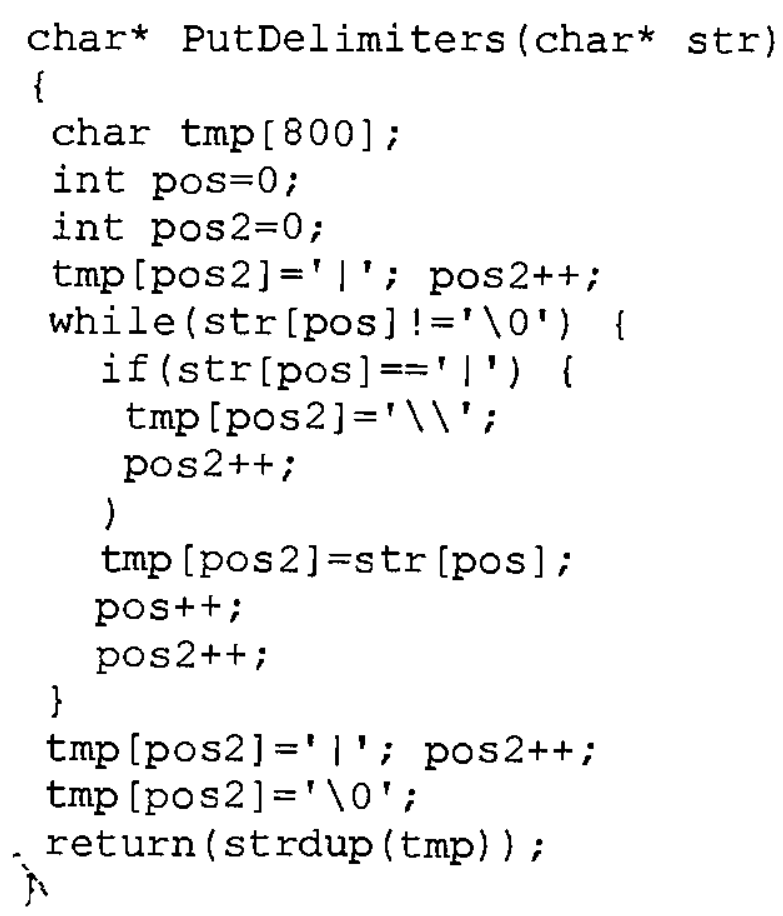


int length, $i$;

char *upper_string=strdup (string) ;

length $=$ strlen (string);

for ( $i=0 ; i<$ length; $i++)$

I

\}

$$
\text { upper_string }[i]=\operatorname{toupper}(\operatorname{string}[i]) \text {; }
$$

f

return (upper_string); 